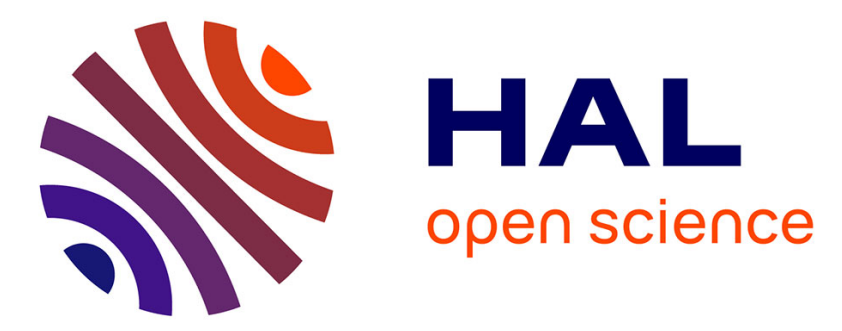

\title{
La terre sigillée décorée à la molette à motifs chrétiens dans la stratigraphie maastrichtoise (Pays-Bas) et dans le nord-ouest de l'Europe
}

Wim Dijkman

\section{- To cite this version:}

Wim Dijkman. La terre sigillée décorée à la molette à motifs chrétiens dans la stratigraphie maastrichtoise (Pays-Bas) et dans le nord-ouest de l'Europe. Gallia - Fouilles et monuments archéologiques en France métropolitaine, 1992, 49, pp.129-172. 10.3406/galia.1992.2933 . hal-01915300

\author{
HAL Id: hal-01915300 \\ https://hal.science/hal-01915300
}

Submitted on 29 Jan 2020

HAL is a multi-disciplinary open access archive for the deposit and dissemination of scientific research documents, whether they are published or not. The documents may come from teaching and research institutions in France or abroad, or from public or private research centers.
L'archive ouverte pluridisciplinaire HAL, est destinée au dépôt et à la diffusion de documents scientifiques de niveau recherche, publiés ou non, émanant des établissements d'enseignement et de recherche français ou étrangers, des laboratoires publics ou privés.

\section{(1) (1) $\$$}

Distributed under a Creative Commons Attribution - NonCommercial - NoDerivatives| 4.0 


\title{
La terre sigillée décorée à la molette à motifs chrétiens dans la stratigraphie maastrichtoise (Pays-Bas) et dans le nord-ouest de l'Europe
}

\author{
par Wim DIJKMAN ${ }^{1}$
}

\begin{abstract}
Maastricht est situé dans l'extrême sud des Pays-Bas, tout près de la frontière belge. Durant la dernière décennie, des fouilles urbaines ont livré 29 tessons de terre sigillée décorée à la molette à motifs chrétiens. De fo ${ }^{3}$ lles antérieures, seulement 4 tessons similaires sont connus. A la différence de beaucoup d'autres sites du $\mathrm{N}_{3 i} \mathrm{i}$ de la Gaule, plusieurs tessons ont été trouvés dans un contexte stratigraphique précis.

Les trouvailles maastrichtoises permettent de suivre l'évolution de cette céramique typique du $v^{e} \mathbf{s}$. au VIC. Une typochronologie plus précise de la céramique du Bas-Empire est basée sur la terre sigillée décorée à la no $t$ tte et la terre rugueuse provenant des coupes fouillées stratigraphiquement.

Sur l'un des sites fouillés, des traces d'une production de céramique datant du $\mathbf{v}^{\mathrm{e}} \mathbf{s}$. ont été découvertes. Les (aît s de répartition de chaque molette chrétienne reflètent la dispersion de la céramique à décors chrétiens. Plus généralement, cette céramique témoigne de l'ínstallation de la première communauté chrétienne des Pays-Bas.
\end{abstract}

Maastricht is a town in the extreme southern part of the Netherlands, near the Belgian border. During urban archaeological excavations in the past decade 29 potsherds in Samian Ware with rouletted decoration of christian symbols were found. From all previous excavations in Maastricht only 4 similar sherds were known. Different from most other sites in Northern Gaule several sherds were still located in their original stratigraphical position.

The Maastricht finds enable us to follow the evolution of this typical pottery during the 5th and 6th century A.D. A more precise typochronology of the late Roman pottery is based upon the Samian Ware with rouletted decoration and the Coarse Ware, found in the stratigraphically digged sequences.

Traces of a pottery-production in the 5th century were found on one of the excavated sites.

Distribution maps of each christian roulette reflect the spread of the pottery with christian symbols. In a broader sens, these objects are the relics of the first christian community of the Netherlands.

Mots clés : terre sigillée, Bas-Empire, Maastricht, stratigraphie, chronologie, production, christianisme.

1 Wim Dijkman, Conservateur au Service Municipal des Fouilles, Postbus 1115, 6201 BC, Maastricht, Pays-Bas. Je tiens à remercier ici tous ceux qui m'ont aidé pour la préparation de cet article et en premier lieu M. P. Van Ossel, Chargé de recherches au C.NRS, sans qui cet article n'aurait pas pu être publié comme il faut, et toutes les personnes qui m'ont confié des fragments de sigillée à décors chrétiens pour étude et ont accepté que je les signale avant leur propre publication :
MM. L. Bakker (Augsburg), A. Heidinga (Amsterdam), D. Perrugot (Sens), M. Perse (Jülich), J. Plumier (Namur), J. Thijssen (Nijmegen) et $P$. Van Ossel (Paris). Je voudrais aussi remercier M. T. Panhuysen, archéologue municipal de Maastricht pour ses remarques critiques et $M^{\text {lle }} \mathrm{A}$. van de Berg et MM. M. Bastings et $\mathrm{G}$. Veldman, qui ont dessiné toutes les figures reproduites dans cet article. 
La ville de Maastricht est située le long de la Meuse, à l'extrémité méridionale des Pays-Bas, près de la frontière belge. Depuis l'installation d'un service municipal des fouilles, en 1979 , de nombreuses informations ont été obtenues sur l'occupation romaine et médiévale de cette cité mosane.

Durant le Haut-Empire, Maastricht était une petite agglomération le long de la chaussée BavayCologne, tout près du pont sur la Meuse. Un sanctuaire et un complexe thermal constituaient les principaux bâtiments publics de cette agglomération qui assurait vraisemblablement une fonction centrale pour la région. La proximité de Tongres - le cheflieu de la Civitas Tungrorum -, situé à $25 \mathrm{~km}$ plus à l'ouest, a freiné le développement de Maastricht jusqu'au Bas-Empire.

La construction d'une enceinte pour la défense du pont et l'inhumation de Servais, le premier évêque de la Civitas Tungrorum au Iv ${ }^{\mathrm{e}} \mathrm{s}$, dans un cimetière à l'ouest de la localité ont été les éléments déterminants d'une continuité entre le Bas-Empire et le Haut Moyen Age.
La terre sigillée décorée à la molette à motifs chrétiens, trouvée principalement dans les environs de l'église épiscopale (fig. 1), peut être considérée comme un indicateur typo-chronologique important pour cette époque de transition ${ }^{2}$.

Jusqu'en 1968, on ne connaissait à Maastricht que deux fragments de cette céramique ${ }^{3}$. Une étude plus approfondie des collections du Bonnefantenmuseum à Maastricht a permis d'ajouter encore deux autres fragments, également ornés de motifs chrétiens ${ }^{4}$.

2 Schallmayer, 1987 , p. 492 : "Die rädchenverzierte Argonnensigillata stellt jedenfalls für die Chronologie der Spätantike auch eine Warengruppe dar, welcher der Charakter des "Leitfossils" zukommt".

3 Hübener, 1968, p. 272.

4 Ces fragments n'étaient pas encore reconnus en 1985 , lorsque nous présentions un premier aperçu de ce groupe de production : cf. Dijkman, 1985, p. 57. Je voudrais encore remercier $M$. de Grooth pour son autorisation de publier ce matériel inédit.
Fig. 1 - Carte de répartition des chantiers de fouille (1924-1988).

1. Stokstraat $\left(\mathrm{n}^{\mathrm{os}} 1,3\right)$;

2. Grote Staat $\left(n^{\circ} 2\right)$;

3. Stokstraat $\left(n^{\circ} 4\right)$;

4. O.L.V.-plein $\left(n^{\mathrm{os}} 5,6\right)$;

5. Havenstraat $\left(n^{\circ} 7\right)$;

6. Site de Mabro (nos $8-15)$;

7. Houtmaas $\left(n^{\circ} 16\right)$;

8. Hondstraat $\left(\mathrm{n}^{\circ \mathrm{s}} 17,18\right)$;

9. Site de Derlon (nos 19-32);

10. Jodenstraat ( $\left.n^{\circ} 33\right)$.

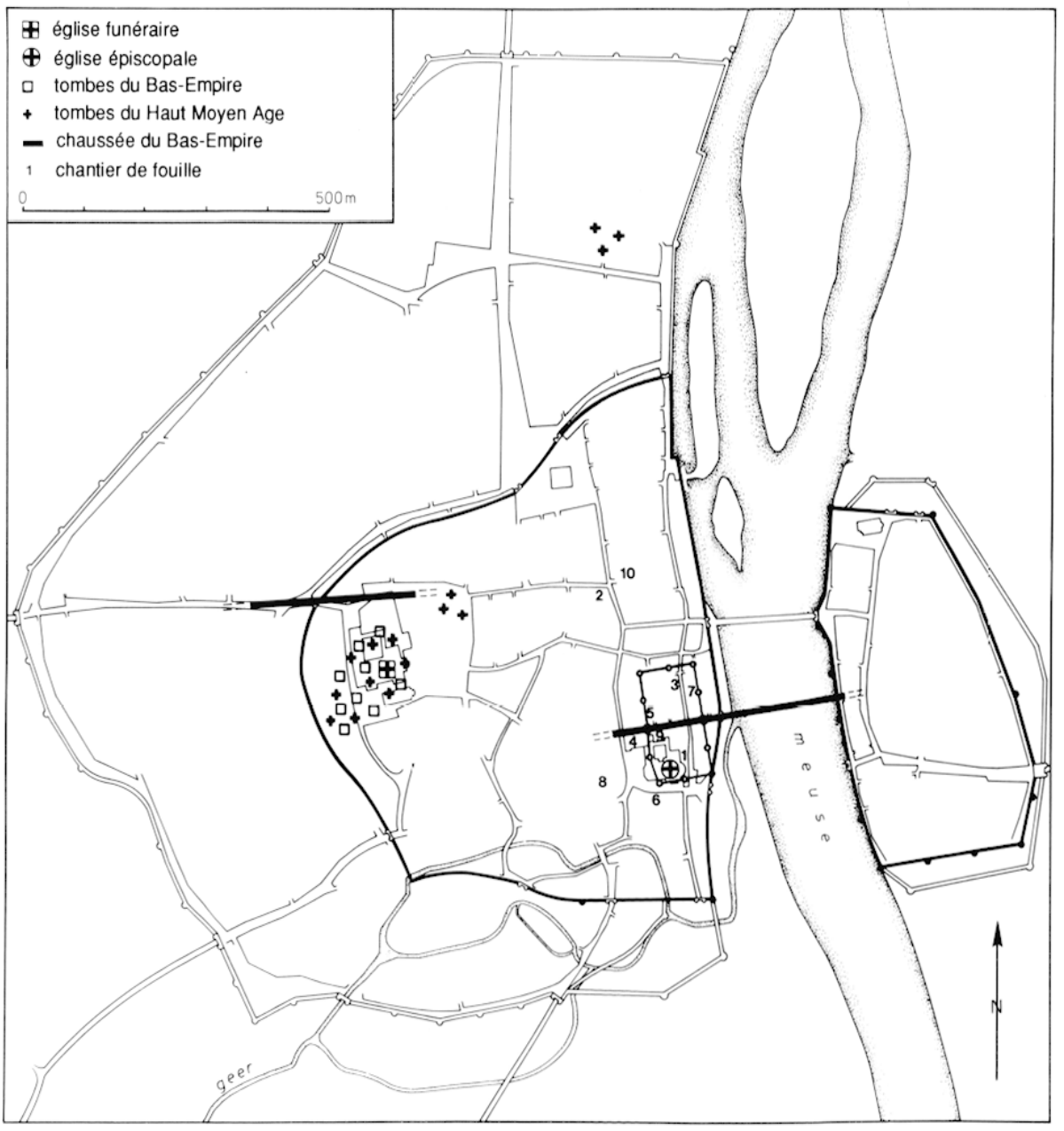




\begin{tabular}{|c|c|c|c|}
\hline Site & Année & No de trouvaille & No de molette \\
\hline 1. Stokstraat & 1924 & 2338.50 & Var. 181 \\
\hline 2. Grote Staat & 1932 & 2320 C23 & Var. 184 \\
\hline 3. Stokstraat & 1939 & $7 \mathrm{~d}$ & Var. 184 \\
\hline 4. Stokstraat & 1963 & Mst $63-114$ & Var. 182 \\
\hline 5. O.L.V.-plein & 1980 & $1-\mathrm{X}-3$ & 181 \\
\hline 6. O.L.V.-plein & 1980 & $2-1-0$ & $183(=259)$ \\
\hline 7. Havenstraat & 1980 & $1-2-O B$ & 181 \\
\hline 8. Mabro & 1981 & 1-3-OC (F3) & 186 \\
\hline 9. Mabro & 1982 & $2-0 A-0$ & 186 \\
\hline 10. Mabro & 1982 & $2-0 A-8$ & M 1 \\
\hline 11. Mabro & 1982 & 2-OA-11 & M 1 \\
\hline 12. Mabro & 1982 & 2-OG-6 & Var. 173 \\
\hline 13. Mabro & 1982 & 2-OG-6 & 181 \\
\hline 14. Mabro & 1982 & 3-6-4 (E5) & 181 \\
\hline 15. Mabro & 1982 & 3-7-18 (E6) & 258 \\
\hline 16. Houtmaas & 1982 & $1-1-0$ & M 2 \\
\hline 17. Hondstraat & 1982 & $1-4-9$ & $183(=259)$ \\
\hline 18. Hondstraat & 1982 & $1-6-0$ & 186 \\
\hline 19. Derlon & 1983 & trouvaille isolée & 181 \\
\hline 20. Derlon & 1983 & trouvaille isolée & M 4 \\
\hline 21. Derlon & 1983 & $1-3-3$ & M 3 \\
\hline 22. Derlon & 1983 & 1-3-19 & M 3 \\
\hline 23. Derlon & 1983 & $1-3-9$ & M 5 \\
\hline 24. Derlon & 1983 & $1-9-10$ & Var. 184 \\
\hline 25. Derlon & 1983 & $1-\mathrm{OA}-0$ & 257 \\
\hline 26. Derlon & 1983 & 1-OG-3 & 186 \\
\hline 27. Derlon & 1983 & $2-5-30$ & M 4 \\
\hline 28. Derlon & 1983 & 2-0J-12 (A7) & 181 \\
\hline 29. Derlon & 1983 & 2-OM-3 (B4) & Var. 182 \\
\hline 30. Derlon & 1983 & 2-OM-3 (B4) & 258 \\
\hline 31. Derlon & 1983 & 2-OM-5 (B3) & Var. 181 \\
\hline 32. Derlon & 1983 & 2-OM-5 (B3) & M 6 \\
\hline 33. Jodenstraat & 1988 & $1-2-3$ & Var. 181 \\
\hline
\end{tabular}

- Fig. 2 - Répertoire des fragments de céramique sigillée décorée à la molette à motifs chrétiens, trouvés à Maastricht. Numéros de molettes selon Chenet, 1941, pl. XXXIII et Maastricht 1-6 (cf. fig. 3). Les indications entre parenthèses renvoient aux numéros des couches des stratigraphies (cf. fig. 11).

Depuis 1980 , date à laquelle le service municipal des fouilles a entrepris plusieurs opérations de sauvetage dans le centre de la ville, vingt-neuf nouveaux fragments de cette céramique ont été découverts (fig. 1 et 2).

Avec les stèles paléochrétiennes ${ }^{5}$ et les coupes en verre ornées de symboles chrétiens ${ }^{6}$ cette céramique forme un groupe caractéristique, qui peut être considéré comme une des plus anciennes sources archéologiques chrétiennes du bassin mosan?

Les fouilles des sites de Maastricht permettent de suivre et d'illustrer, dans un contexte stratigraphique précis, la fabrication de la terre sigillée décorée à la molette à motifs chrétiens entre le $v^{e}$ et le $\mathrm{VI}^{\mathrm{e}} \mathrm{s}^{\mathrm{8}}$.

\section{Catalogue}

1. Fragment de bord. Pâte brun orangé et grise au cœur. Engobe rouge brunâtre, a perdu son brillant. Diamètre de l'ouverture : $17,3 \mathrm{~cm}$.

La molette est une variante de Chenet 181 et est identique aux nos 31 et 33 . Le total des casiers est dans les deux cas de huit, mais l'impression de la molette originale de Châtel-Chéhéry s'étend sur $8,6 \mathrm{~cm}$, celle de Maastricht sur 7,3 cm. La hauteur des casiers est dans le premier cas de $0,8 \mathrm{~cm}$, dans le deuxième de $0,6 \mathrm{~cm}$. Les casiers de la molette de Maastricht sont donc plus petits que ceux de ChâtelChéhéry.

Les casiers sont presque les mêmes dans les deux cas. Les casiers 3 et 4 de la molette de Maastricht ont été changés et orientés autrement : la grappe est située dans le troisième casier et la tige est orientée vers la droite; le calice se trouve dans le quatrième casier, ouverture à gauche. La colombe du casier 5 a été placée à l'envers. Les chrismes des

5 Boppert, 1986.

6 Dasnoy, 1956.

7 Straus, 1985; De Boe, 1986

8 Dijkman, 1985, p. 57. 
casiers 6 sont presque identiques. La croix du casier 7 de Maastricht est ornée de globules, celle de Châtel-Chéhéry d'annelets. Les traits horizontaux du casier 8 sont presque identiques. Déroulement minimal : 4 bandes superposées.

2. Fragment de paroi. Pâte brun orangé, grise au cœur. Engobe rouge brunâtre, a perdu son brillant. Variante de la molette Chenet 184 , se déroulant sur six bandes superposées. Longueur: $7,7 \mathrm{~cm}$. La somme des casiers est de 8 . Casier 1 : le $\mathrm{P}$ du chrisme est un peu plus prononcé chez Chenet, les casiers 2 sont identiques; le casier 3 de notre molette doit être placé entre les casiers 2 et 3 de la molette de Chenet. Il s'agit d'un deuxième chrisme. Les casiers 4 et 5 sont identiques aux casiers 3 et 4 de Chenet. Le casier avec la grappe est plus large chez Chenet que sur notre exemplaire. Le total des globules (i.c. raisins) est de 13 sur le prototype de Chenet, sur notre molette, il est de 10. Le casier 7 de notre exemplaire et le casier 6 de la molette de Chenet sont presque identiques. Entre notre casier 8 et le casier 7 de Chenet, on constate deux différences: la forme de la colombe n'est pas la même et sur la molette de Maastricht, on observe 3 globules au-dessus de l'oiseau; chez Chenet il n'y en a que 2. C'est bien cette molette qui figure dans la liste des molettes chrétiennes de MM. Breuer et Roosens ${ }^{9}$.

3. Fragment de paroi. Pâte brun orangé, grise au cœur. Engobe rouge brunâtre, a perdu son brillant. Variante de la molette Chenet 184. Déroulcment minimal : 3 bandes superposées. La molette est identique à celle des $n^{o s} 2$ et 24 . Il s'agit de trois récipients différents.

4. Fragment de paroi. Pâte rouge orangé, engobe un peu moins clair. Variante de la molette Chenet 182. Les cadres de décoration, présents sur la molette de Chenet, manquent ici.

La molette est comparable au $n^{0} 29$. Déroulement minimal : 4 bandes superposées.

5. Fragment de base. Pâte rouge orangé, engobe de la même couleur, mais plus foncée. A l'intérieur, l'engobe a complètement disparu. Le fragment a été noirci par le feu. Diamètre de l'anneau de base: $8,0 \mathrm{~cm}$. Fragment de fond d'un bol de la forme Chenet 320 , portant un décor à la molette 181 . Déroulement minimal : 1 bande.

6. Fragment de bord. La pâte est rouge orangé, l'engobe est un peu moins clair et très mal conservé.

9 Breuer et Roosens, 1957.
Fragment d'un bol de la forme Chenet 320 , décoré à la molette Chenet $183(=259)$. Déroulement minimal : 3 bandes superposées. Diamètre de l'ouverture : $16,0 \mathrm{~cm}$.

7. Fragment de base. L'engobe est rouge orangé clair, la pâte est d'une teinte un peu plus claire et grise au cœur. L'engobe est très mal conservé, surtout à l'intérieur et à la partie inférieure du bol. Diamètre de l'anneau de base : $9,0 \mathrm{~cm}$. Molette 181 . Déroulement minimal : 3 bandes superposées.

8. Fragment de paroi. La pâte est rouge orangé, l'engobe est un peu moins clair. L'engobe a partiellement disparu à l'intérieur. Fragment d'un bol de la forme Chenet 320, décoré à la molette Chenet 186 . Déroulement minimal : 2 bandes superposées.

9. Fragment de bord. La pâte est brun orangé, l'engobe rouge brunâtre a perdu son brillant. Le tesson montre une cassure conchoïdale et à l'intérieur des traces d'usure. Fragment d'un bol de la forme Chenet 320 , décoré à la molette 186 .

Déroulement minimal : 2 bandes superposées. Diamètre de l'ouverture : $16,0 \mathrm{~cm}$.

10. Fragment de base. La pâte est brun orangé et grise au cœur. L'engobe est rouge brunâtre et a perdu son brillant. Diamètre de l'anneau de base : $8,5 \mathrm{~cm}$. La démarcation entre le récipient et son support est moins nette que chez les bols de type Chenet 320 . Il est difficile d'identifier la molette avec certitude parce que l'empreinte est effacée partiellement. L'étude des impressions sur les fragments ${ }^{\text {os }} 10$ et 11 permet d'affirmer que la molette se compose de 8 casiers. Le casier 1 comprend des traits verticaux, le casier 2 une croix oblique ornée de globules, le casier 3 un treillage, le casier 4 une croix à quatre globules, le casier 5 des traits horizontaux. Les casiers 6 et 8 sont presque illisibles. Le chrisme du casier 7 est le plus reconnaissable sur le $n^{\circ} 11$. Longueur de la molette $: 6,5 \mathrm{~cm}$.

Sigillée tardive, dérivée de la forme Chenet 320 ; molette Maastricht 1 (M-1). Déroulement minimal : 5 bandes superposées.

11. Fragment de paroi. Même bol que le $n^{0} 10$ et même situation stratigraphique. Description ci-dessus.

12. Fragment de paroi. La pâte est rouge brunâtre, mais grise au cœur. L'engobe est brun. La molette est une variante de la molette Chenet $173(=$ Nicolle $8)^{10}$. Déroulement minimal : 5 bandes. La molette a 
été imprimée à l'envers. Sur la molette de Chenet, le chrisme du casier 2 n'est pas imprimé complètement et est entouré par cinq globules. Le chrisme du casier 7 de notre exemplaire est imprimé complètement et entouré par sept globules. La croix multiple du casier 3 de la molette de Chenet n'est pas coupée en deux par une ligne verticale comme c'est le cas sur notre molette. Le globule central du casier 4 de la molette de Chenet est identique aux autres, l'annelet au milieu du casier 5 de notre molette est plus grand que les autres. Les autres casiers contiennent presque les mêmes motifs : arête de poisson (4), cocardes (1), traits horizontaux (3), hachures obliques (2). Sigillée tardive, dérivée de la forme Chenet 320.

13. Fragment de paroi. La pâte est rouge orangé, mais grise au cœur. L'engobe a la même couleur mais est un peu plus foncé. La paroi est mince. Fragment d'un bol de la forme Chenet 320 , décoré à la molette 181. Déroulement minimal : 2 bandes superposées.

14. Fragment de bord. La pâte est rouge orangé, l'engobe est un peu moins clair. Fragment d'un bol Chenet 320, décoré à la molette 181. Déroulement minimal: 2 bandes superposées. Diamètre de l'ouverture : $21,5 \mathrm{~cm}$.

15. Fragment de paroi avec un petit reste du bord. La pâte est grise, l'engobe est brun à l'extérieur et rouge brunâtre à l'intérieur. Fragment d'un bol de la forme Chenet 320 , décoré à la molette 258. Déroulement minimal : 6 bandes superposées.

16. Fragment de base. La pâte est grise. L'engobe brun rouge et a perdu son brillant. Diamètre de l'anneau de base : $9,1 \mathrm{~cm}$. La démarcation entre le récipient et son support est moins nette que sur les bols de type Chenet 320 . Molette complète et inédite : 6 casiers. Casier 1 : croix à globules; casier 2 : croix multiple; casier 3 : croix de Malte, ornée de quatre globules; casier 4 : colombe, ornée d'un pion et cinq globules; casier 5 : chrisme, orné de trois globules; casier 6 : treillage. Déroulement minimal : 3 bandes superposées. Longueur de la molette : $7,3 \mathrm{~cm}$. Sigillée tardive, dérivéc de la forme Chenet 320 ; molette Maastricht 2 (M 2).

17. Fragment de paroi. La pâte est brun orangé, l'engobe est brun foncé et a perdu son brillant. La surface montre plusieurs stries. La molette, à peine lisible, est vraisemblablement une Chenet 183 (=259). Déroulement minimal : 2 bandes superposées. Sigillée tardive.

18. Fragment de base. La pâte est brun orangé, mais grise au cœur. L'engobe rouge brunâtre a perdu son brillant et est très mal conservé. Diamètre de l'anneau de base : $8,2 \mathrm{~cm}$. La démarcation entre le récipient et son support est moins nette que sur les bols de type Chenet 320 . Sigillée tardive, dérivée de la forme Chenet 320, ornée à la molette Chenet 186 .

19. Fragment de paroi. La pâte est rouge orangé, l'engobe est un peu moins clair. Fragment d'un bol Chẹnet 320, décoré à la molette 181. Déroulement minimal : 2 bandes superposées.

20. Fragment de bord. La pâte est brun orangé et grise au cœur. L'engobe rouge brunâtre a perdu son brillant. Diamètre de l'ouverture $: 15 \mathrm{~cm}$. Terre sigillée tardive, dérivée de la forme Chenet 320. La molette complète, Maastricht 4 (M 4), est identique au no 27. Description ci-dessous. Déroulement minimal : 3 bandes superposées.

21. Un fragment avec profil complct. La pâte est brune claire et grise au cœur. L'engobe brun a presque complètement disparu. La céramique est de mauvaise qualité : pâte feuilletée. Terre sigillée tardive, dérivée de la forme Chenet 320 . La baguette autour du rebord n'est plus prononcée. La démarcation entre le récipient et son support est moins nette que chez les bols de type Chenet 320. Diamètre de l'ouverture : $17,7 \mathrm{~cm}$. Diamètre de l'anneau de base : $7,8 \mathrm{~cm}$. Hauteur : $8,3 \mathrm{~cm}$. Molette complète Maastricht 3 (M 3), comprennant 7 casiers. Casier 1 : traits horizontaux ; casier 2 : croix oblique, multiple, ornée de deux globules; casier 3 : treillage ; casier 4 : croix oblique, ornée de quatre globules; casier $\overline{5}$ : croix oblique, encadrée d'un carré et ornée de quatre globules; casier 6 : chrisme, entouré de quatre globules; casier 7 : colombe ornée de deux globules et deux motifs triangulaires. Longueur de la molette : $6,9 \mathrm{~cm}$. Déroulement minimal : 5 bandes superposées.

22. Fragment de bord. Même bol que le no 21 et situation stratigraphique comparable. Description ci-dessus.

23. Fragment de base. La pâte est brun orangé et grise au cour. L'engobe rouge brunâtre a perdu son brillant. Diamètre de l'anneau de base : $7,9 \mathrm{~cm}$. Sigillée tardive, dérivée de la forme Chenet 320 . Molette incomplète Maastricht 5 (M 5), comprenant 6 casiers". Casier 1 : chrisme entouré de quatre globules; casier 2 : croix oblique, multiple, ornée de deux globules; casier 3 : treillage; casier 4 : croix

11 Bayard, 1990, fig. 8 montre la molette complétée (cf. fig. 35). 
oblique dont les extrémités sont terminées par des globules; casier 5 : croix oblique finissant en globules et entourée de quatre globules; casier 6 : colombe ornée d'un pion et de quatre globules.

24. Fragment de paroi. La pâte est brun orangé, mais grise au cœur. L'engobe rouge brunàtre a perdu son brillant. Sigillée tardive, dérivée de la forme Chenet 320. Variante de la molette Chenet 184, identique à $n^{\circ} 2$. Description ci-dessus. Déroulement minimal : 5 bandes superposées.

25. Fragment de paroi. La pâte est brun orangé, mais grise au cceur. L'engobe rouge brunâtre a perdu son brillant. Sigillée tardive. Molette 257. Déroulement minimal : 2 bandes superposées.

26. Fragment de paroi. La pâte est orange clair, le noyau gris. L'engobe rouge orangé a perdu son brillant. Fragment d'un bol de la forme Chenet 320, décoré à la molette 186. Déroulement minimal: 2 bandes superposées.

27. Fragment de paroi. La pâte est brun orangé et grise au cœur. L'engobe est rouge brunâtre. Sigillée tardive, dérivée de la forme Chenet 320. Molette complète Maastricht 4 (M 4), identique au n ${ }^{\circ} 20$. Elle se compose de six casiers. Casier 1 : à gauche en bas, une "crèche" et au-dessus le ventre de la colombe, à droite six globules empilés dans une forme pyramidale; casier 2: trois globules, flanqués par deux bàtonnets; casier 3 : treillage ; casier 4 : croix multiple, entourée de six globules; casier 5 : chrisme; casier 6: traits horizontaux. Longueur de la molette : $7,5 \mathrm{~cm}$. Déroulement minimal : 3 bandes superposées.

28. Fragment de base. La pâte est brun orangé et grise au cœur. Pàte savonneuse. L'engobe brun rougeâtre est brillant. Le tesson est noirci par le feu. Diamètre de l'anneau de base : $8,4 \mathrm{~cm}$. Sigillée tardive, dérivée de la forme Chenet 320 , décorée à la molette 181. Déroulement minimal : 3 bandes superposées.

29. Fragments de base et de bord. La pâte est brun clair, l'engobe brun. La céramique est de mauvaise qualité, la pâte feuilletée. La baguette autour du rebord n'est plus prononcée. Diamètre de la base : $8,0 \mathrm{~cm}$. Sigillée tardive, dérivée de la forme Chenet 320 , décorée à la molette : variante de Chenet 182. Les cadres de décoration sur la molette de Chenet manquent ici. La molette est comparable à notre $n^{0} 4$. Déroulement minimal : 4 bandes superposées.

30. Fragment de bord. La pâte est rouge orangé, l'engobe orange et brillant. Fragment d'un bol du type Chenet 320, décoré à la molette 258. Déroulement minimal : 2 bandes superposées.

31. Fragment de bord. La pâte est rouge orangé et grise au cœur. L'engobe a perdu son brillant. Diamètre de l'ouverture : $16,0 \mathrm{~cm}$. Sigillée tardive, dérivée de la forme Chenet 320. La molette est une variante de Chenet 181. Déroulement minimal : 1 bande.

32. Fragment de bord. La pâte est rouge orangé et grise au cœur. A l'intérieur l'engobe est brun rougeâtre, à l'extérieur plus brun orangé. Sigillée tardive, dérivée de la forme Chenet 320. Molette complète Maastricht 6 (M 6), comprenant 7 casiers. Casier 1 : colombe stylisée, entourée d'au moins trois globules; casier 2 : staurogramme avec à gauche en bas un pion et à droite trois globules; casier 3 : traits verticaux; casier 4 : traits horizontaux; casier 5 : croix de saint André; casier 6 : hachures; casier 7 : traits verticaux. Longueur de la molette $: 6,9 \mathrm{~cm}$. Déroulement minimal : 4 bandes superposées.

33. Fragment de base. La pâte et l'engobe sont rouge orangé. L'engobe a perdu son brillant. Le noyau est gris. La molette est une variante de Chenet 181 et identique aux $n^{\text {os }} 1$ et 31 . Déroulement minimal : 3 bandes superposées.

\section{DESCRIPTION}

Une analyse détaillée de chaque casier s'impose, pour mieux connaître les molettes à décors chrétiens. Nous avons fait une distinction entre les molettes publiées par G. Chenet et celles inconnues de lui. D. Bayard ${ }^{12}$ a souligné la valeur chronologique de l'iconographie des décors et a proposé de diviser ces molettes en deux phases : 3 et $4^{13}$. Les molettes Maastricht 1 à 6 , publiées en $1985^{14}$ (fig. $3, n^{\text {os }} 10$, $16,20,21,23$ et 32), sont exactement celles attribuées par D. Bayard à sa phase 4. Elles comportent toujours un ou deux symboles chrétiens, la croix et la colombe. Nous reviendrons plus loin sur les problèmes de chronologie que soulèvent ces décors (voir infra p. 154-155).

Le calice (1) est toujours lié à la grappe (2) (fig. 4). Les deux motifs font référence au sang du Christ, symbolisé par le vin qui provient du raisin.

12 Bayard, 1990, p. 293-294.

13 Bayard, 1990, fig. 8.

14 Dijkman, 1985, pl. II. 


\begin{tabular}{|c|c|c|c|c|c|}
\hline 1 & 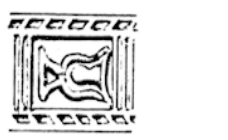 & calice (7) & 12 & 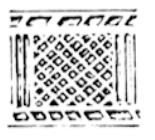 & croisillons (5.) \\
\hline 2 & ] & grappe (7) & 13 & 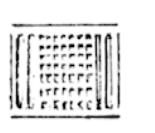 & treillage (1) \\
\hline 3 & 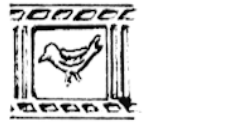 & colombe (10) & 14 & & hachures obliques (1) \\
\hline 4 & & staurogramme (10) & 15 & & arête de poisson (1) \\
\hline 5 & 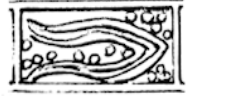 & poisson (1) & 16 & $\begin{array}{l}\text { ब. } \\
6 \\
6\end{array}$ & annelets (1) \\
\hline 6 & 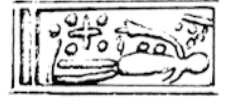 & homme couché (1) & 17 & & globules (1) \\
\hline 7 & 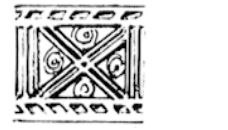 & $\begin{array}{l}\text { croix de saint André } \\
\text { entourée de globules (11) }\end{array}$ & 18 & & motif $\mathrm{M}(1)$ \\
\hline 8 & $D / \Delta$ & croix (3) & 19 & 国 & motif encadré (1) \\
\hline 9 & & croix double (8) & 20 & $7 \%$ & motif géométrique (1) \\
\hline 10 & 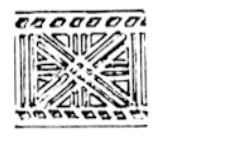 & “ Union Jack » (1) & 21 & : & motif AG (1) \\
\hline 11 & 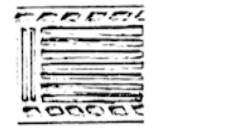 & traits horizontaux (11) & 22 & 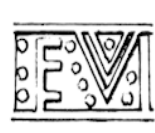 & motif EV (1) \\
\hline
\end{tabular}

Fig. 1 - Fréquence des différents motifs sur les molettes chrétiennes publiées par Chenet (1941).

La colombe (3) symbolise le Saint Esprit. Le staurogramme ${ }^{15}$ de Christ (4) est formé par les deux premières lettres du nom XPISTOS.

Le poisson (5), en grec IXTVS, est l'acrostiche de l'expression grecque "Jèsos Christos Theou Uios Sotèr", c'est-à-dire : Jésus Christ, fils de Dieu.

L'homme couché (6) est associé aux motifs AG (= aghios, saint en grec) et EV. Selon Chenet ${ }^{16}$ il

15 Kirschbaum (è.), 1970, p. $570: 9$.

16 (henet, 1941, p. 118. s'agirait de saint Eustache, qui a participé au concile de Nicae en 325. Selon d'autres ${ }^{17}$ c'est peut-être le Christ lui-même.

Les motifs 7-10 sont des variantes sur le thème de la croix. Les motifs 11 à 17 sont d'ordre géométrique. Les motifs 18-22 sont énigmatiques.

Les douze molettes publiées par Chenet ${ }^{18}$ contiennent 24 motifs différents, dont 13 appa-

17 Docquier et alii, 1984, IV : pl. 12.

18 Chenet, 1941. 
1

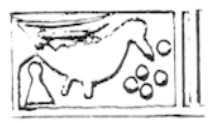

2

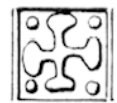

3

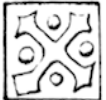

4

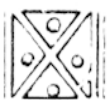

5

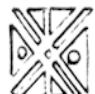

6

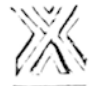

7

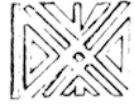

colombe (4)

croix stylisée (6)

croix de Malte (3)

croix de saint André (5)

croix de saint André

double (3)

croix (1)

croix double (1)
8

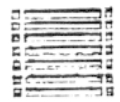

traits horizontaux (4)

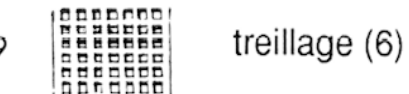

10

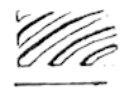

hachures obliques (1)

11

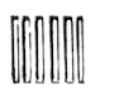

traits verticaux (3)

12

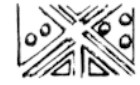

motif de croix compliquée (2)

combinaison de traits

et globules (6)

Fig. 5-Fréquence des différents motifs sur les molettes chrétiennes Maastricht 1 à 6 (M 1 à M 6).

raissent une fois, répartis dans 87 casiers. Le nombre moyen des casiers est de 7,25 par molette.

Quatre molettes $(181,182,257$ et 258$)$ possèdent un cadre décoratif. Les molettes 173 et 186 présentent un caractère différent : elles se composent de motifs qui n'apparaissent pas dans les autres (173: 4 motifs sur 7 et 186 : 5 motifs sur 5 ). Sur les autres molettes, le calice, la grappe, la colombe et le chrisme sont assez fréquents. Toutes les molettes, sauf le $n^{\circ} 186$, comprennent le casier aux traits horizontaux.

Sur les molettes M 1-6 (fig. 5), le calice et la grappe ne sont plus utilisés. La colombe (1), toujours assez fréquente, est désormais très stylisée.

Les différentes croix ( 2 à 7 ) sont les symboles décisifs pour identifier les molettes chrétiennes.

Les motifs 8 à 11 sont géométriques, les motifs 12 à 13 sont énigmatiques. Les six molettes inédites de Chenet contiennent 19 motifs différents, dont 11 une fois, répartis dans 45 casiers. Le nombre moyen des casiers est de 6,43 par molette. Les motifs les plus fréquents sont le treillage et la croix stylisée, qui s'est développée à partir du staurogramme. Tous deux figurent sur cinq des six molettes inédites de Chenet.

Une comparaison des diamètres de la base (D.B.) et de l'ouverture (D.O.), des hauteurs (H) des bols de Maastricht et de ceux du reste du NordOuest de l'Europe (cf. fig. 6), montre une grande cohérence des données. Les différences entre les extrêmes sont plus grandes pour ceux du Nord-Ouest de l'Europe, mais cela s'explique par le nombre d'exemplaires plus élevé.

La longueur (L.M.) et la largeur (E.M.) de la molette sont presque identiques pour les deux groupes. La molette la plus courte (M 5) est aussi la molette la plus étroite ( $n^{\circ} 23$ ).

Le nombre des bandes (N.B.) des molettes de Maastricht varie de 3 à 6 . A notre connaissance, trois bols seulement en comprennent 7 (B2: 2 fois) ou 8 (B3 : 1 fois) bandes superposées.

Cette analyse montre que les dimensions des bols, l'application et les variantes des molettes chrétiennes découvertes à Maastricht ne diffèrent guère de celles trouvées ailleurs.

Pour atteindre une longueur de molette de 5,8 à 


\begin{tabular}{|c|c|c|c|c|c|c|c|}
\hline $\mathrm{N}^{\circ}$ & M. & D.B. & D.O. & $\mathrm{H}$. & L.M. & E.M. & N.B. \\
\hline 1 & var. 181 & & 17,0 & & 7,3 & 0,7 & $>3$ \\
\hline 2 & var. 184 & & & & 7,7 & 0,9 & 6 \\
\hline 3 & var. 184 & & & & 7,7 & 0,9 & $>3$ \\
\hline 4 & var. 182 & & & & 7,2 & 1,1 & $>4$ \\
\hline 5 & 181 & 8,0 & & & 8,9 & 1,1 & $>1$ \\
\hline 6 & 183 & & 16,0 & & 8,7 & 0,6 & $>3$ \\
\hline 7 & 181 & 9,0 & & & 8,9 & 1,1 & $>3$ \\
\hline 8 & 186 & & & & 7,5 & 0,8 & $>2$ \\
\hline 9 & 186 & & 16,0 & & 7,5 & 0,8 & $>2$ \\
\hline 10 & M 1 & 8,5 & & & 6,8 & 0,6 & $>5$ \\
\hline 11 & M 1 & & & & 6,8 & 0,6 & $>5$ \\
\hline 12 & var. 173 & & & & 7,5 & 0,8 & 5 \\
\hline 13 & 181 & & & & 8,9 & 1,1 & $>2$ \\
\hline 14 & 181 & & 21,5 & & 8,9 & 1,1 & $>2$ \\
\hline 15 & 258 & & & & 7,1 & 0,9 & $>6$ \\
\hline 16 & M 2 & 9,1 & & & 7,8 & 0,9 & $>3$ \\
\hline 17 & 259 & & & & 8,7 & 0,8 & $>2$ \\
\hline 18 & 186 & 8,2 & & & 7,5 & 0,8 & $>5$ \\
\hline 19 & 181 & & & & 8,9 & 1,1 & $>2$ \\
\hline 20 & M 4 & & 15,0 & & 7,5 & 0,8 & 3 \\
\hline 21 & M 3 & 7,8 & 17,7 & 8,3 & 7,5 & 0,7 & 5 \\
\hline 22 & M 3 & & & & 7,5 & 0,7 & 5 \\
\hline 23 & M 5 & 7,9 & & & 5,8 & 0,7 & $>4$ \\
\hline 24 & var. 184 & & & & 7,7 & 0,9 & $>5$ \\
\hline 25 & 257 & & & & 7,1 & 0,9 & $>2$ \\
\hline 26 & 186 & & & & 7,5 & 0,8 & $>2$ \\
\hline 27 & M 3 & & & & 7,5 & 0,8 & 3 \\
\hline 28 & 181 & 8,4 & & & 8,9 & 1,1 & $>3$ \\
\hline 29 & var. 182 & 8,0 & & & 7,2 & 1,1 & 4 \\
\hline 30 & 258 & & & & 7,1 & 0,9 & $>2$ \\
\hline 31 & var. 181 & & 16,0 & & 7,3 & 0,7 & $>1$ \\
\hline 32 & M 6 & & & & 7,0 & 0,7 & 4 \\
\hline 33 & var. 181 & & & & 7,3 & 0,7 & $>3$ \\
\hline
\end{tabular}

Fig. 6 - Comparaison entre les mesures des bols et des molettes trouvées à Maastricht et ailleurs.

\begin{tabular}{|c|c|c|c|c|c|c|c|}
\hline Site & M. & D.B. & D.O. & $\mathrm{H}$. & L.M. & E.M. & N.B. \\
\hline F 6 & 263 & 9,6 & 17,6 & 7,6 & 7,2 & 0,8 & 4 \\
\hline F 12 & 181 & 8,4 & & & & & \\
\hline F 14 & $\mathrm{M} 2$ & & & & 7,8 & 0,9 & \\
\hline F 18 & 276 & 9,6 & 16,8 & 7,5 & 6,7 & 0,7 & 3 \\
\hline B 1 & B 1 & 7,8 & 14,1 & 6,3 & 9,2 & 0,9 & 4 \\
\hline B 2 & 181 & & & 14,6 & 6,0 & & \\
\hline B 2 & 182 & 8,4 & 17,4 & 6,4 & 6,4 & 1,1 & 6 \\
\hline B 2 & 263 & 8,1 & 17,4 & 6,3 & 6,5 & 0,8 & 3 \\
\hline B 2 & 259 & 7,5 & 15,6 & 7,2 & 8,4 & 0,7 & 7 \\
\hline B 2 & 182 & 8,0 & 15,3 & 6,4 & 6,4 & 1,1 & 4 \\
\hline B 2 & 259 & 7,8 & 13,8 & 6,3 & 8,4 & 0,7 & 4 \\
\hline B 2 & 263 & 8,1 & 15,0 & 6,3 & 7,8 & 0,8 & 7 \\
\hline B 3 & M 4 & 8,6 & & & & & 8 \\
\hline B 4 & 184 & 7,8 & 15,5 & 8,1 & 6,7 & 0,7 & 5 \\
\hline B 4 & 185 & 7,2 & 16,0 & 7,2 & 7,5 & 0,7 & 4 \\
\hline B 6 & 257 & & & 16,5 & 7,1 & & \\
\hline В 10 & B 1 & 8,4 & 14,5 & 7,0 & 9,2 & 0,9 & \\
\hline B 11 & var. 184 & 7,8 & & 6,6 & & & \\
\hline В 13 & M 3 & 8,7 & & & 6,0 & 0,6 & $>2$ \\
\hline B 14 & 259 & 8,4 & 16,8 & 8,8 & 8,7 & 0,8 & 6 \\
\hline B 14 & 259 & 7,2 & 14,7 & 6,8 & 8,7 & 0,8 & 4 \\
\hline В 15 & 182 & 7,5 & 15,0 & 8,3 & 7,2 & 1,1 & 5 \\
\hline В 16 & 186 & 6,2 & 14,5 & 7,0 & 7,0 & 0,9 & \\
\hline L 1 & 181 & & & 14,7 & & & $>3$ \\
\hline L 1 & 257 & & & 16,5 & & & $>3$ \\
\hline D 1 & var. 173 & 8,2 & 15,6 & 6,4 & 7,6 & 0,7 & 5 \\
\hline D 2 & 258 & & & & 6,2 & & 4 \\
\hline D 3 & 181 & 8,6 & 18,0 & 6,8 & 8,9 & 0,9 & 3 \\
\hline N 3 & 186 & 8,0 & & & & & $>3$ \\
\hline N 4 & M 2 & & & & 7,8 & 0,9 & \\
\hline
\end{tabular}

\begin{tabular}{|l|c|c|c|c|c|c|}
\cline { 2 - 7 } \multicolumn{1}{c|}{} & D.B. & D.O. & H. & L.M. & E.M. & N.B. \\
\hline Europe & $6,2-9,6$ & $\begin{array}{c}13,8- \\
18\end{array}$ & $6-8,8$ & $\begin{array}{c}6,2- \\
9,2\end{array}$ & $\begin{array}{c}0,7- \\
1,1\end{array}$ & $3-8$ \\
\hline $\begin{array}{l}\text { Maas- } \\
\text { tricht }\end{array}$ & $7,8-9,1$ & $\begin{array}{c}15,0- \\
21,5\end{array}$ & 8,3 & $\begin{array}{c}5,8- \\
8,9\end{array}$ & $\begin{array}{c}0,6- \\
1,1\end{array}$ & $3-6$ \\
\hline
\end{tabular}


Fig. 7 -

I)iamètres des cylindres des molettes utilisées pour décorer les bols à motifs chrétiens.

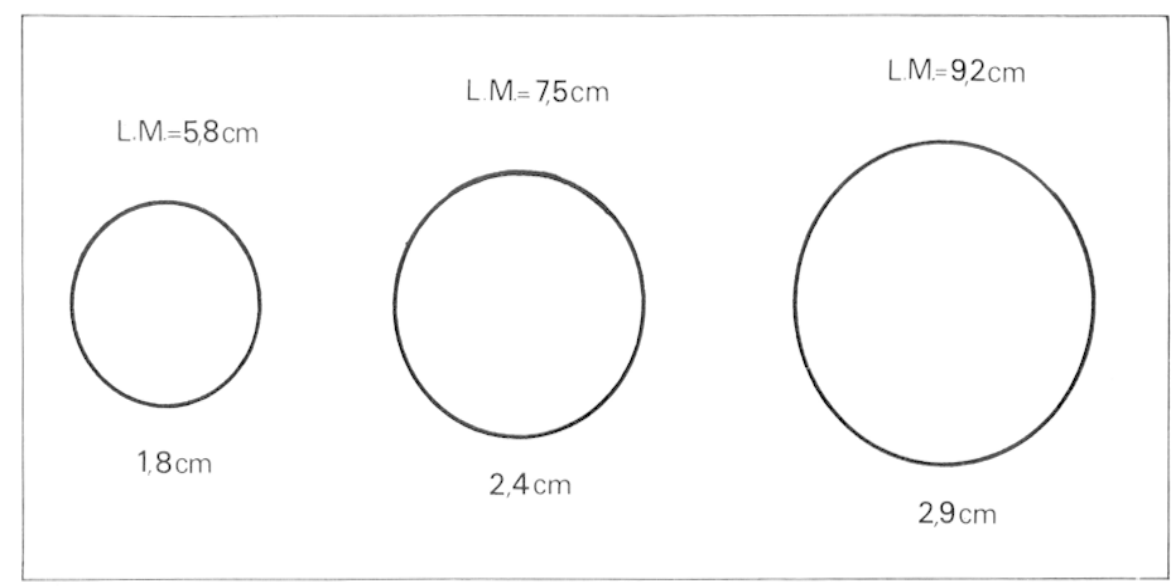

$9.2 \mathrm{~cm}$, il faut un cylindre d'un diamètre de 1,8 à $2.9 \mathrm{~cm}$. Par exemple, pour une molette d'une longueur de $7,5 \mathrm{~cm}$, le diamètre du cylindre doit ètre 2,4 cm (fig. 7).

(i. Chenet ${ }^{19}$ signale à propos de ces cylindres que "la plupart des casiers de la série chrétienne de Châlel-Chéhéry ... laissent croire aussi qu'il y en eut de bronze ciselè". Le restaurateur du Service municipal des fouilles de Maastricht, M. P. A. Rossèl, a réalisé une empreinte convenable de la molette Chenet 181 en utilisant la technique de la cire perdue. Mais on pouvait atteindre un résultat comparable avec d'autres matières ${ }^{20}$, surtout quand il s'agit de molettes moins compliquées et détaillées.

\section{STRATIGRAPHIE ET CHRONOLOGIE}

Depuis 1980, le service municipal des fouilles a ouvert plusieurs chantiers dans le centre de Maastricht. Les fouilles ont révélé les restes d'une enceinte entourée par un fossé (fig. 8). Une tour de cette enceinte a été dégagée au lieu-dit Houtmaas. I.es fondations reposaient sur une couronne de pieux en chêne, qui ont été soumis à une analyse dendrochronologique. Tous les bois paraissent bien avoir été coupés au printemps de l'année 333 après J.-C. ${ }^{21}$. I)ans la mesure où aucune réfection n'a été constatée, cette date peut vraisemblablement être étendue à la construction de la totalité de l'enceinte.

Des niveaux de l'époque constantinienne ont été découverts dans plusieurs endroits du castrum, en particulier sur les sites de Derlon, Havenstraat et Houtmaas.

19 Chenet. 1941, p. 46

20 Homes-Frederica, Franken, 1984, p. 197.

21 Panhuysen, 1986, p. 129; 1991, n. 50.
Cne accumulation de couches, datées de la seconde moitie du $\mathrm{IV}^{\mathrm{e}} \mathrm{s}$. et du $\mathrm{V}^{\prime \prime}$ s., recouvrant les niveaux de l'époque constantinienne, est attestée sur site de Mabro comme sur le site de Derlon (fig. 9).

Pour tout le IV"s., les monnaies (fig. 10) sont un support utile pour établir la chronologie des séquences stratigraphiques. Les relations entre les couches contenant de la céramique et des monnaies sont représentées sur la figure 11. 149 monnaies du IV $\mathrm{V}^{\mathrm{r}}$ s. ont été découvertes dans les coupes concernées. I a plupart datent de l'époque constantinienne et du dernier quart du $\mathrm{IV}^{\mathrm{e}} \mathrm{s}$.

La figure 11 indique les rapports entre les différentes couches des coupes A-F (fig. 9). L'échelle de gauche montre les intervalles de la séquence chronologique, couvrant les $\mathrm{I}^{\mathrm{e}}$ et $\mathrm{v}^{\mathrm{e}} \mathrm{s}$. Chaque intervalle correspond à un demi ou à un quart de siècle et est représenté dans 1 à 6 coupes. Les coupes choisies comptent de 3 à 9 couches. Le début (première moitié du IV s. ou IVA) et la fin (seconde moitié du $v^{*}$ s. ou VB) de la séquence ne sont pas connus avec précision.

Des fragments de céramique à motifs chrétiens ont été trouvés dans les couches A7, B3-4 et E5-6. Les autres tessons décorés ont été découverts dans des couches remaniées ou dans des secteurs trop éloignés des coupes retenues pour notre démonstration.

Cette observation est, pour le site de Mabro, confirmée par les monnaies provenant d'autres parties de la fouille ${ }^{22}$. Le hiatus dans les séries monétaires entre 348 et 364 est également constaté ailleurs ${ }^{23}$. Pour les uns ${ }^{24}$, il témoigne d'un abandon temporaire de certains sites. C'est le cas pour diffé-

22 Van der Vin et Panhuysen, 1983, p. 124-125.

23 Ravetz, 1964, p. 64 , fig. 1.

24 Brulet, 1978 , p. 84-85. 


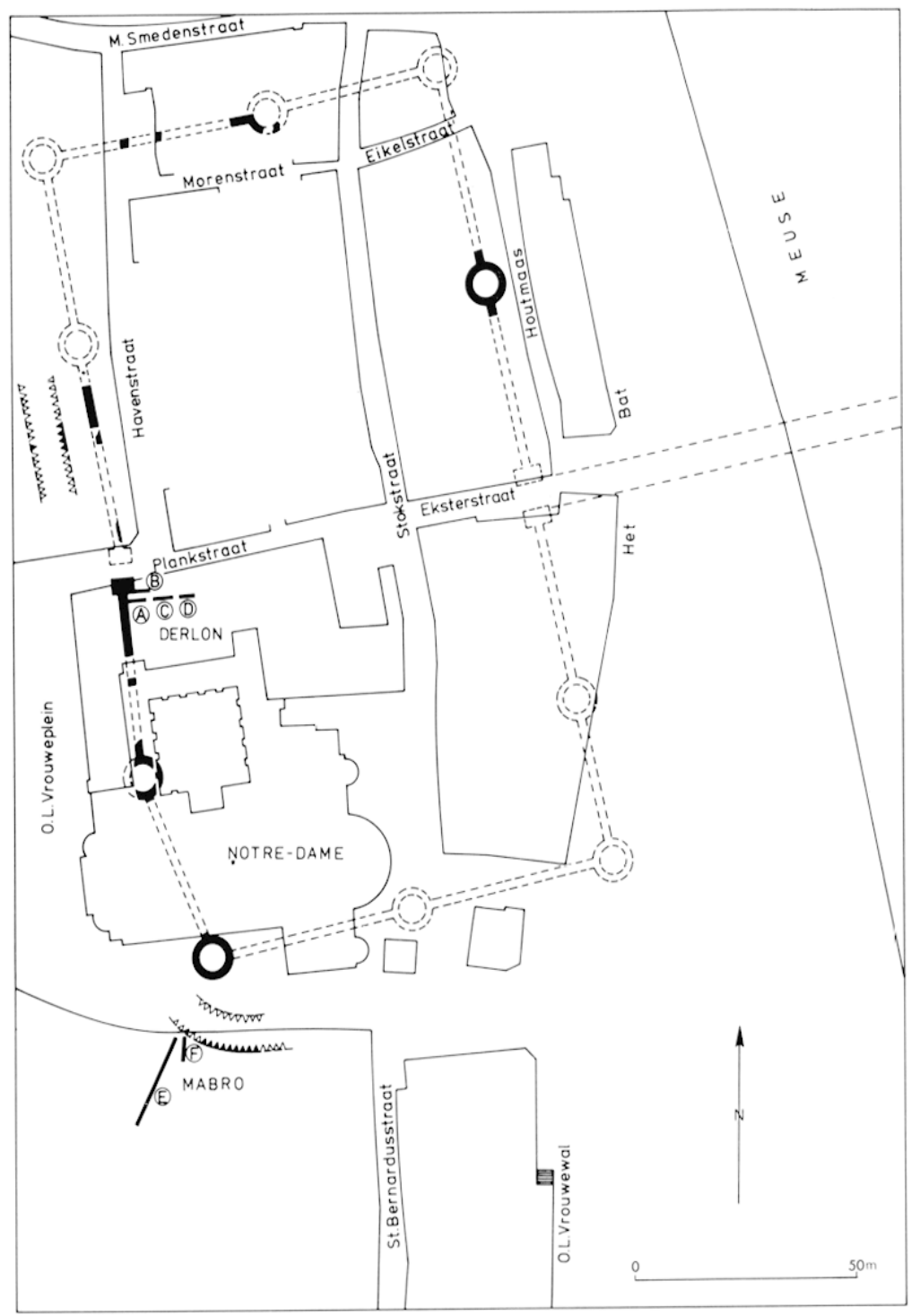

Fig. 8-Maastricht :

localisation des sites de Derlon et Mabro par rapport à l'enceinte du Bas-Empire. Indication des coupes $\mathrm{A}$ à $\mathrm{F}$.

Fig. 9-Site de I)erlon : coupes A à I). Site de Mabro : coupes $\mathrm{F}$ et $\mathrm{F}$ (N.A.P. $=$ Nieuw Amsterdams Peil, nivellement général des Pays-Bas).
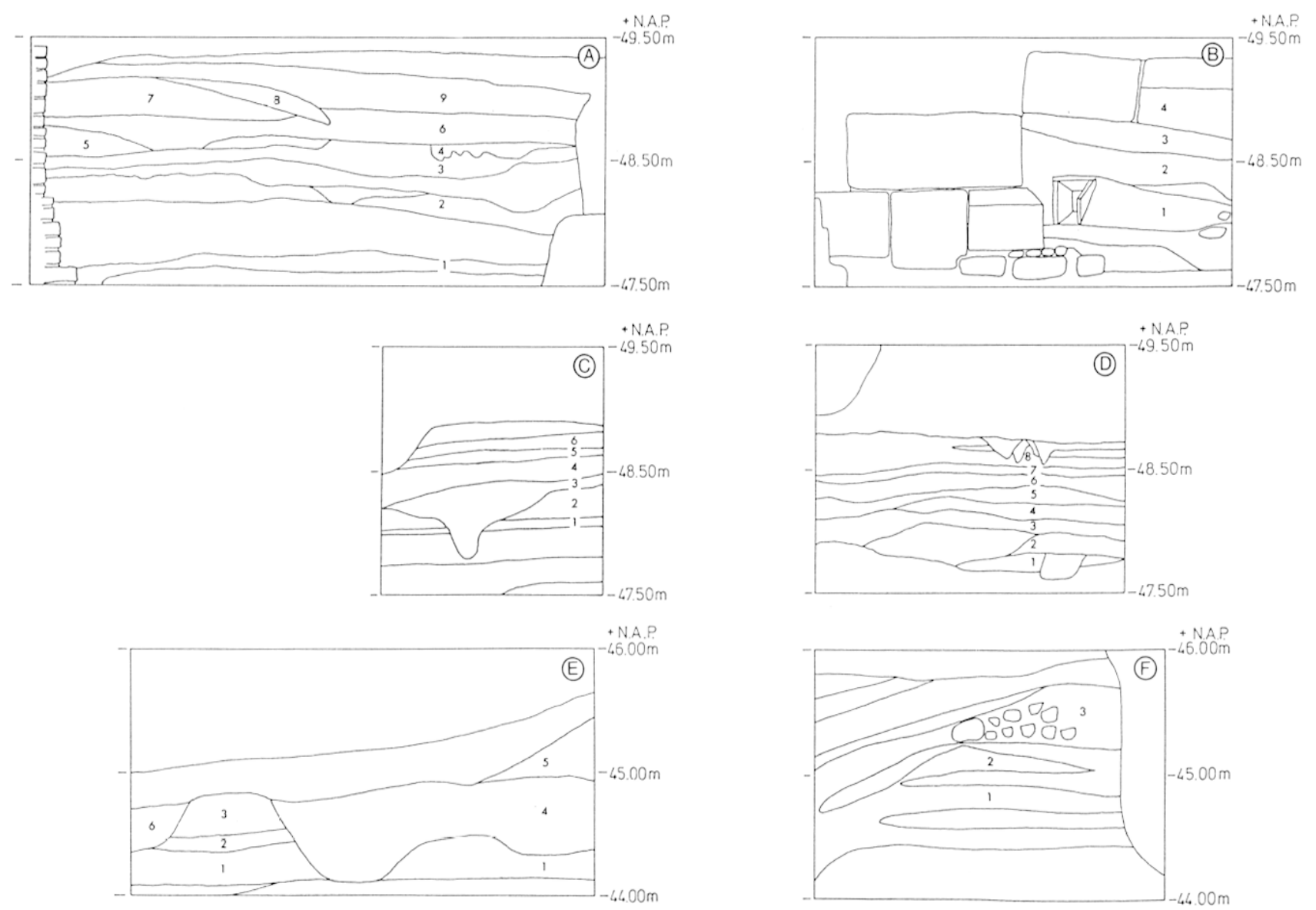


\begin{tabular}{|c|c|c|}
\hline Ensemble & Monnaie & $\begin{array}{l}\text { Terminus } \\
\text { post quem }\end{array}$ \\
\hline N 1 & $\begin{array}{l}1 \text { follis au type Constantinopolis } \\
(330-337)\end{array}$ & 335 \\
\hline $\mathrm{N} 2$ & $\begin{array}{l}1 \text { follis au type Roma, Lyon ( } 330 \text { - } \\
331 \text { ) } \\
1 \text { aes IV Gratien (378-388) } \\
1 \text { aes III Valens, Trèves? (367-375) }\end{array}$ & 380 \\
\hline N 3 & $\begin{array}{l}31 \text { pièces e.o. } 1 \text { aes IV Valentinien } \\
\text { II Rome (383-387) } \\
1 \text { aes IV Valentinien II, Aquilée } \\
\text { (388-392), } \\
1 \text { aes IV Valentinien II, Lyon (388- } \\
\text { 392) }\end{array}$ & 390 \\
\hline N 4 & $\begin{array}{l}1 \text { follis Severus II, Aquilée (305- } \\
306)\end{array}$ & 305 \\
\hline N 5 & $\begin{array}{l}97 \text { pièces : } 2 \text { aes IV Valentinien II } \\
(388-395)\end{array}$ & 390 \\
\hline N 6 & $\begin{array}{l}6 \text { pièces: } 1 \text { aes II Magnus Maxi- } \\
\text { mus (383-388) }\end{array}$ & 385 \\
\hline N 7 & 1 follis Constantinus $( \pm 315)$ & 315 \\
\hline N 8 & $\begin{array}{l}1 \text { follis (fils de) Constantin (335- } \\
341 \text { ) }\end{array}$ & 340 \\
\hline N 9 & 1 aes IV (365-400) & 365 \\
\hline N 10 & $\begin{array}{l}7 \text { pièces: } 1 \text { follis de Constance } \\
(347-348) \\
1 \text { follis (fils de) Constantin (335- } \\
341)\end{array}$ & 350 \\
\hline N 11 & $\begin{array}{l}1 \text { aes II Gratien, Valentinien II, ou } \\
\text { Theodose I, Arles (378-388) }\end{array}$ & 380 \\
\hline
\end{tabular}

Fig. 10 - Ensembles numismatiques dans les stratigraphies de Derlon et de Mabro.

rents fortins belges, comme Furfooz, Dourbes ou Éprave. Pour d'autres ${ }^{25}$, cette carence est liée à des problèmes militaires ou encore à une stagnation de la circulation monétaire. Quoi qu'il en soit, l'augmentation sensible des monnaies à Maastricht durant les deux dernières phases ( 7 et 8 ) de Ravetz ${ }^{26}$ marque une activité maximale du castrum vers la fin du Ives. Comme partout en Gaule, les séries monétaires s'arrêtent au début du $v^{*} s$.

Sur le site de Derlon (fig. 9, coupes A-D) la transition entre le $\mathrm{I}^{\mathrm{e}}$ et le $\mathrm{v}^{\mathrm{e}} \mathrm{s}$. se situe à $48,50 \mathrm{~m}$ audessus du niveau de la mer (= N.A.P). Au-dessus de

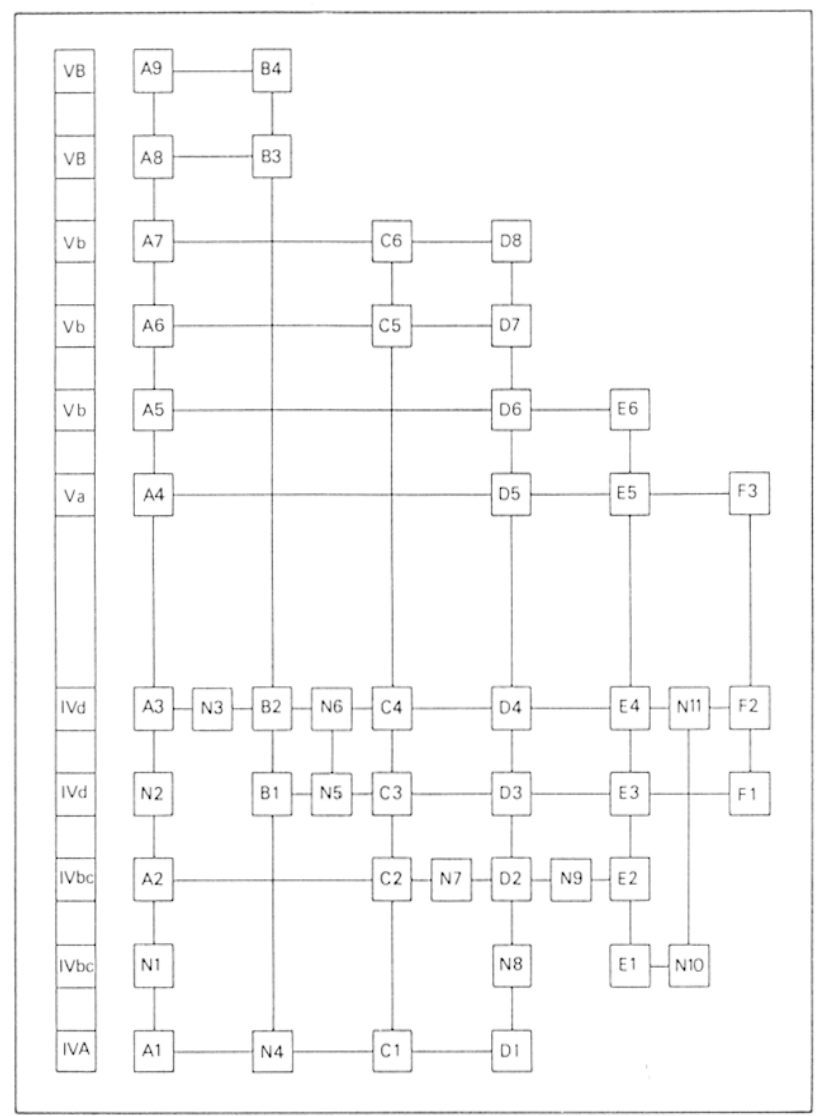

Fig. 11 - Les relations entre les couches contenant de la céramique (A-F) et des monnaies (N 1-11) du Bas-Empire.

ce niveau, on ne trouve plus de monnaies du BasEmpire in situ. Dans les coupes A-D, aucun fragment de terre sigillée décorée à la molette aux motifs chrétiens n'a été trouvé en dessous de $48,50 \mathrm{~m}$ N.A.P. Sur le site de Mabro (fig. 9, coupes E, F) la transition ne correspond pas à un niveau particulier, parce que dans la seconde moitié du Ive s. le terrain est inondé par le Geer. Ces inondations ont apporté d'importants dépôts sableux contre le flanc méridional de la forteresse du Bas-Empire (fig. 21). Le niveau de ces dépôts augmente vers le nord pour finalement redescendre près du fossé entourant l'enceinte ${ }^{27}$. Les tessons décorés de motifs chrétiens se situent dans une phase de construction creusée dans ces sables (E5 et F3) et dans des remblais recouvrant ces sables (E6) (fig. 21).

Les sites de Mabro et de Derlon ont livré des quantités fort importantes de céramique du BasEmpire. Il s'agit principalement de la terre sigillée - souvent décorée à la molette - et de la terre rugueuse, dite de l'Eifel (Allemagne). Sur le site de 


\begin{tabular}{|c|c|c|c|c|c|c|c|c|c|c|}
\hline \multirow{2}{*}{ Couche } & \multirow{2}{*}{ No de molette } & \multicolumn{8}{|c|}{ Groupe Hübener } & \multirow{2}{*}{ Atelier } \\
\hline & & 1 & 2 & 3 & 4 & 5 & 6 & 7 & 8 & \\
\hline A $4-1$ & & & - & & & & & & & \\
\hline A $4-2$ & & & & . & & & & & & \\
\hline A $4-3$ & Chenet 353 & & & & & & & - & & \\
\hline A6-1 & & & & - & & & & & & \\
\hline A6-2 & Chenet 179 & & & & & & & - & & Pont-des-Quatre-Enfants \\
\hline$A 7-1$ & Chenet 99 & & & & & & - & & & Chàtel-Chéhéry \\
\hline $\mathrm{A} 7-2$ & Chenet 68 & & & & & & - & & & Vauquois \\
\hline A $7-3$ & Chenet 181 & & & & & & & & - & Châtel-Chéhéry \\
\hline A $8-1$ & Chenet 243 & & & - & & & & & & Allieux B \\
\hline A $8-2$ & & & & & - & & & & & \\
\hline A $8-3$ & & & & & • & & & & & \\
\hline A $8-4$ & Robert 9 (= Thijssen 5) & & & & & - & & & & \\
\hline A $8-5$ & Piton, Bayard 29 & & & & & - & & & & \\
\hline B2-1 & Var. Chenet 334 (= Paar, Rüger 13) & & & & & & - & & & \\
\hline B3-1 & Var. Chenet 181 & & & & & & & & - & Chàtel-Chéhéry \\
\hline B3-2 & M 6 & & & & & & & & • & \\
\hline B3-3 & Chenet 178 & & & & & & & • & & $\begin{array}{l}\text { Pont-des-Quatre-Enfants ou Vau- } \\
\text { quois }\end{array}$ \\
\hline B3-4 & & & & - & & & & & & \\
\hline B3-5 & & & & & & & & - & & \\
\hline B4-1 & Var. Chenet 182 & & & & & & & & - & \\
\hline B4-2 & Chenet 258 & & & & & & & & • & Chàtel-Chéhéry \\
\hline B4-3 & Chenet 131 & & & & & - & & & & Chàtel-Chéhéry \\
\hline $\mathrm{C} 2-1$ & Chenet 288 & - & & & & & & & & Allieux B \\
\hline $\mathrm{C} 2-2$ & & & & - & & & & & & \\
\hline D1-1 & Chenet 158 & & - & & & & & & & plusieurs centres de potiers \\
\hline D5-1 & Chenet 163 & & & & & - & & & & Vauquois \\
\hline D5-2 & & & & - & & & & & & \\
\hline D5-3 & & & & & - & & & & & \\
\hline D5-4 & & & & - & & & & & & \\
\hline D5-5 & & & & & - & & & & & \\
\hline D5-6 & & & & & - & & & & & \\
\hline
\end{tabular}

Fig. 12 - La céramique décorée à la molette dans les stratigraphies de Derlon et de Mabro. 


\begin{tabular}{|c|c|c|c|c|c|c|c|c|c|c|}
\hline E1-1 & Chenet 250 & & & & & & & • & & Allieux B \\
\hline E1-2 & & & & - & & & & & & \\
\hline E1-3 & & & & - & & & & & & \\
\hline E2-1 & molette inédite & - & & & & & & & & \\
\hline E2-2 & molette inédite & & & & & & • & & & \\
\hline E2-3 & Chenet 190 & & & - & & & & & & \\
\hline E2-4 & Chenet 67 & & & & & & • & & & Allieux A \\
\hline E2-5 & Chenet 158 & & - & & & & & & & plusieurs centres de potiers \\
\hline E3-1 & Gricourt 32 & $\cdot$ & & & & & & & & \\
\hline E3-2 & Chenet 304 & & - & & & & & & & \\
\hline E3-3 & Chenet 310 & & & & & & & • & & \\
\hline E3-4 & Chenet 68 & & & & & & • & & & Vauquois \\
\hline E4-1 & & & & $\cdot$ & & & & & & \\
\hline E4-2 & Chenet 174 & & & & & & & $\bullet$ & & Châtel-Chéhéry \\
\hline E4-3 & Chenet 307 & & - & & & & & & & \\
\hline E4-4 & Chenet 352 & & & & & • & & & & \\
\hline E4-5 & & & & & $\cdot$ & & & & & \\
\hline E5-1 & Chenet 124 & & & & & • & & & & Châtel-Chéhéry \\
\hline E5-2 & Chenet 124 & & & & & - & & & & Châtel-Chéhéry \\
\hline E5-3 & Chenet 119 & & & & & - & & & & Châtel-Chéhéry \\
\hline E5-4 & Chenet 181 & & & & & & & & $\cdot$ & Châtel-Chéhéry \\
\hline E5-5 & Chenet 68 & & & & & & • & & & Vauquois \\
\hline E5-6 & molette inédite & & & & & - & & & & \\
\hline E6-1 & & & & & - & & & & & \\
\hline E6-2 & & & & & - & & & & & \\
\hline E6-3 & & & & • & & & & & & \\
\hline E6-4 & molette inédite & & & & & & - & & & \\
\hline E6-5 & Chenet $150(=152)$ & & & & & & & • & & plusieurs centres de potiers \\
\hline E6-6 & Chenet 71 & & & & & & & • & & \\
\hline E6-7 & Chenet 258 & & & & & & & & $\cdot$ & \\
\hline F1-1 & Chenet 96 & & & & & - & & & & Lavoye \\
\hline F2-1 & & & & & $\cdot$ & & & & & \\
\hline F3-1 & & & & & $\cdot$ & & & & & \\
\hline F3-2 & Chenet 131 & & & & & • & & & & Châtel-Chéhéry \\
\hline F3-3 & Chenet 186 & & & & & & & & $\cdot$ & Châtel-Chéhéry \\
\hline
\end{tabular}


Derlon, ces deux catégories de céramique représentent environ $80 \%$ de l'ensemble, les $20 \%$ restants comprenant de la céramique commune (environ $10 \%$ ) et de la céramique vernissée (également environ $10 \%$ ), ce qui semble être la norme pour l'époque ${ }^{28}$. Les autres sites livrent des pourcentages semblables. La terre sigillée décorée à lamolette à motifs chrétiens forme un groupe particulier dans l'ensemble de la terre sigillée du BasEmpire. Une partie de cette céramique a été trouvée dans des positions stratigraphiques sûres. Seule la céramique sigillée décorée à la molette provenant des quatre coupes du site de Derlon (fig. 9, A-D) et de deux autres, du site de Mabro (E-F), a été étudiée dans le cadre de cet article, dans la mesure où ces dernières sont les seules à avoir été fouillées stratigraphiquement (cf. inventaire, fig. 12).

Les couches correspondant à la construction de l'enceinte, datée par dendrochronologie en 333, sont bien reconnaissables à Derlon $(\mathrm{A} 1 ; \mathrm{C} 1,2 ; \mathrm{D} 1,2)$ et à Mabro (E1) (fig. 12). Une partie de la terre sigillée issue de ces niveaux est décorée de molettes à oves (fig. 15-16). Elles relèvent du groupe 1 de Hübener ${ }^{29}$ et paraissent caractéristiques de cette période ${ }^{30}$. Durant la seconde moitié du $I^{e}$ s. et au $v^{e} s$., les décors à la molette les plus fréquemment utilisés appartiennent aux groupes 2 à 7 de Hübener.

Les tessons de rebord en terre rugueuse trouvés dans les couches constantiniennes (E1-1, D2-1 et 2, C2-1, 2, 3 et 4), peuvent être comparés aux fragments de Zell-Alteburg ${ }^{31}$, Kolverath ${ }^{32}$ et Neef ${ }^{33}$. Les formes Alzei 27, $28^{34}$ et Niederbieber $113^{35}$ sont caractéristiques de la première moitié $d u{ } v^{e} s$. Les rebords des urnes du type Alzei 27 sont cordiformes ${ }^{36}$; les pelves du type Alzei 28 présentent des bulbes prononcés à l'intérieur et une rainure à l'extérieur ${ }^{37}$.

On rencontre les formes Alzei 27, 28, 29, 30 et 34 dans les couches d'occupation de la seconde moitié du Ive s. (A 2, 3 et 4; B1 ; C3; D3, 4 et 5). Le nombre de pelves Alzei 28 semble diminuer à la fin du IVe $\mathbf{s}$.

28 Gilles, 1985, p. 95.

29 Iübener, 1968

30 Bakker, 1981, p. 245; von Petrikovits, 1937, p. 328.

31 Gilles, 1985, p. 96, 100 et pl. 46-43II.

32 Gilles, 1985, p. 97, 99 et pl. 46-45E.

33 Gilles, 1985, p. 97 et pl. $47: 46 \mathrm{G}$.

34 Unverzagt, 1916.

35 Oelmann, 1914.

36 Fellmann, 1952, p. 165: type C; Gilles, 1985, pl. $46:$ G1.

37 Fellmann, 1952; Gilles, 1985, pl. 46 : F, G et H; Spors, 1986, p. 433-434.
(A7, D5). En revanche, la tèle Alzei 31 (A9, B5, 6) n'apparaît qu'au début du v $v^{e} s$. Elle est déjà connue en nombre limité au camp d'Altrip, abandonné vers 406-407. L'apparition de la tèle Alzei 31 est datée à Echternach ${ }^{38}$ de la fin du Ive ou du début du $v^{e} s$. D'après les données numismatiques, les tèles du type Alzei 31 doivent être datées après $380(=\mathrm{E} 4)$. L'urne Alzei 27 et plus particulièrement sa variante la plus récente, avec son bord en faucille (A 6,$7 ; \mathrm{D} 6$, 8 ; E 5) reste abondante durant le $\mathrm{v}^{\mathrm{e}} \mathrm{s} .{ }^{39}$. Cependant il n'y a pas d'évolution claire dans les formes des rebords durant la seconde moitié du Ive $\mathbf{s}$. et le $\mathbf{v}^{\mathbf{e}} \mathbf{s}$. Des parallèlles sont connus à Trèves ${ }^{40}$ et dans l'Eifel ${ }^{41}$. Les vases du type Alzei 30 se sont développés à partir du type Niederbieber 95 . Ils sont abondants à Trèves ${ }^{42}$ et à Neef ${ }^{43}$. Les urnes de type Alzei $32 / 33$ sont quasi absentes dans les stratigraphies de Maastricht.

En 1968, W. Hübener a publié un ouvrage sur la terre sigillée décorée à la molette. Il a divisé l'ensemble des molettes en neuf groupes auxquels il a tenté d'associer une chronologie. Son schéma a été critiqué par plusieurs auteurs ${ }^{44}$. La subdivision en groupes n'est effectivement guère satisfaisante : ces groupes ne sont pas homogènes; il existe des molettes attribuées à deux groupes différents et seule la moitié des molettes connues actuellement est représentée.

En conséquence, la chronologie pose de nombreux problèmes. Seuls les groupes 1 et 8 peuvent être datés avec une plus grande assurance, respectivement dans la première moitié du $1 v^{e} \mathbf{s}$. (jusqu'à $360)$ et au v $v^{e}$ s. Les datations des autres groupes sont plutôt le résultat d'un développement présumé, à partir de molettes simples, évoluant vers des molettes plus compliquées.

La figure 19 montre un schéma corrigé globalement, suivant encore la division de Hübener. Cette chronologie n'est qu'indicative, parce qu'il faut pour chaque molette chercher des dates fixes, qui nous aident à mieux connaître les intervalles dans lesquels

38 Bakker, 1981, p. 249

39 Fellmann, 1952, p. 65 : types C et D; Gilles, 1985 , pl. 46, types 43 : A-L; Spors, 1986, p. 432.

40 Ilussong, Cüppers, 1972, Umbaukeramik type 34a-b et Barbarathermen, type 27a-b.

41 Gilles, 1985, type 47F.

42 Hussong, Cüppers, 1972, Umbaukeramik type 46a-b et Barbarathermen, type 35 .

43 Gilles, 1985, type 48G-II.

44 Mitard, 1975, p. 83-84; Piton, Bayard, 1978, p. 22; Bakker, 1981, p. 320 ; Gilles, 1985, p. 91. 

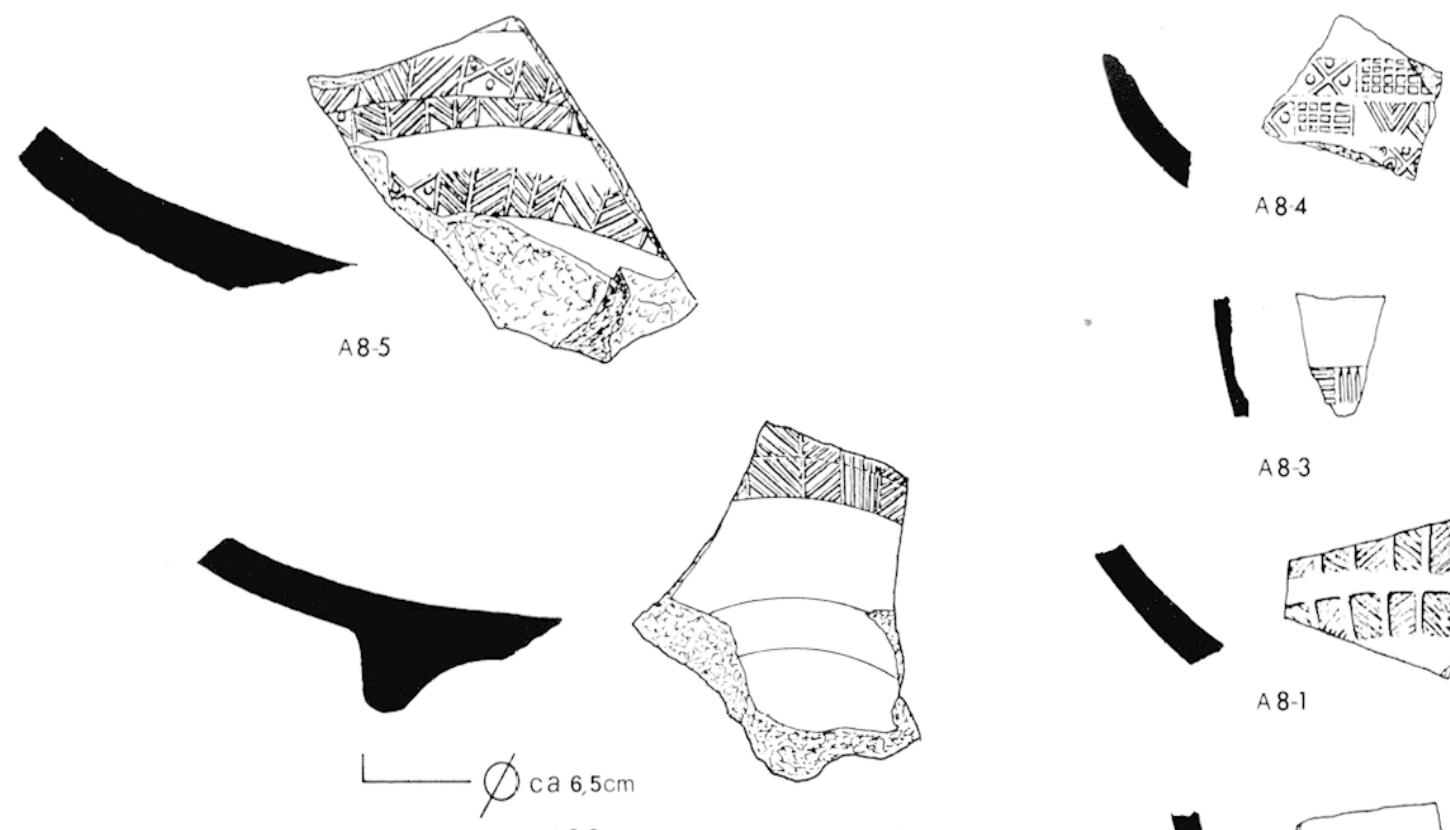

A 8-3

A 8-2
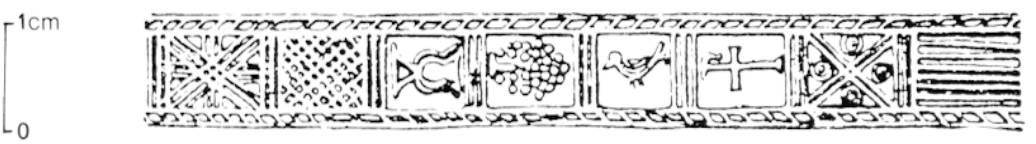

A 7-3
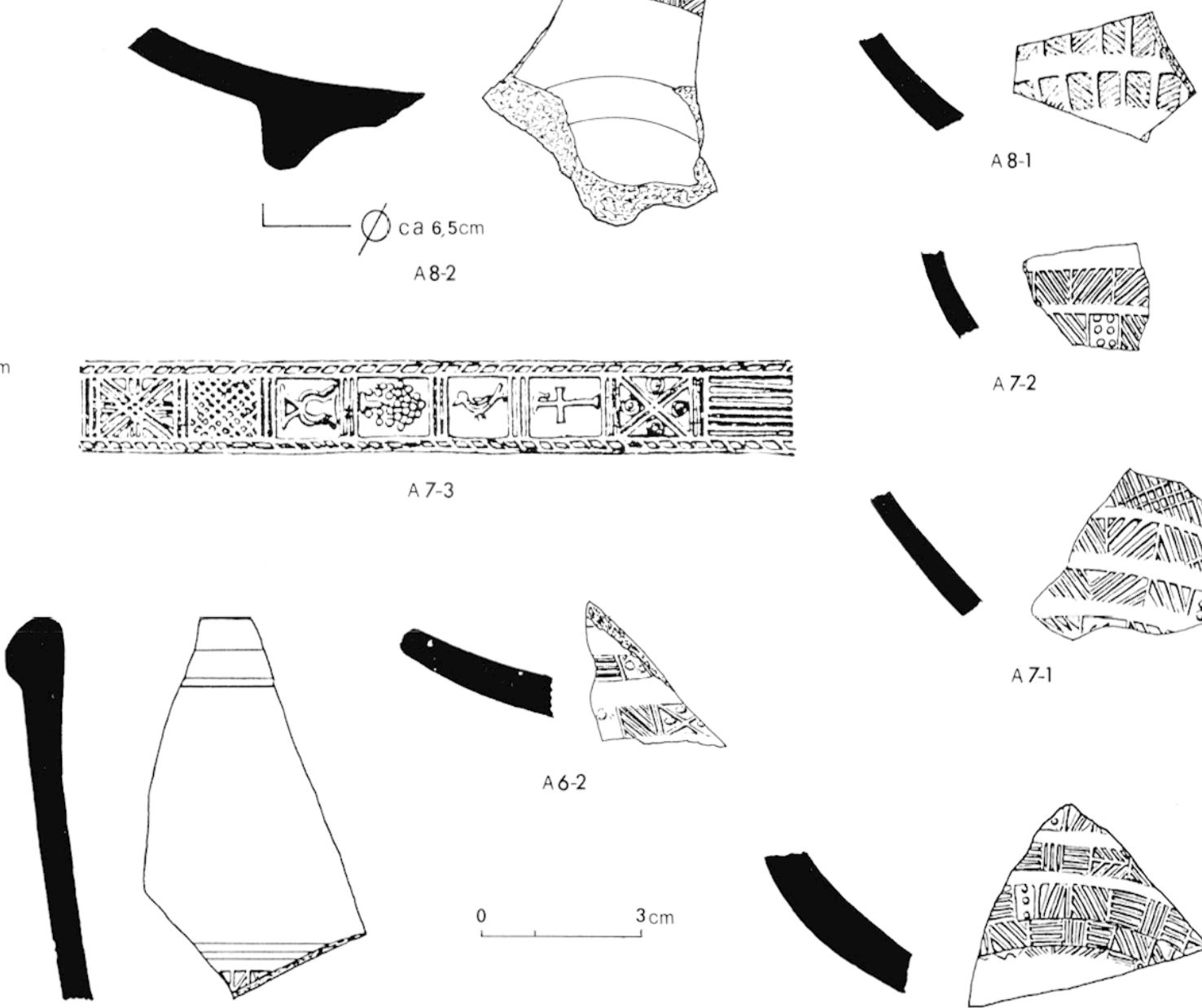

A 8-1

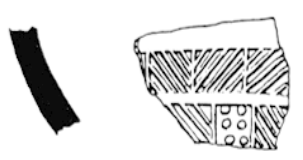

A 7-2
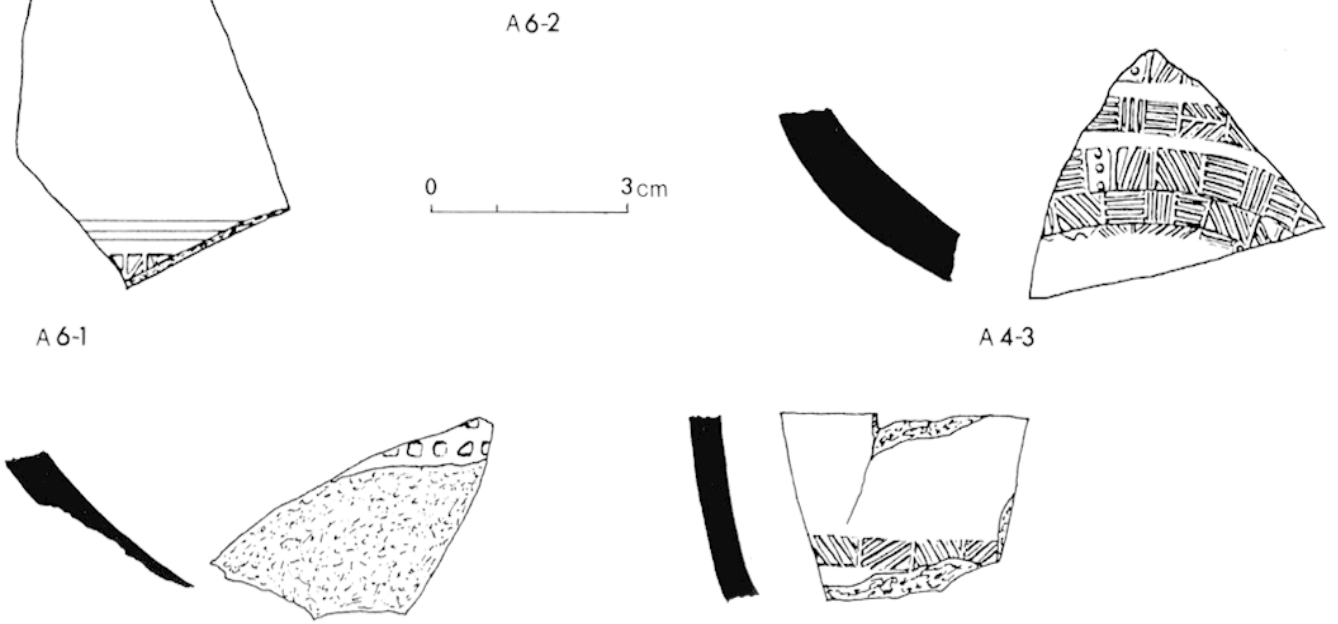

A 4-1

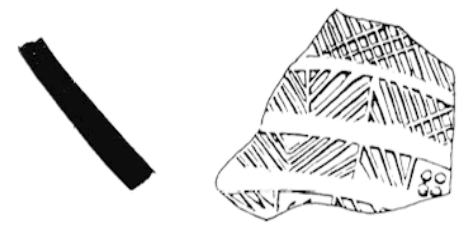

A 7-1

A $4-3$

A 4-2

Fig. 13 - Site de Derlon. Terre sigillée décorée à la molette provenant de la coupe A. 


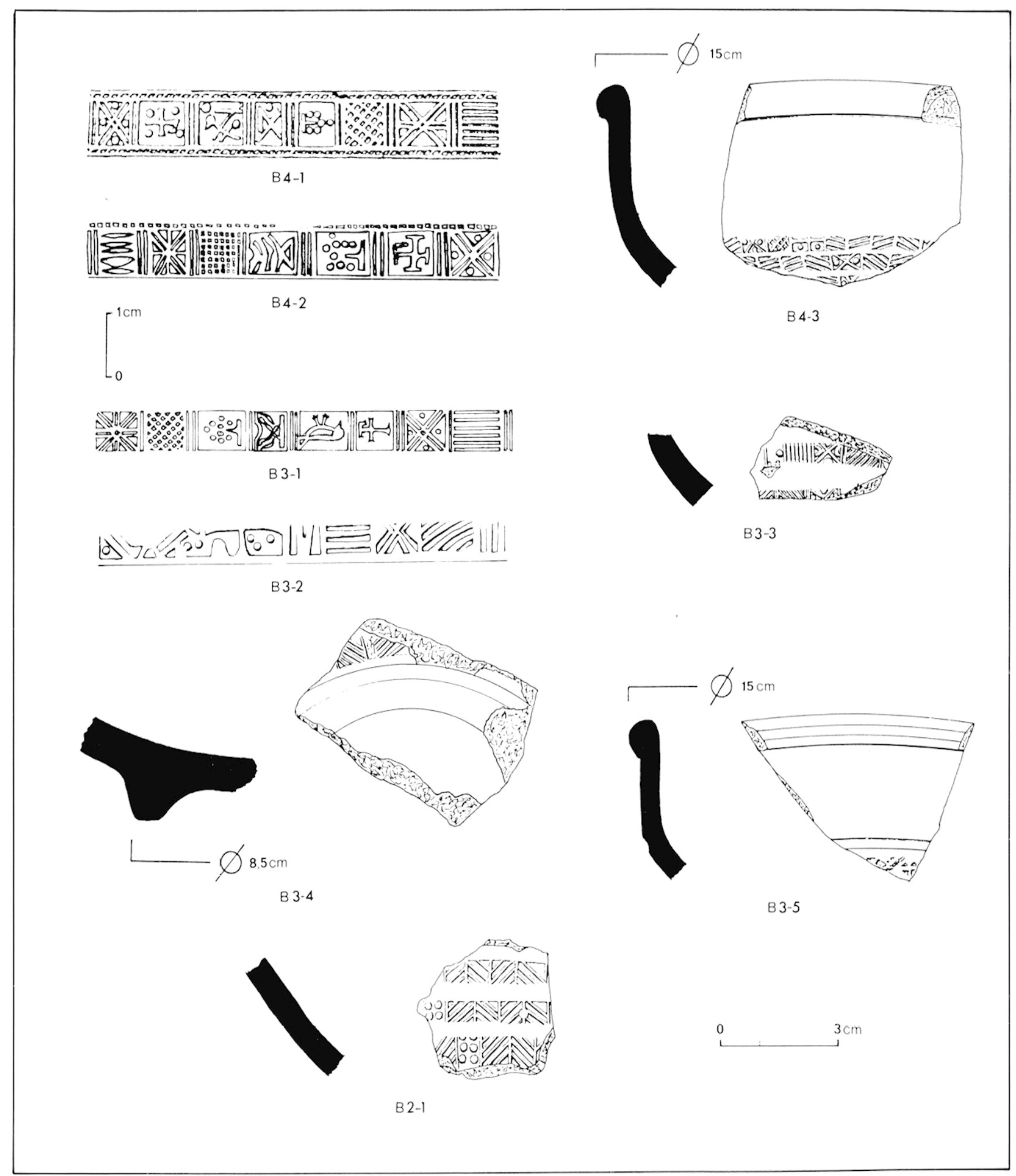

Fig. 14 - Site de Derlon. Terre sigillée décorée à la molette provenant de la coupe B. 

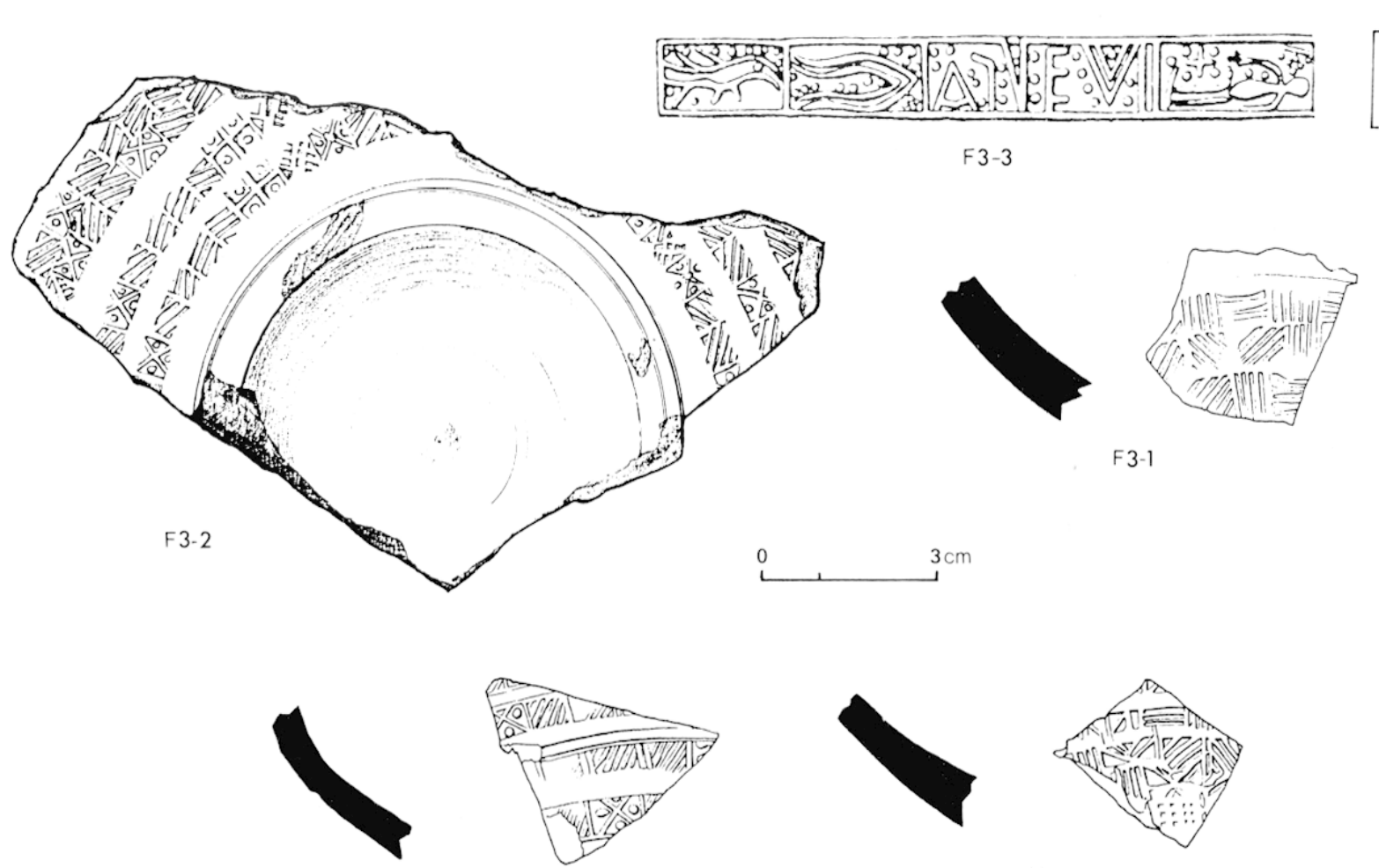

F1-1

F 2-1

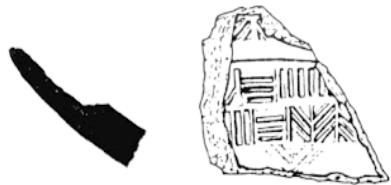

D5-6
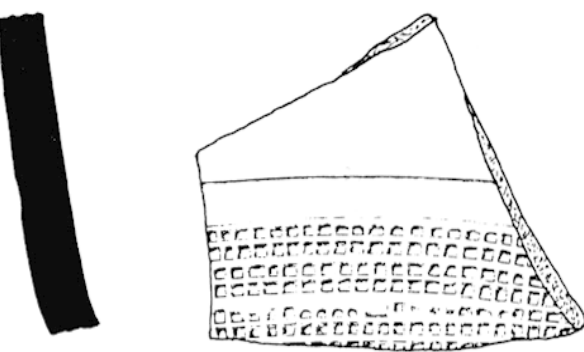

D1-1

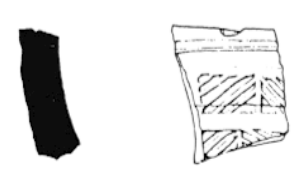

D5-5

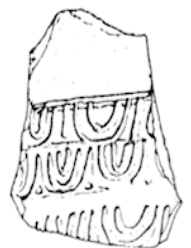

C2-1
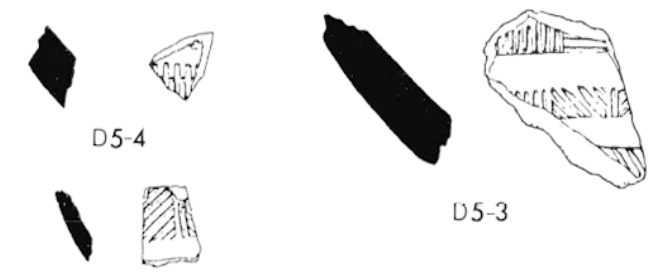

D5-3

D5-2
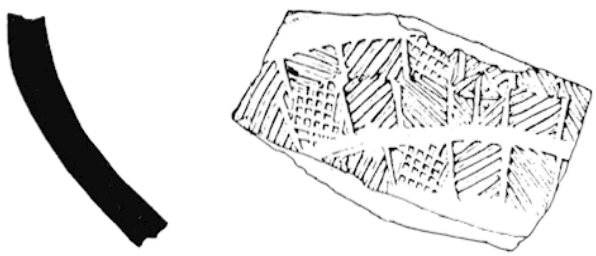

D5-1
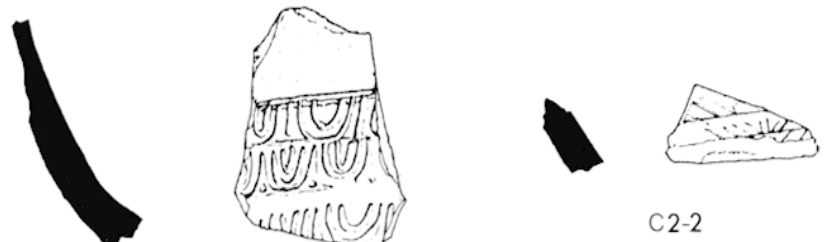

C2-2

Fig. 15 - Sites de Derlon et Mabro. Terre sigillée décorée à la molette provenant des coupes C, D et F. 


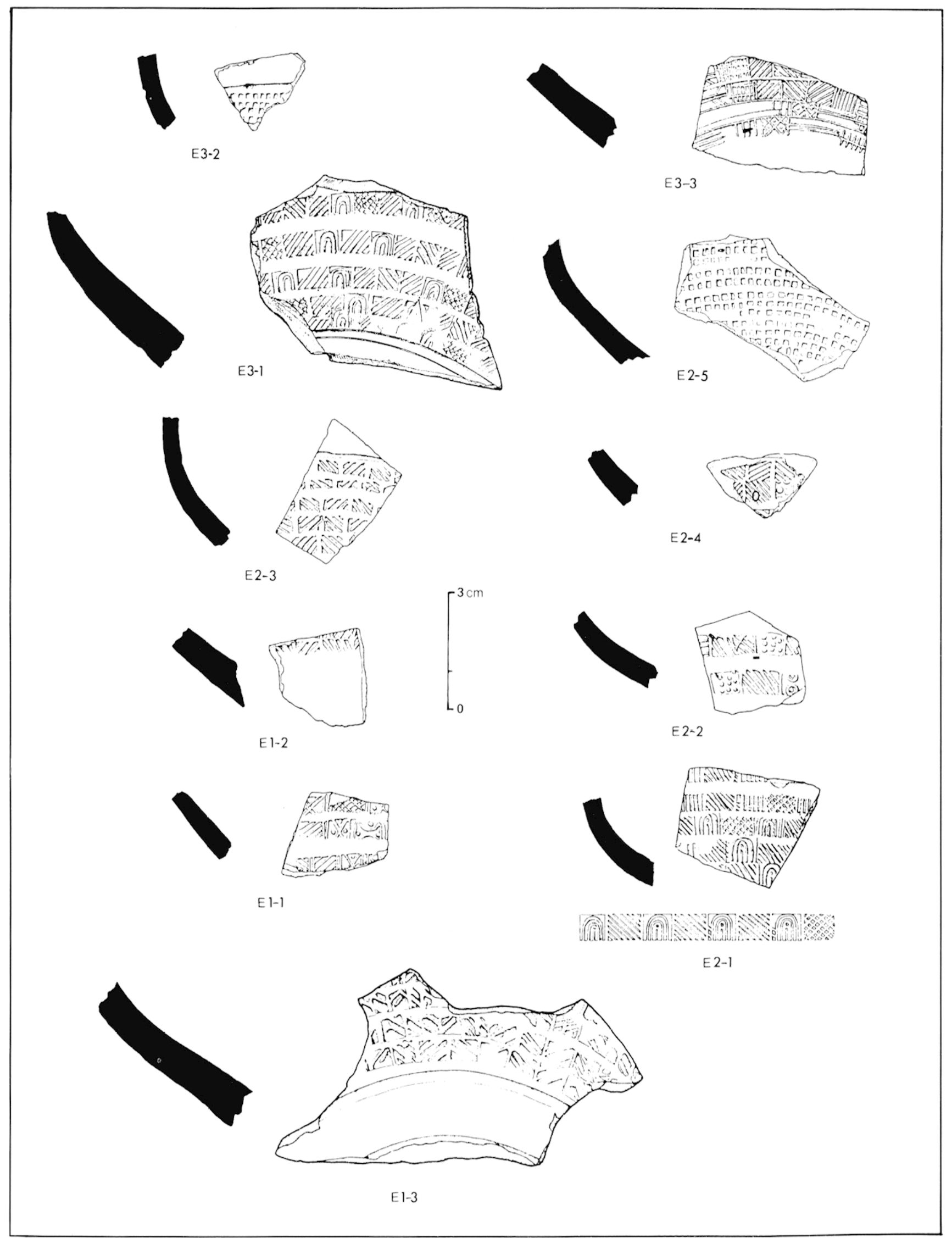

Fig. 16 - Site de Mabro. Terre sigillée décorée à la molette provenant de la coupe E. 

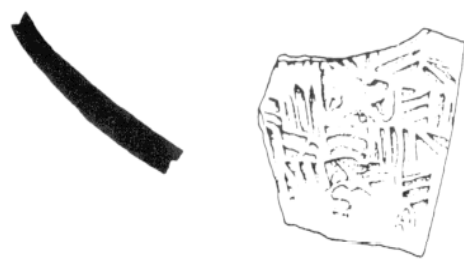

E5.6
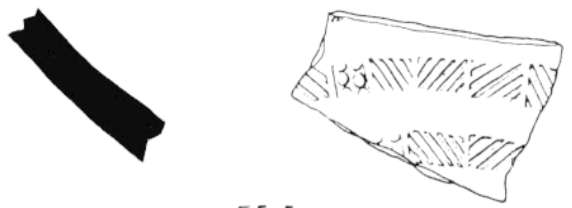

E5-5
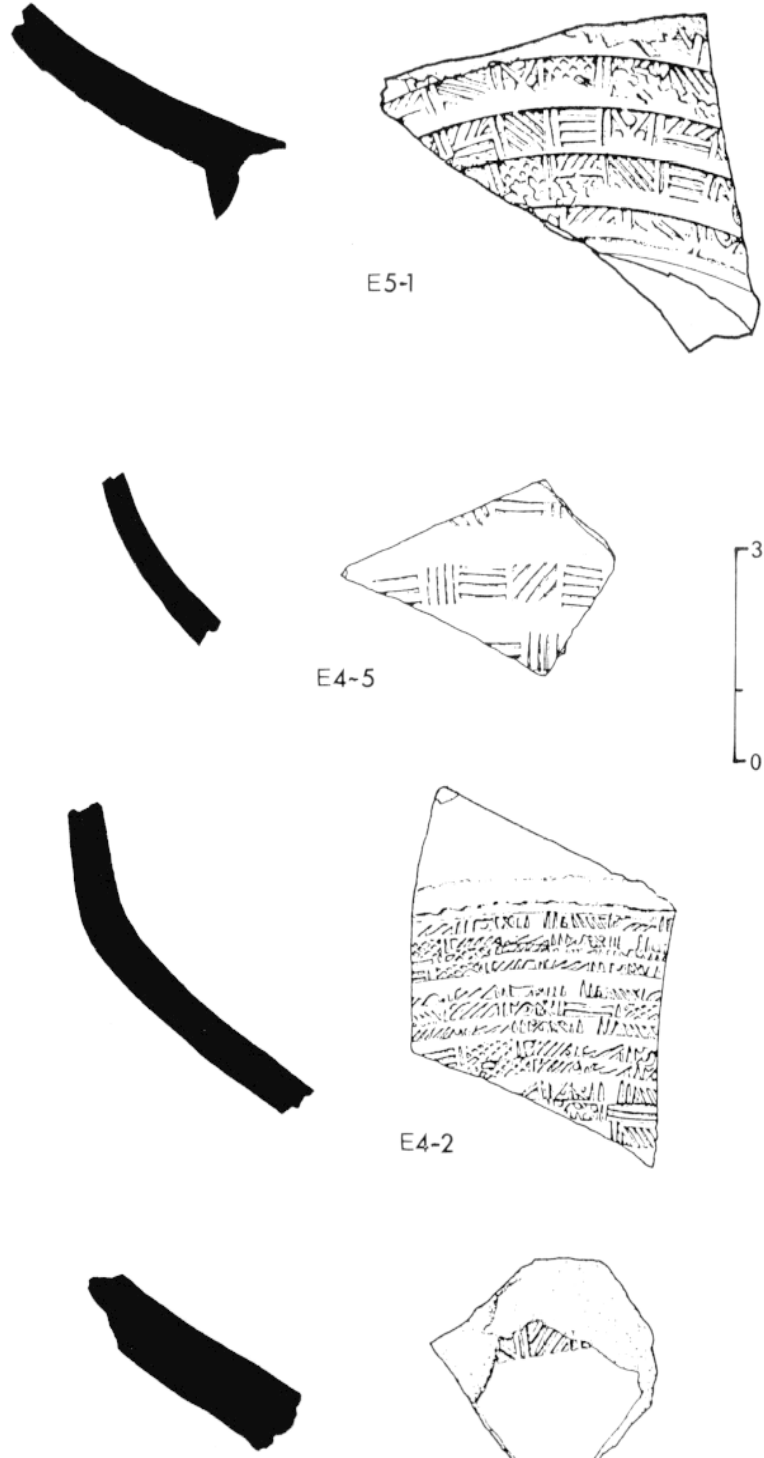

E4-1

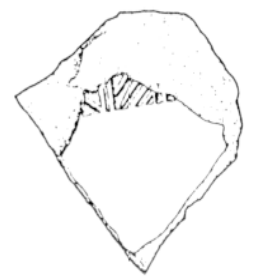

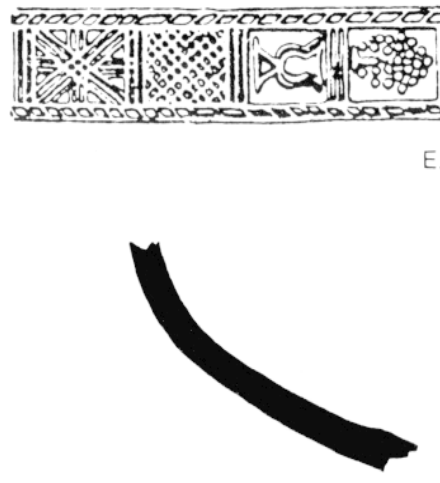

E5-4
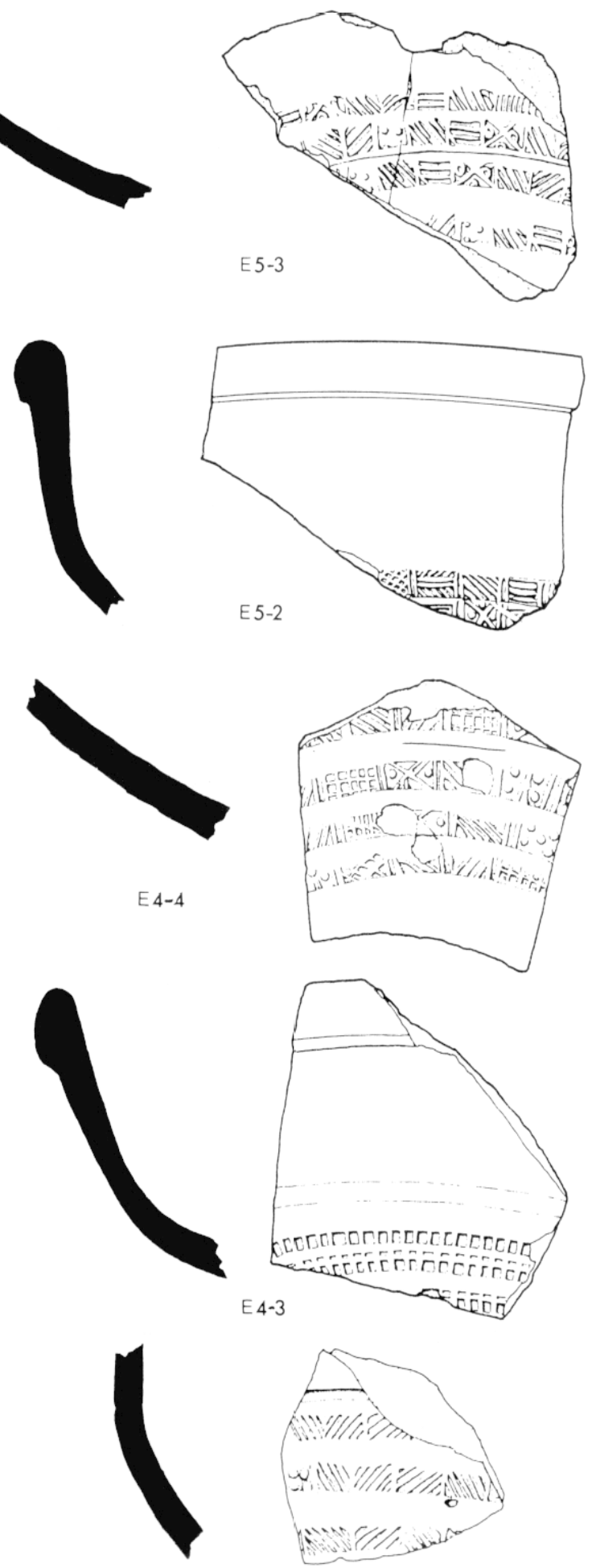

E3-4

Fig. 17 - Site de Mabro. Terre sigillée décorée à la molette provenant de la coupe E. 


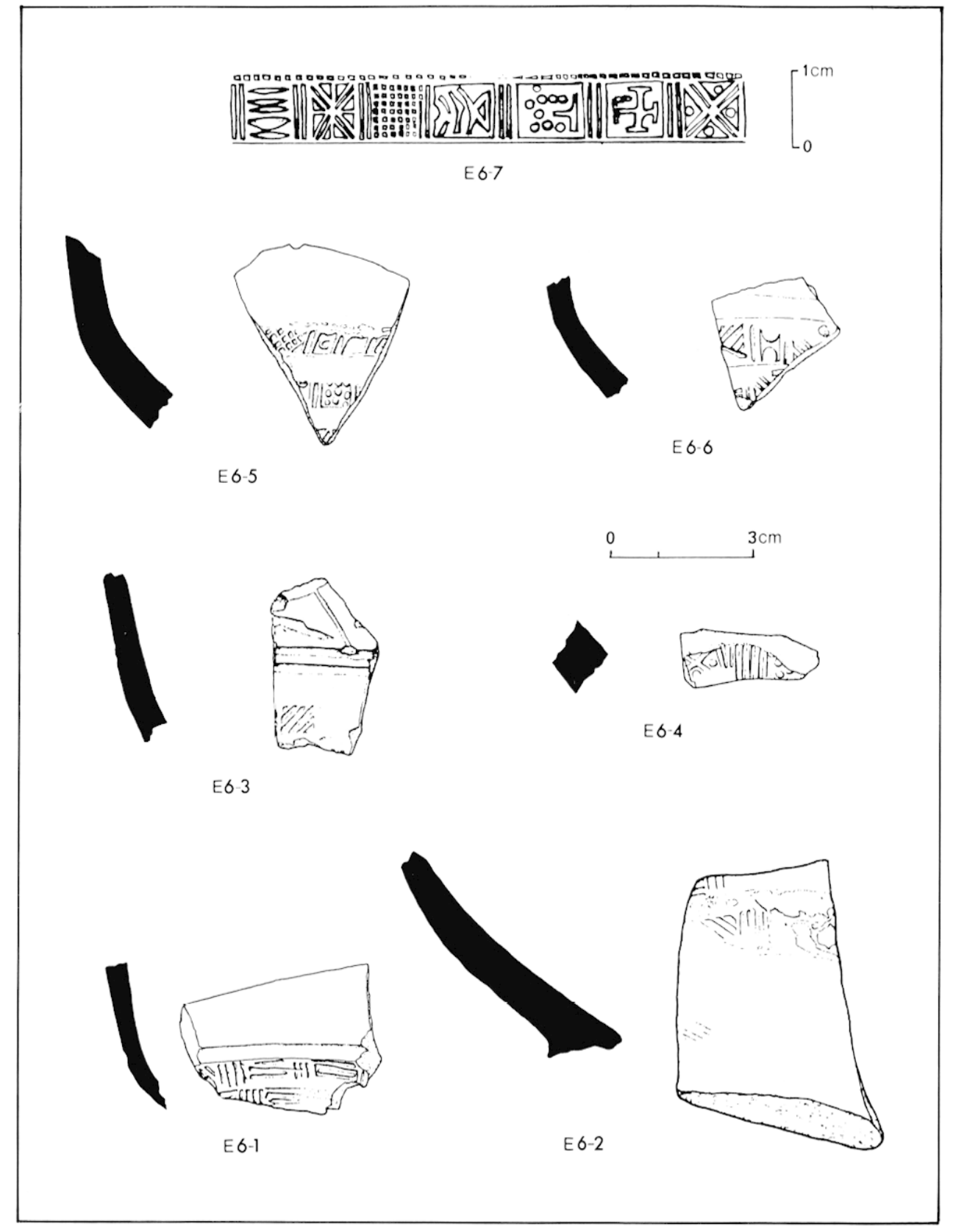

Fig. $18-$

Site de Mabro. Terre sigillèe décorée à la molette provenant de la coupe $\mathrm{E}$. les molettes individuelles ont été utilisées. Les corrections sont fondées sur les stratigraphies des sites de Derlon et de Mabro de Maastricht (fig. 11).

Les molettes à petits rectangles (groupe 2) font leur apparition dans la couche D 1 (IVA); les molettes à oves (groupe 1), celles à hachures obliques (groupe 3), à croix de saint André (groupe 5) et les molettes dites "compliquées" (groupe 7) apparaissent dans les couches A 2, C 2, D 2, E 1 et E 2 (deuxième et troisième quarts du Iv ${ }^{e} \mathrm{~s}$.) ; les molettes à hachures horizontales et verticales (groupe 4) se retrouvent à partir des couches A 8, D 5, E 4 et F 2 (dernier quart du Ive s.), les molettes à six globules (groupe 6) à partir des couches A 7, B 2 et E 2 (troisième quart du IVe s.); les molettes "chrétiennes" (groupe 8) enfin n'apparaissent qu'à partir des couches A7, B3, E5 et F3 (premier quart du $\mathrm{v}^{\mathrm{e}} \mathrm{s}$.).

Une comparaison avec les données numismatiques (fig. 11) montre que le groupe 2 apparaît déjà avant 335 , les groupes $1,3,5$ et 7 à partir de 335 , le groupe 6 après 350 et enfin les groupes 4 et $G$, après 375 environ.

Cette chronologie présente de nombreux points de ressemblances avec le schéma chronologique 


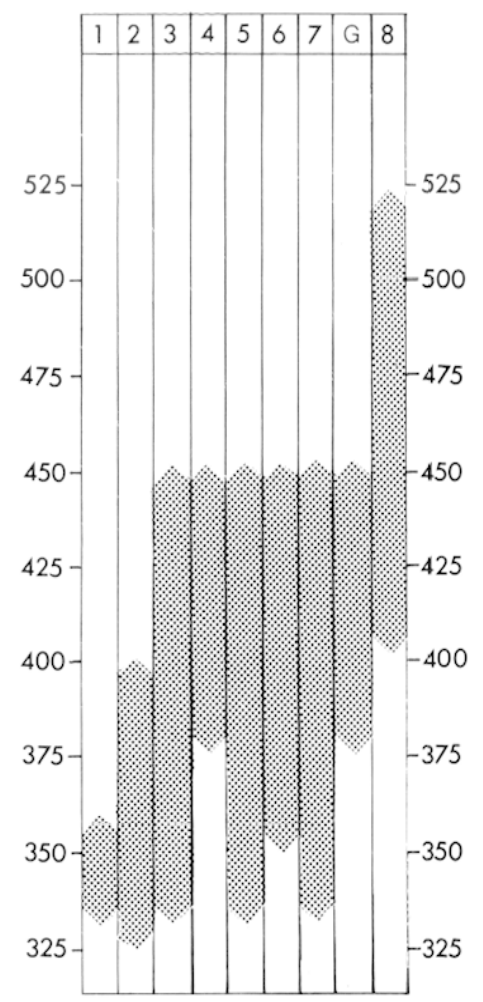

Fig. 19 - Chronologie de la terre sigillée décorée à la molette, suivant la division en groupes $(1-8, G)$ de Hübener

(1968) et corrigée après les données de Maastricht.

developpé par L. Bakker ${ }^{45}$, à partir d'une étude de 3000 molettes environ, trouvées en Allemagne. Néanmoins, il faut souligner que, suivant ce schéma, une partie des molettes reste indéterminable et que trop de molettes ont été classées par Hübener dans deux groupes différents ${ }^{46}$. L'ouvrage de Hübener représente un essai de chronologie et il a le mérite d'avoir été le premier à proposer une classification des molettes en groupes.

\section{ÉVOLUTION CHRONOLOGIQUE}

Huit des trente-trois fragments de bols hémisphériques à rebord en baguette du type Chenet 320 , décorés à la molette à motifs chrétiens, ont été trouvés dans des séquences stratigraphiques non perturbées du site de Mabro au sud de l'église Notre-Dame et du site de Derlon, au nord de cette dernière (fig. 20).

45 Bakker, 1981, communication à Koblenz en mai 1986 et Table ronde à Metz en septembre 1987.

46 Hübener, 1968, molettes 104, 114, 224, 232, 234 et
Ces fragments forment un groupe hétérogène : la forme, la pâte, l'engobe et la qualité de l'impression de la molette sont très variés. Globalement, on peut discerner trois groupes typochronologiques.

Dans un premier stade, la cuisson est bonne, l'engobe est rouge orangé, l'anneau de base est prononcé et les molettes figurent toutes dans le catalogue de Chenet ${ }^{47}$.

La cuisson des pièces de la deuxième phase est déjà moins bonne, le cœur est gris ou même noir, l'engobe orange brun et l'anneau de base est moins prononcé. Des variantes apparaissent en plus des molettes publiées par Chenet.

Enfin, dans la troisième phase, la cuisson est souvent mauvaise, l'engobe est beige ou brun et l'anneau de base a presque disparu. Les molettes sont toutes des variantes ou des inconnues de Chenet ${ }^{48}$.

Cette typochronologie est confirmée par les données stratigraphiques et numismatiques. Le plan archéologique de Maastricht (fig. 20) montre un fossé entourant l'enceinte du Bas-Empire. Au site Mabro, ce fossé - une fois comblé - a été recouvert par des couches de sable. Une phase de construction est implantée dans ces sédiments. Au même niveau se trouvent des débris d'une autre phase de construction. Ces deux phases de construction sont à leur tour recouvertes par des nouvelles couches de sable. Un deuxième fossé est alors creusé dans les couches inférieures. Enfin, une couche contenant des trouvailles $\mathrm{du} \mathrm{vII}^{\mathrm{e}} \mathrm{s}$. recouvre la totalité de cette séquence stratigraphique ${ }^{49}$.

Environ 150 tessons de terre sigillée décorée à la molette ont été découverts dans le remplissage du premier fossé et les couches de sable inférieures (fig. 21, fossé du Bas-Empire), mais aucun fragment n'est orné de motifs chrétiens. Les données numismatiques permettent de dater ces couches des environs de 400 après J.-C. ${ }^{50}$. Deux tessons à motifs chrétiens (fig. 2 et $3, n^{\text {us }} 8$ et 14 ), appartenant à la première phase d'évolution typologique, ont été découverts parmi les restes de construction recouvrant les couches de sable inférieures ( $E 5$ et $F 3$ ). Cette phase doit donc débuter immédiatement après 400. Un fragment à motif's chrétiens (fig. ' 2 et 3 , $\left.n^{\circ} 15\right)$ de la deuxième phase typologique provient des remblais (E 6) de la seconde phase de construction. La position stratigraphique de cette couche semble être la même que celle de la première phase

47 Chenet, 1941.

48 Panhuysen, 1984, p. 76-78.

49 Panhuysen, 1984, p. 70-71.

50 Van der Vin, Panhuysen, 1983, p. 124-125. 


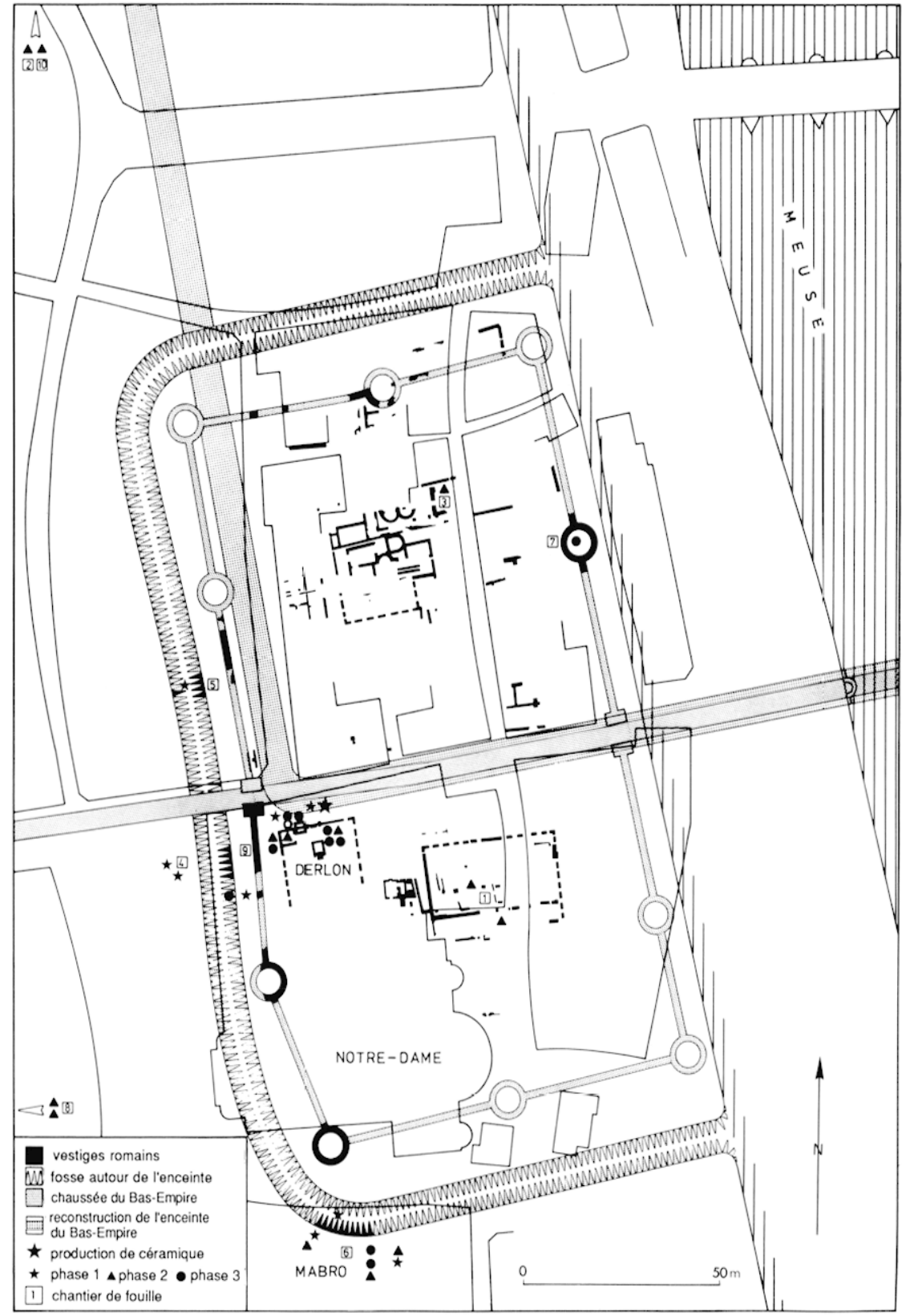

Fig. 20

Plan archéologique de Maastricht, avec indication des chantiers de fouilles et des découvertes de molettes chrétiennes. de construction, mais le matériel est typique du deuxième quart $d u v^{e} s$. Cette deuxième phase doit se prolonger jusque vers 450 au moins. Selon H. Bernhard ${ }^{51}$, les assiettes du type Chenet 304 sont produites en terre sigillee jusque vers 430 et en « rotgestrichene Ware" (= céramique peinte en rouge), après cette date. Les fouilles récentes d'Alzei ${ }^{52}$ ont montré que ce camp a connu une phase d'occupation après $435 / 436$; l'argument chronologique d'un abandon final en $435 / 436$ n'est plus acceptable. Olden-

51 Bernhard, 1981, fig. 37.

52 Oldenstein, 1986, note 49. stein souligne que la "rolgestrichene Ware" fait son apparition dans la première moitié $d u v^{e} s$., sans autre précision. Il me semble qu'à Maastricht les bols décorés à motifs chrétiens apparaissent peu après 400 et que le passage entre la première et la deuxième phase typologique se situe vers 430 .

Il n'est pas toujours facile d'attribuer les exemplaires trouvés hors de Maastricht à un groupe particulier. Beaucoup de ces fragments de bols ne sont pas décrits ni dessinés avec suffisamment de précision. Les plus nombreux proviennent de centres urbains importants du Bas-Empire, comme Reims ( $F$ 19), Trèves (D 3) ou Châtel-Chéhéry (F 5), seul centre connu de production de la céramique décorée à la 
Fig. 21 -

Plan de fouille du site de Mabro.

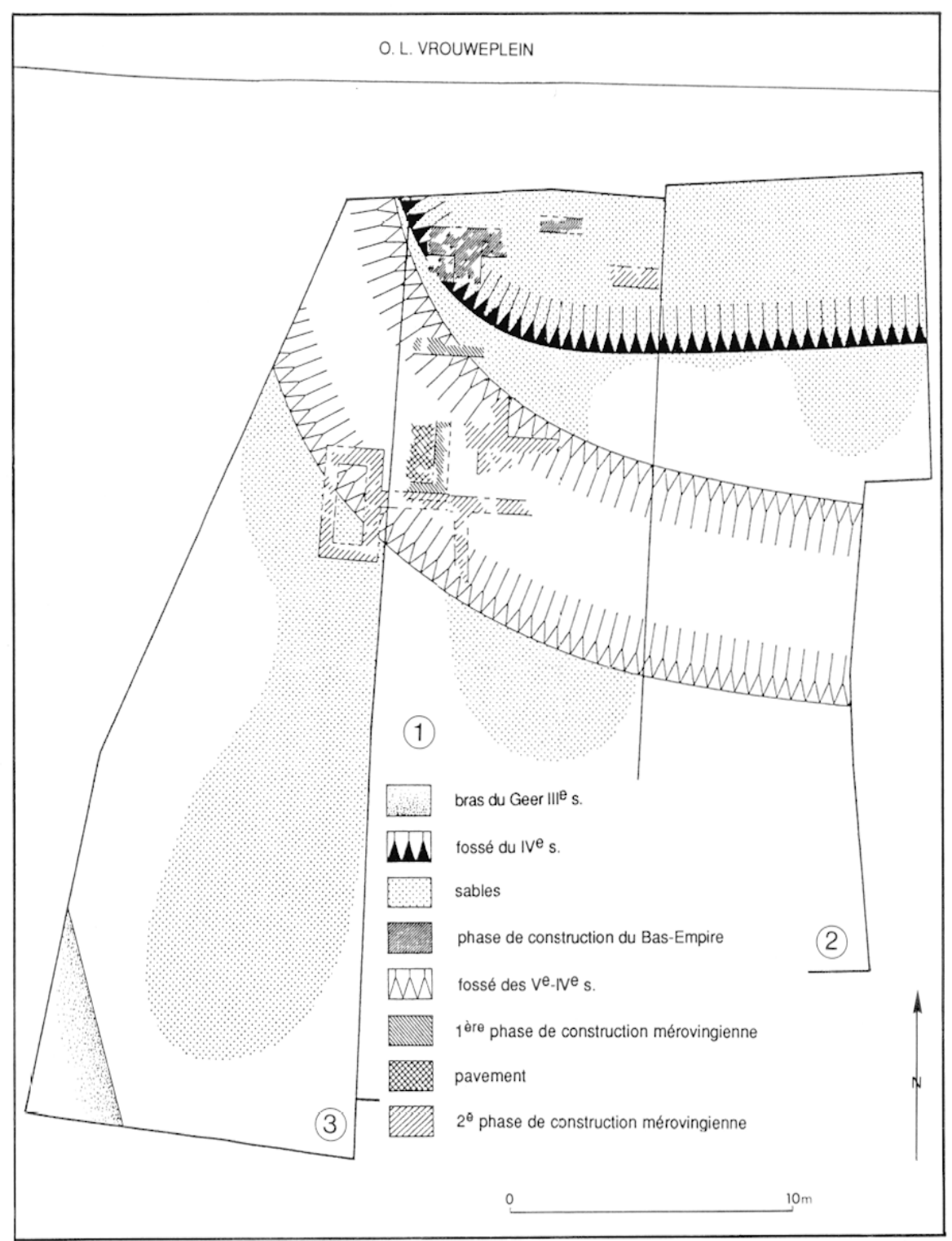

molette à motifs chrétiens. L'ensemble du grand amphithéâtre de $\operatorname{Metz}\left(\mathrm{F}_{13}\right)$ a été publié récemment dans cette même revue ${ }^{53}$.

Les photos et dessins des (fragments de) bols provenant de Reims ${ }^{54}$, Trèves ${ }^{55}$ et Châtel-Chéhéry ${ }^{56}$ ont été publiés dans l'article de Wautelet ${ }^{57}$. Ces fragments sont bien ceux qui ont servi de prototypes à

53 Bayard, 1990.

54 Wautelet, 1977, fig. $3, \mathrm{n}^{\circ} 1$.

55 Wautelet, 1977, fig. $3 \mathrm{n}^{\text {os }} 2$ et 3 .

56 Wautelet, 1977, pl. II.

57 Wautelet, 1977
Chenet ${ }^{58}$. La majorité de ces tessons est attribuable à la deuxième phase. Si on se fonde non seulement sur des critères typologiques, mais aussi sur des données archéologiques, les trouvailles de BornheimWiddig (D 1) ${ }^{59}$ Echternach (L 1) ${ }^{60}$, Haillot (B 4) ${ }^{61}$, Fallais (B 2) ${ }^{62}$, Rochefort (B 15) ${ }^{63}$, Huy (B 7) ${ }^{64}$,

58 Chenet, 1941, pl. XXXIII, n ${ }^{\text {กs } 173, ~ 181-186 ; ~}$ pl. XXXVI, nos $257-259,263,276$.

59 Bakker, 1977, p. 610.

60 Bakker, 1981, p. 320.

61 Brever, Roosens, 1957, p. 248.

62 Van Ossel, 1982a, p. 187-194.

63 Dasnoy, 1968, p. 7.

64 Willems, 1973, p. 17. 
Herstal (B 6) ${ }^{65}$ et Titz-Hasselsweiler (D 2) ${ }^{66}$ doivent appartenir à la deuxième phase typologique.

Revenons au site de Mabro, deux tessons appartenant à la troisième phase (fig. 2 et $3, n^{\text {os }} 10$ et 11) ont été trouvés dans le remplissage du deuxième fossé (fig. 21 : fossé des $\mathrm{V}^{\mathrm{e}}-\mathrm{VI}^{\mathrm{e}} \mathrm{s}$.). Il est difficile de dater ce fossé avec précision, car le remplissage contient de nombreux tessons résiduels, provenant des couches inférieures. Les tessons les plus récents peuvent être datés avec vraisemblance du vi ${ }^{\mathrm{e}} \mathrm{s}$. Quoi qu'il en soit, ce fossé devait être rempli avant la formation de la couche supérieure, datable du vir ${ }^{\mathrm{e}} \mathrm{s}$. La transition entre la deuxième et la troisième phase est difficile à dater, mais elle doit se situer dans la seconde moitie du $v^{\mathbf{e}} \mathrm{s}$. Signalons que les bols décorés avec une molette inédite de Chenet (caractéristique de la troisième phase) ont èté trouvés dans des tombes datant du vi ${ }^{\mathrm{e}} \mathrm{s}$. à Éprave (B 1) ${ }^{67}$, Merlemont $(B \quad 10)^{68}$ et peut-être Ophoven (B 13) ${ }^{69}$. Il est possible que la troisième phase se prolonge dans la première moitié du $\mathrm{VI}^{\mathrm{e}} \mathrm{s}$.

La stratigraphie du site de Derlon confirme l'évolution typologique décrite plus haut. Ici aussi, les tessons typologiquement les plus récents ont èté découverts dans les couches supérieures (B 3, B 4). Malheureusement ces couches ont été remaniées, mélangeant les fragments des deuxième et troisième groupes typochronologiques (fig. 3, $\mathrm{n}^{\circ \mathrm{*}}$ 29-32). Le tesson trouvé dans la couche A7 est attribuable au second groupe. Un fragment de bord d'une coupe à collerette en terre sigillée noire ${ }^{70}$ a été découvert dans la même couche.

C'est principalement pour le dernier groupe que la fouille de Derlon a apporté des éléments nouveaux. Tandis que le site de Mabro n'a livré qu'une molette inédite (Maastricht 1), le site de Derlon en a fourni quatre, inconnues de Chenet (Maastricht 3, 4, $5,6)$.

La molette Maastricht 2 vient du Houtmaas (fig. 20, $n^{\circ} 7$ ); elle ressemble beaucoup à la molette découverte dans un crassier antique à Vireux-Wallerand $(\mathrm{F} 24)^{\mathrm{rl}}$, daté du dernier quart du $\mathrm{v}^{\mathrm{e}}$ et du début du vie s. IIn autre exemplaire a été découvert à Ferwerd $\left(\mathrm{N}\right.$ 4) en Frise ${ }^{72}$, mais, dans la mesure où

6.5 Van Ossel, 1984

66 Renseignement. M. Perse (Jülich), juin 1988.

67 Wautelet, 1977, p. 33, lig. 22, n"1.

68 Wautelet, 1967, p. 52-53, fig. 32, no 4.

69 Claassen, Heymans, 1974, p. 181.

70) Van Ossel, 1986, p. 68, fig. 5.

71 Lemant, 1981, p. 218, pl. 3, n" 3

72 Boeles, 1951, fig. $36, n^{\circ} 7$. cet exemplaire n'est pas associé à d'autres objets ${ }^{73}$, la datation proposée (première moitié du ve $\mathrm{s}$.) me paraît trop précoce. D'autres tessons décorés à la molette Maastricht 2 ont été recueillis dans l'Yonne ${ }^{74}$ (F 14) et en Seine-et-Marne (Meaux-Penchard) ${ }^{75}$ (F 17).

La molette Maastricht 3 est représentée sur un bol trouvè à Ophoven, dans un cimetière mérovingien ${ }^{76}$. Un tesson décoré de la molette Maastricht $4^{77}$ a été découvert tout près de cette dernière localité, à Geistingen. Malheureusement, ces dernières molettes ne donnent aucune information exacte sur la typochronologie. C'est également le cas pour Berry-au$\mathrm{Bac}^{78}$, où une molette Maastricht 4 a été trouvée. Le musée de Tourcoing ${ }^{79}$ possède d'autre part un bol décoré à la molette Maastricht 5 . Les molettes Maastricht 1 et 6 n'ont pas encore été découvertes hors de Maastricht.

Enfin, on peut conclure avec la classification des molettes chrétiennes de Maastricht, suivant la division proposée en groupes typochronologiques (les numéros correspondent à ceux de la figure 2 et du catalogue) :

\begin{tabular}{|c|c|c|}
\hline $1(\mathrm{Va})$ & $2(\mathrm{Vb}-\mathrm{c})$ & $3(\mathrm{Vd}-\mathrm{V} \mathrm{Ia})$ \\
\hline & $\mathrm{n}^{\circ \mathrm{s}} 1,2,3,4,9$, & \\
& $12,13,15,17,18$, & $\mathrm{n}^{\text {os }} 10,11,16,20$, \\
& $24,25,28,29,30$, & $21,22,23,27,32$ \\
& 31,33 & \\
\hline
\end{tabular}

Fig. 22 - Groupes typochronologiques.

La moitié des tessons (environ $55 \%$ ) appartient au second groupe, qui doit être daté des second et troisième quarts du $\mathrm{v}^{\mathrm{e}} \mathrm{s}$. Environ $15 \%$ s'intègrent au groupe typochronologique 1, qui date du premier quart du $v^{\prime \prime} s$. Le groupe 3 (environ $30 \%$ de l'ensemble) date du dernier quart $d u v^{e} s$. et du début du vI" s. (fig. 23).

D. Bayard ${ }^{80}$ date les molettes chrétiennes dans ses phases 3 et 4 , c'est-à-dire entre 430 et 530 . Cela signifierait que le groupe typochronologique 1 manque à Metz. En effet, la majorité des fragments

73 Boeles, 1951, p. 494; renseignement E. Knol (Amsteriam), novembre 1990 .

74 Renseignement D. Perrugot (Sens), aoùt 1986.

75 Thion, 1984, p. 144, no 424.

76 Claassen, Heymans, 1974.

77 Renseignement L. Bakker (Augsburg), juin 1986.

78 Bayard, 1990, p. 318.

79 Bayard, 1990, p. 319 et fig. 8.

80 Bayard, 1990, p. 287-293. 


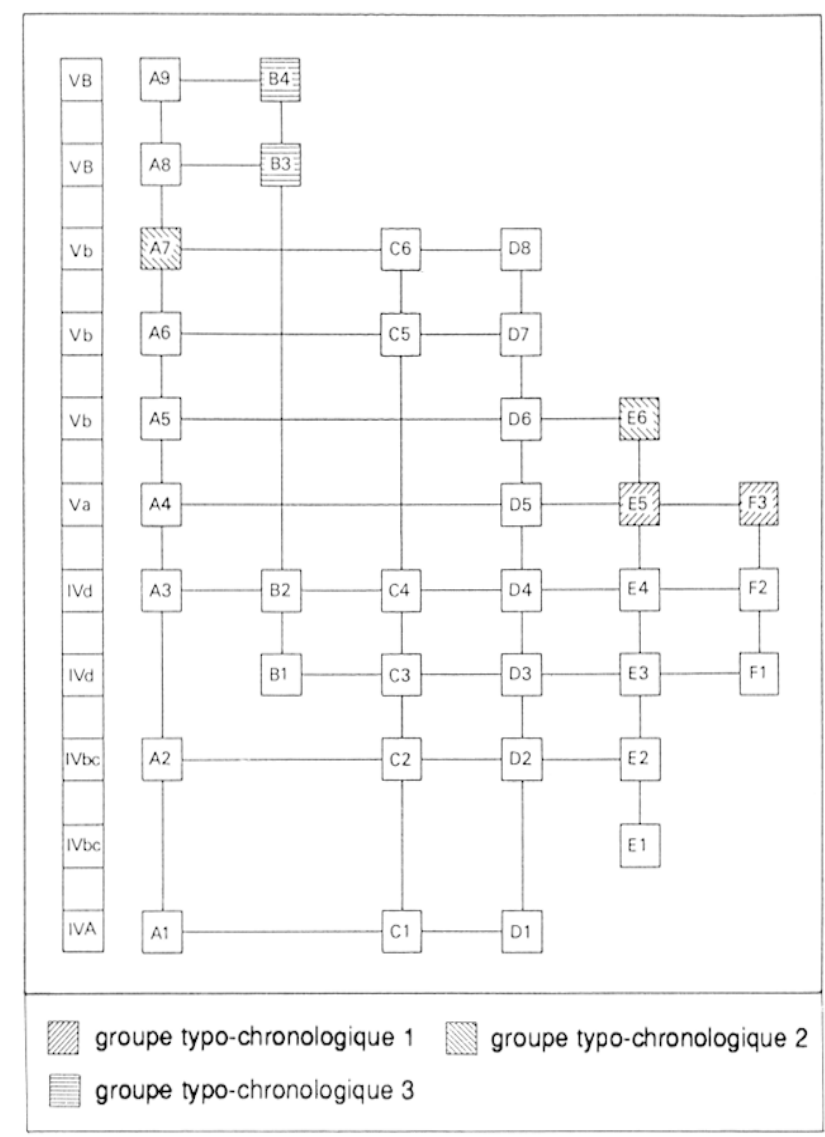

Fig. 23 - Rapports horizontaux (synchrones) et verticaux (diachrones) entre les couches des coupes A-F (Derlon et Mabro).

messins publiés par D. Bayard ${ }^{81}$ semble appartenir au deuxième groupe typochronologique. Surtout le cœur gris ou noir semble indiquer l'appartenance au groupe 2. L'absence de noyau sombre et la présence d'un noyau légèrement plus foncé que la pâte, peuvent être considérées comme typique du groupe 1. Selon le catalogue, une partie des molettes peut être intégrée dans le groupe $1^{\mathbf{8 2}}$. Cela est très probable, car D. Bayard dit lui-même qu'il «semble bien que l'ensemble de l'amphithéâtre de Metz se soit constilué pendant la première moilié $d u v^{e} s$. " ${ }^{83}$. L'absence de variantes de molettes publiees par Chenet et de molettes inédites de Chenet suggère une datation dans la première moitié du $\mathrm{v}^{\mathrm{e}} \mathrm{s}$. Si on accepte la chronologie de Bayard, cela implique que le matériel a été déposé d'un coup vers le milieu du $v^{\mathbf{e}} \mathbf{s}$. Au contraire, toutes les conclusions chronologiques dans 127.

81 Bayard, 1990, annexe $1: n^{\circ s} 2,3,5,6,7,66,72,95$,

82 Bayard, 1990, annexe $1: n^{\text {os }} 8$ et 125 .

83 Bayard, 1990, p. 294. la publication de Bayard tendent vers une datation "longue» d'un demi-siècle.

Enfin, les molettes chrétiennes font leur apparition au début du $\mathrm{v}^{\mathrm{C}} \mathrm{s}$. avec les prototypes Chenet 181 et 186 ; les autres molettes publiées par Chenet (183, 257, 258 et 259 ainsi que Chenet 173, 181, 182, 184 et leurs variantes) apparaissent vers les années $430 / 440$. Ces molettes disparaissent vers les années 470-480, période à laquelle les molettes inédites de Chenet ont été introduites. Elles restent en usage jusqu'aux années $520-530$.

Toutefois, il faut se rendre compte que les limites et transitions ne sont pas très fixes et qu'elles devront être précisées dans l'avenir.

\section{Production}

Grâce aux découvertes de Chenet ${ }^{84}$, on sait que la terre sigillée décorée à la molette à motifs chrétiens a été fabriquée à Châtel-Chéhéry, en Argonne (F 5). En revanche, il n'est pas évident que ce site soit le seul centre de production. Les molettes Chenet 173 (fig. 26) et 184 (fig. 30) ne figurent pas parmi la liste des molettes chrétiennes découvertes à Châtel-Chéhéry. L'hypothèse a été avancée ${ }^{85}$ qu' "aux abords de 400 les ateliers argonnais cessent définitivement leurs activités et que des groupes d'artisans s'établissent dans la vallée mosane où ils entreprennent bientôt de reconstruire des fours et de produire une nouvelle sigillée»". Il est vrai que la céramique sigilléc à décors chrétiens change beaucoup après le début du $v^{e} \mathrm{~s}$. Mais on ne peut plus admettre aujourd'hui la thèse selon laquelle les fragments décorés à la molette à motifs chrétiens, trouvés à Châtel-Chéhéry, datent systématiquement d'avant 400/406. Seules de nouvelles fouilles à Châtel-Chéhéry ${ }^{86}$, associées à la découverte de fours de potier dans la vallée mosane, pourraient prouver un déménagement des potiers argonnais vers le bassin mosan.

Il est significatif, à ce sujet, de constater que des fragments d'un fond de bol du type Chenet 320, déformé et surcuit, ont été trouvés sur le site de Derlon (fig. 20 : grande étoile). Ces tessons, avec d'autres déchets de cuisson, proviennent d'une couche datable du deuxième quart du ve s. (fig. 23, D 7) : terre sigillée des types Alzei $1^{87}$ (= Chenet 320)

84 Chenet, 1941, p. 39-41.

85 Wautelet, 1977, p. 48-49.

86 Compte rendu de la Table ronde sur la céramique d'Argonne, Metz, septembre 1987, p. 2.

87 Unverzagt, 1916, pl. I et II. 


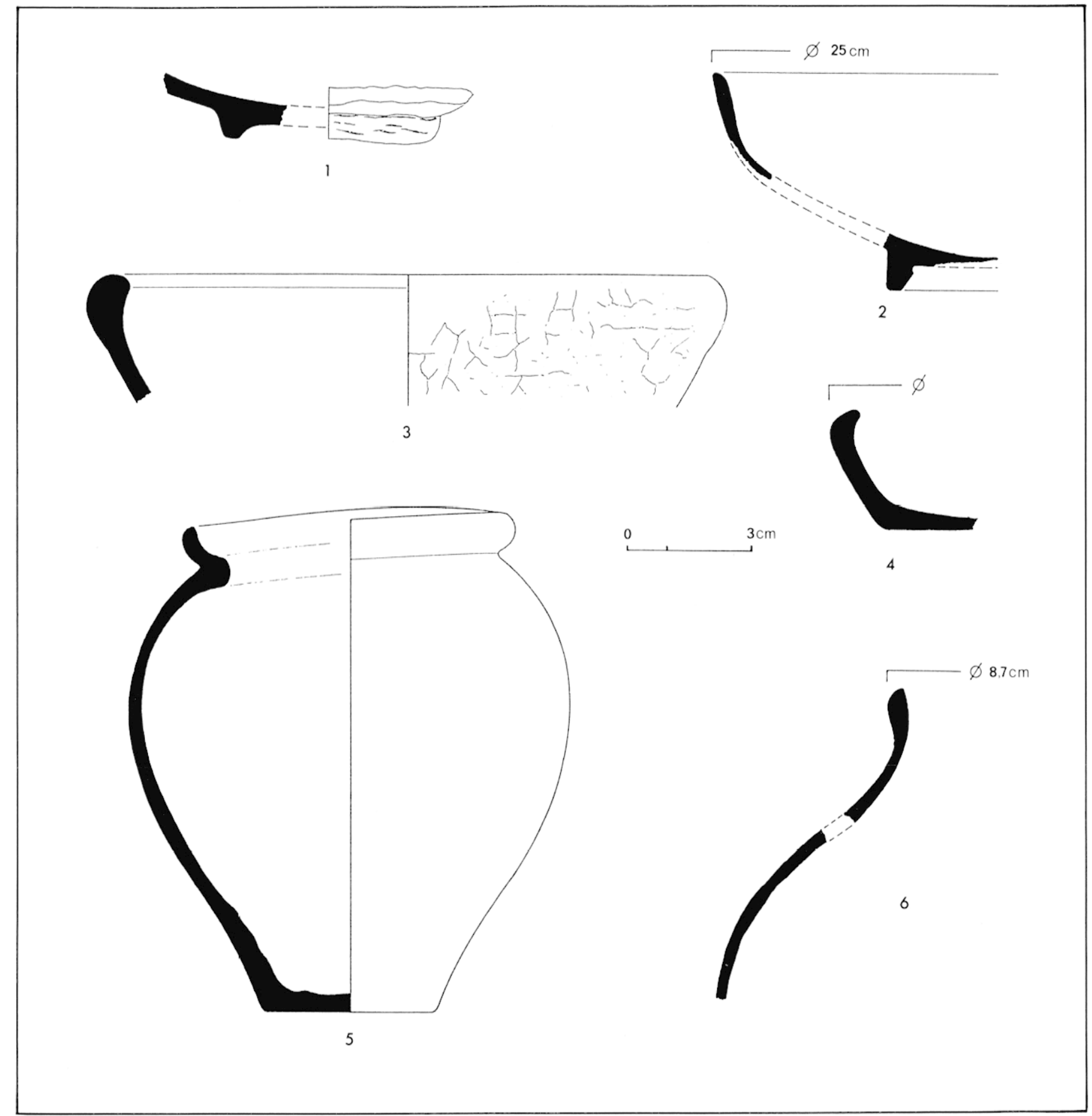

Fig. 24 - Maastricht - Site de Derlon. Coupe D - couche 7. Déchets de cuisson : 1, fragment de fond : type Chenet 320 ; 2 , fragments de fond et de bord : type Alzei $9 / 11 ; 3$, fragment de bord : type Alzei $29 / 34 ; 4$, fragment avec profil complet : type Alzei 29/31; 5, urne presque complète : type Alzei $27 ; 6$, fragments de bord et de paroi : type Alzei 30 .

et Alzei $9 / 11$; céramique rugueuse des types Alzei $27,29 / 34$ et 30 (fig. 24) ${ }^{88}$. Mais aucun rebut d'un bol décoré à la molette à motifs chrétiens n'a été retrouvé à ce jour.

88 Van Ossel, 1986, p. 63-71.
Ces indices d'une fabrication de terre sigillée tardive et la concentration de fragments en sigillée à décors chrétiens du ve s. à Maastricht sont deux données tout à fait intéressantes. Dans cette période de transition entre le Bas-Empire et le Haut Moyen Age, des productions locales, imitant les prototypes argonnais, sont toujours possibles. La quasi-absence de la céramique ornée de motifs chrétiens du groupe 
Maastricht 1-6 (tabl. X) à Châtel-Chéhéry ${ }^{89}$ peut toutefois indiquer une production limitée, hors de l'Argonne.

\section{Évaluation}

Tous les fragments à décors chrétiens de Maastricht proviennent de zones d'habitat (fig. 1 et 20). Le vaste cimetière situé au Vrijthof et sous l'église Saint-Servais ( $\mathrm{IV}^{\mathrm{e}}-\mathrm{X}^{\mathrm{e}} \mathrm{s}$.), fouillé dans les dernières décennies (Pandhof 1953-54 $4^{90}$, Vrijthof 1969-70 ${ }^{91}$, église Saint-Servais 1981-89 ${ }^{92}$ ), n'a livré aucun tesson décoré à la molette à motifs chrétiens. Il faut signaler que les inhumations $d u v^{e} s$. ne contenaient pas de mobilier funéraire. Inversement il existe, dans le bassin mosan, plusieurs nécropoles où des bols à décors chrétiens ont été découverts, comme à Fallais $(\mathrm{B} 2)^{93}$, Huy Saint-Victor (B 7) ${ }^{94}$, Haillot (B 4) ${ }^{95}$, Vieuxville (B 18) ${ }^{96}$ et Dieue (F 6) ${ }^{97}$ (fig. 25). Sur 181 exemplaires, 31 , soit $17 \%$, proviennent de tombes, où ils ont èté utilisés comme offrande funéraire. Dans quelques cas il n'est plus possible de discerner s'il s'agit d'un contexte funéraire ou non (par exemple à Ophoven [B 13] ${ }^{98}$ ). Il n'y a pas de molette particulière pour accompagner le défunt : toutes les molettes connues sont représentées sur la figure 25 . L'aire de répartition fait ressortir une concentration très nette dans la vallée mosane moyenne : $80 \%$ de l'ensemble (fig. 25). Les trouvailles en France (F 6, F 8, F 10, F 15 et F 18) et en Allemagne (D 1) restent des cas isolés.

Aux Pays-Bas, ces molettes manquent presque complètement; le seul lieu de découverte est Ferwerd (N 4) ${ }^{99}$. En Belgique, la plupart des nécropoles concernées (B 1, B 2, B 4, B 14 et B 16) ont livré plus d'un exemplaire. A Maastricht, les fragments de céramique décorée à la molette à motifs chrétiens proviennent tous de l'intérieur ou des environs immédiats de l'enceinte du Bas-Empire (fig. 20).

89 Un fragment décorẹ à la molette Maastricht 2 a été découvert par J.-P. Lémant dans ce site: Bayard, 1990 , p. 318 .

90 Verwers, 1986.

91 Bloemers, 1973 et 1974.

92 Panhuysen, 1990.

93 Van Ossel, 1982a.

94 Docquier et alii, 1984.

95 Breuer, Roosens, 1957.

96 Alenus-Lecerf, 1982.

97 Guillaume, 1978.

98 Claassen, Heymans, 1974.

99 Renseignement E. Knol (Amsterdam), novembre 1990.

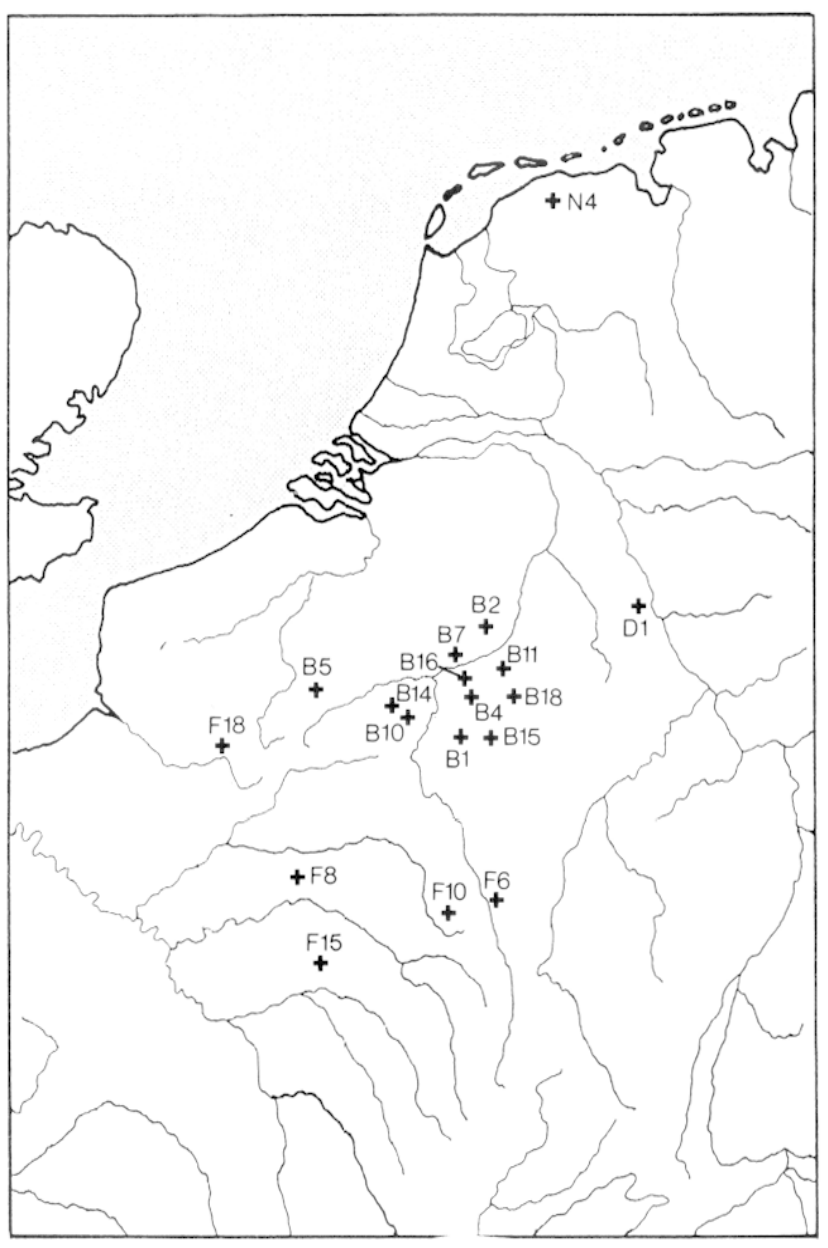

Fig. 25 - Aire de répartition des molettes chrétiennes dans les tombes.

On peut observer une concentration nette (26 sur 33 tessons recueillis, soit $80 \%$ du total) dans un rayon de moins de $50 \mathrm{~m}$ autour de l'emplacement présumé de l'ancienne église épiscopale, qui doit être cherchée sous la basilique Notre-Dame actuelle ${ }^{\mathbf{1 0 0}}$. Une observation semblable a été faite à Auxerre $(\mathrm{F} 2)^{101}$, Rouen (F 20) ${ }^{102}$ et Metz (F 13) ${ }^{103}$.

La date du transfert du siège épiscopal de Tongres (Belgique) vers Maastricht n'est pas connue et on ne sait pas si, au $\mathrm{v}^{\mathrm{e}} \mathrm{s}$., l'évêque résidait à Tongres ou à Maastricht. Ce n'est qu'à partir du début $d u \mathrm{vi}^{\mathrm{e}}$ s. que la présence de l'évêque est attestée avec certitude à Maastricht. Les objets typiques du $v^{e}$ s., comme la sigillée à décors chrétiens, manquent complètement à Tongres ${ }^{104}$. Les données

100 Verbeek. 1958, p. 359: Panhuysen, 1986, p. 132.

101 Vicolle, 1962, p. 385.

102 Jigan, Halbout, 1987, p. 45.

103 Oswald et alii (èd.), 1966, p. 213-214.

104 Vanderhoeven, 1979. 
stratigraphiques à Maastricht témoignent d'une continuité de l'habitat entre le $I^{*} s$. et le $V^{r} s$. D'autre part, le cimetière autour de l'église SaintServais, où fut inhumé le premier évêque de la Civilas Tungrorum, montre une continuité d'utilisation entre le Bas-Empire et Haut Moyen Age ${ }^{105}$. Selon Chenet ${ }^{106}$, il ne fait pas de doute que parmi les artisans potiers il y avait des adeptes de la religion du Christ. Un bol du type Chenet 320, trouvé en 1940 près d'un four, montre un chrisme, gravé avant cuisson sur le fond. Non seulement les producteurs mais aussi les consommateurs ont laissé des témoignages de leurs convictions religieuses. Toujours selon Chenet ${ }^{107}$, un bol du type Chenet, 320 , trouvé à Juvigny (Marne), avait été "décoré" sous le pied avec un chrisme gravé après cuisson.

On retrouve cette même décoration symbolique sur les coupes en verre trouvées dans les nécropoles de Fallais (B 2), Haillot (B 4), Huy Saint-Victor (B 7), Samson (B 16) et Vicuxville (B 18), à côté de céramiques ornées de symboles chrétiens ${ }^{108}$. De telles coupes en verre n'ont pas été découvertes à Maastricht dans les zones d'habitat ${ }^{109}$ mais, d'une manière générale, la verrerie ressemble beaucoup à celle des cimetières du Namurois (B 4, B 16 el B 18$)^{110}$.

In autre groupe d'objets, dont le caractère chrétien est indiscutable, est constitué par les stèles funéraires, découvertes dans l'église saint-Servais. Ces stèles datent des $v^{\prime \prime}-v^{p}$ s. et portent des inscriptions chrétiennes "'. Parmi les éléments de décora- tion utilisés, on retrouve le chrisme et la colombe ${ }^{112}$, proches des motifs employés sur les bols décorés à la molette de la troisième phase. La datation de ce groupe (fin du v $v^{\prime}$ - début du $v^{e} \mathrm{~s}$.) correspond à celle des stèles concernées ${ }^{113}$.

La fabrication des bols du type Chenet 320 s'est poursuivie jusqu'au vi ${ }^{\mathrm{e}} \mathrm{s}$. Durant le ve s., on a cessé d'orner ces bols à la molette, sauf aux molettes chrétiennes. Les molettes inconnues de Chenet (Maastricht 1 à 6), qui appartiennent au troisième groupe, ornent les demiers représentants de cette tradition de céramique romaine, qu'on peut suivre depuis le type I)rag. 29, puis 37 et finalement le type Chenet 320 . Avec la disparition du décor à la molette à motifs chrétiens disparaît aussi le bol du type Chenet 320. Tous ces éléments, c'est-à-dire la concentration des tessons significatifs autour de la résidence de l'évèque à Maastricht, l'apparition de symboles chréticns sur d'autres objets manufacturés contemporains et la persistance des molettes chrétiennes durant l'époque mérovingienne, suggèrent que l'application de motifs chrétiens était intentionelle et significative pour les utilisateurs. L'opinion selon laquelle cette décoration symbolique ne répondrait qu'à des critères de goût et de mode est moins probable et ne correspond guère aux observations mentionnées ri-dessus 114. Dans un sens plus général, toutes ces constatations témoignent de l'installation de la première communauté chrétienne des PaysBas, a Maastricht.

Wim Di.JKMAN

105) Verwers, 1986; Panhuysen, 1986.

106 (henet. 1941, p. 137.

107 (ihenet, 1941, p. 116.

108 Dasnoy, 1956, p. 360-373 et pour Vieuxville: Nenus-Lecerf, 1982, p. 108, fig. 62.

109 Van Lith, 1985, 1987 et 1988.

110 Van Lith, 1987, p. 49.

111 Boppert, 1986.

112 Boppert, 1986, p. 77, 80, 81, 89.

113 Les observations faites par Bayard sont les mèmes (Bayard, 1990, p. 293-294).

11.4 De Boe, 1986, p. 47. 


\section{ANNEXE}

\section{AIRE DE RÉPARTITION DE LA CÉRAMIQUE DÉCORÉE À LA MOLETTE À MOTIFS CHRÉTIENS (fig. 26 à 35)}

$\Delta=$ Céramique à décors chrétiens, trouvée dans un zone d'habitat:

$+=$ Céramique à décors chrétiens, trouvée dans une tombe.

Tableau I - Molette Chenet 173 (+ variantes). Nombre total : 11 (fig. 26)

Site
1. Auxerre
2. Metz
3-5. Paris,
rue de Lutèce
6. Sens
7. Bornheim-Widdig
8. Trier
9. Hatsum
10. Cuyk
11. Maastricht, Mabro

Site

\section{Bibliographie}

Nicolle, 1962, pl. II, n 8

Bayard, 1990, p. 310

Inédits, rens. P. Van Ossel, Paris, septembre 1989

Nicolle, 1962, pl. III, nº 48

Bakker, 1977, p. 605-610,

fig. 1,3 et 4

Chenet, 1941, p. 169

Boeles, 1951, fig. 37, n ${ }^{\circ} 4$

Thijssen, 1979, p. 44

fig. $2, n^{\circ} 12$
Région/Département

Yonne

Moselle

Ville de Paris

Yonne

Vordrhein-Westfalen

Rheinland-Pfalz

Friesland

Noord-Brabant N 2

Limburg N 7
Fig. $26-$

Aire de répartition de la molette Chenet 173

et variantes.

Molettes chrétiennes

\begin{tabular}{|l|c|c|c|}
\hline \multicolumn{1}{|c|}{ Chenet $\mathrm{n}^{\circ}$} & Maastricht & N.-O. Europe & TotaL \\
\hline 173 & 1 & 10 & 11 \\
\hline 181 & 9 & 23 & 32 \\
\hline 182 & 2 & 19 & 21 \\
\hline $183(=259)$ & 2 & 16 & 18 \\
\hline $184(=276)$ & 3 & 13 & 16 \\
\hline $185(=263)$ & - & 8 & 8 \\
\hline 186 & 4 & 12 & 16 \\
\hline 257 & 1 & 20 & 21 \\
\hline 258 & 2 & 13 & 15 \\
\hline sous-total & 24 & 134 & 158 \\
\hline inédites de Chenet & 9 & 14 & 23 \\
\hline Total & $33(18 \%)$ & $148(82 \%)$ & 181 \\
\hline
\end{tabular}

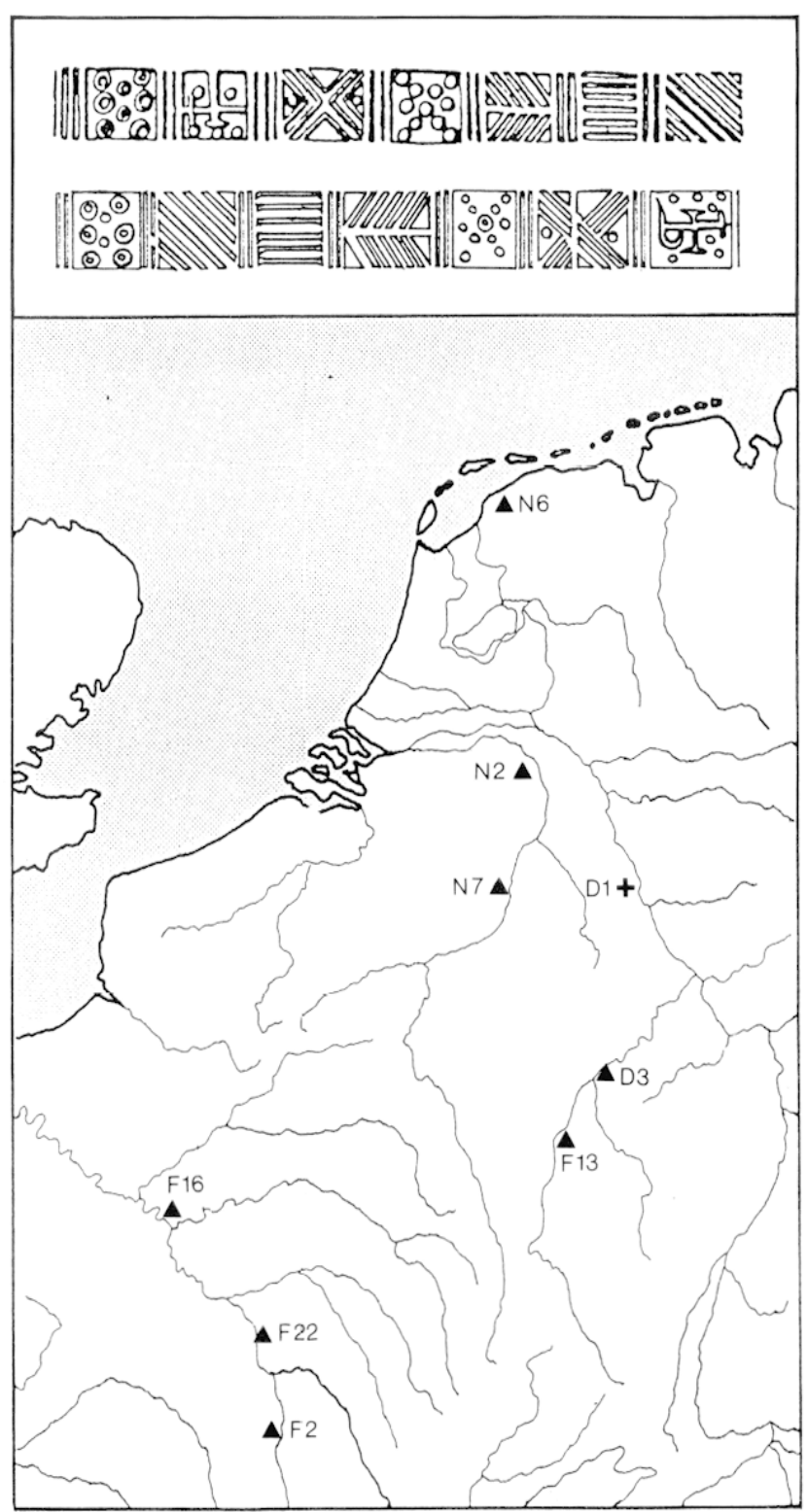


Tableau II - Molette Chenet 181 (+ variantes). Nombre total : 32 (fig. 27)

Site

1. Blois

2. Cambrai

3. Chalons-sur-Marne

4. Chilleurs-aux-Bois

5-7. Châtel-Chéhéry

8. Laon

9. Mantes-la-Jolie

10. Mercin-et-Vaux

11-12. Metz

13. Reims

14. Sens

15. Vincy (Létanne)

16. Vix

17. Trier

18. Echternach

19. Fallais

20. Samson

21-23. Ferwerd

24. Maastricht, Stokstraat

25. Maastricht, O.L.V.-plein

26. Maastricht, Havenstraat

27. Maastricht, Mabro

28. Maastricht, Mabro

29. Maastricht, Derlon

30. Maastricht, Derlon

31. Maastricht, Derlon

32. Maastricht,

Jodenstraat
Bibliographie

Trombetta, 1976, p. 18

Carmelez, 1986, p. 118

Bayard, 1990, p. 311

Bayard, 1990, p. 313

Chenet, 1941, p. 169 ;

Wautelet, 1977, pl. II

Bayard, 1990, p. 312

Rens. P. Van Ossel

Piton, Bayard, 1977, p. 251, pl. 32, n 337 ; Tuffreau-Libre,

1981, p. 110 , fig. $45, \mathrm{n}^{\circ} 94$

Chenet, 1941, p. 169

Bayard, 1990, p. 303, 306

Chenet, 1941, p. 169

Nicolle, 1962, p. 390, pl. III, no 46

Bayard, 1990, p. 313

Chenet, 1941, p. 169

Chenet, 1941, p. 169

Bakker, 1981, p. 325-327, fig. 241, no 41

Van Ossel, 1976, p. 72;

Van Ossel, 1982b, p. 171-172

Wautelet, 1977, pl. II

Boeles, 1951 , p. 494 , fig. 38 , $\mathrm{n}^{\text {os }} 1-3$

fig. $2, \mathrm{n}^{\circ} 1$

fig. $2, n^{\circ} 5$

fig. $2, n^{\circ} 9$

fig. $2, \mathrm{n}^{\circ} 13$

fig. $2, \mathrm{n}^{\circ} 14$

trouvaille isolée, fig. $2, \mathrm{n}^{\circ} 19$

fig. $2, \mathrm{n}^{\circ} 28$

fig. $2, n^{\circ} 31$

fig. $2, \mathrm{n}^{\circ} 33$
Région/Département

Loir-et-Cher

Nord

Marne

Loiret

Ardennes

Aisne

Yvelines

Aisne

Moselle

Marne

Yonne

Ardennes

Côte-d'Or

Rheinland-Pfalz

Luxembourg

Liège

Namur

Friesland

Limburg

Limburg

Limburg

Limburg

Limburg

Limburg

Limburg

Limburg

Limburg
Code

F 3

F 4

F 28

F 29

F 5

F 30

F 11

F 12

F 13

F 19

F 22

F 31

F 25

D 3

L 1

B 2

B 16

N 4

N 7

N 7

N 7

N 7

$\mathrm{N} 7$

N 7

N 7

N 7

N 7

Tableau III - Molette Chenet 182 (+ variantes). Nombre total : 21 (fig. 28)

Site

1. Amiens

2-3. Châtel-Chéhéry

4. La Saulsotte

5. Metz

6. Reims

7. Rouen

8. Sens

9. Vésigneul-sur-Marne

10. Vix

11. Éprave

12-13. Fallais

14. Herstal

15. Huy

16. Huy

17. Namur

18. Rochefort

19. Ferwerd

20. Maastricht,

Stokstraat

21. Maastricht, Derlon
Bibliographie

Bayard, 1990, p. 311

Chenet, 1941, p. 169 ;

Wautelet, 1977, pl. II

Chenet, 1941, p. 169

Chenet, 1941, p. 169

Chenet, 1941, p. 169

Jigan, Halbout, 1987, p. 45

Nicolle, 1962, p. 388, pl. III, no 49

Chenet, 1941, p. 169

Chenet, 1941,p. 169

Dasnoy, 1967-68, p. 70, fig. 2, no 6

Van Ossel, 1982a, p. 187, n ${ }^{\text {os }} 113,114$, fig. $18, n^{\text {os }} 110,112$

Van Ossel, 1984, p. 33, fig. 13, no 35

Docquier et al., 1984, pl. V, IX, ${ }^{0} 1$

Tilkin-Peters, Marcolungo, 1986, p. 201

Inédit, Hospice Saint-Gilles 91 SG 343, fouille SARW

Dasnoy, 1968, p. 7, fig. 4, n ${ }^{\circ} 1$

Boeles, 1951, p. 494, fig. 38

fig. $2, \mathrm{n}^{\circ} 4$

fig. $2, \mathrm{n}^{\circ} 29$
Région/Département

Somme

Code

F 1

Ardennes

Aube

Moselle

Marne

Seine-Maritime

Yonne

Marne

Còte d'Or

Namur

Liège

Liège

Liège

Liège

Namur

Namur

Friesland

F 5

F 9

F 13

F 19

F 20

F 22

F 23

F 25

B 1

B 2

B 6

B 7

B 7

B 12

B 15

N 4

Limburg

Limburg 


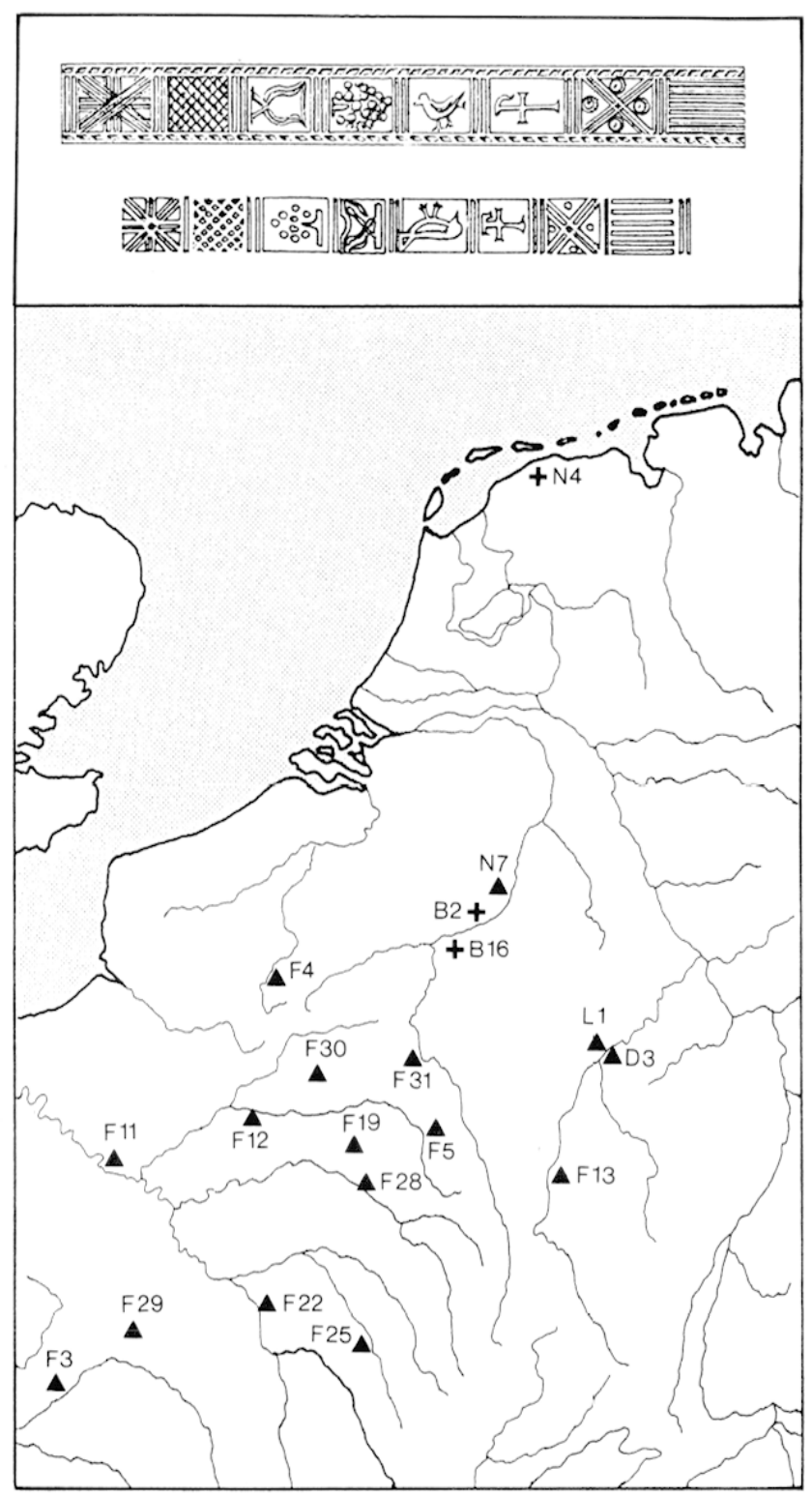

Fig. $27-$

Aire de répartition de la molette Chenet 181 et variantes.

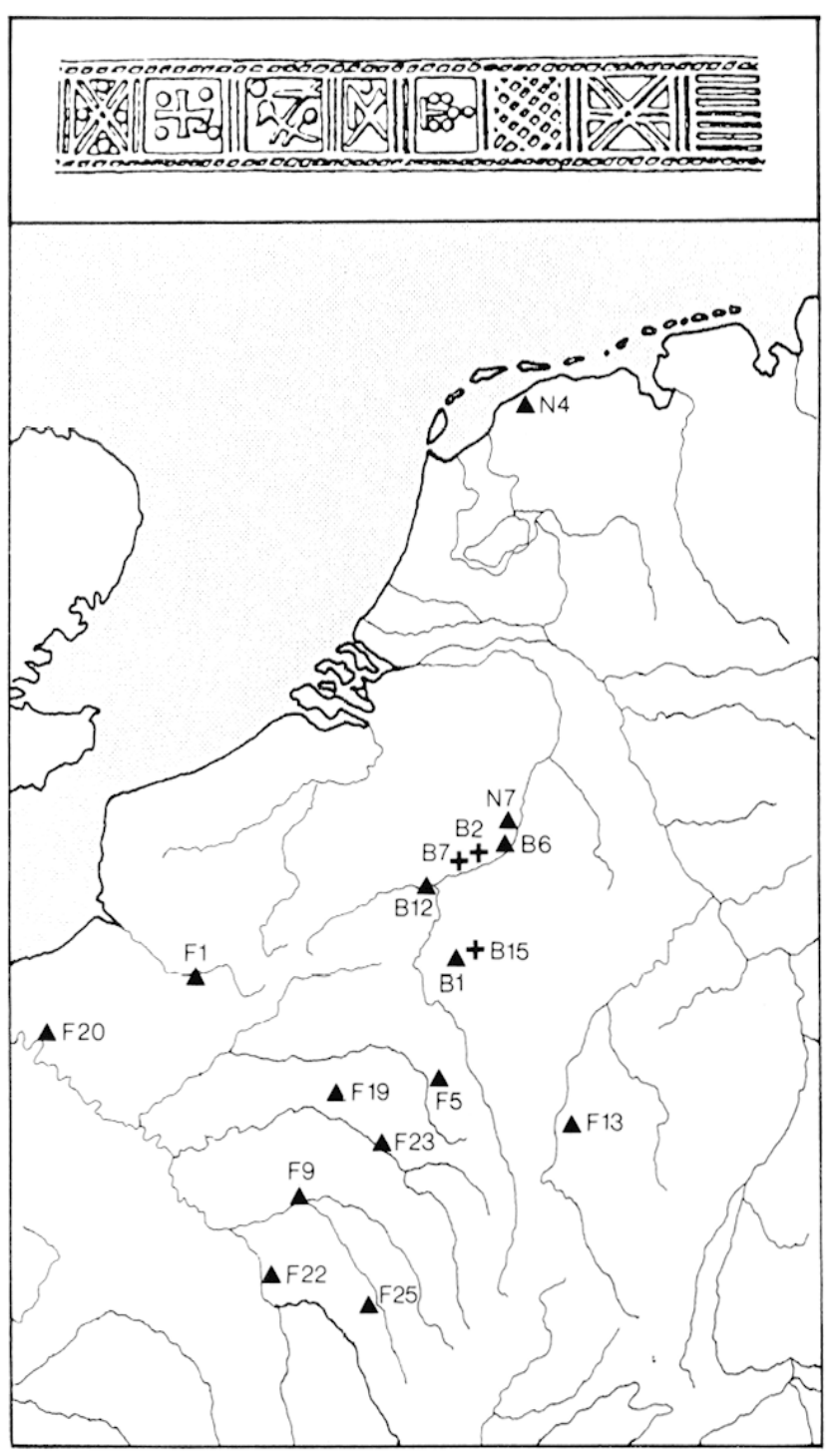


Tableau IV - Molette Chenet $183(=259)$. . Vombre total : 18 (fig. 29)

Site

1. Chatel-Chéhéry

2-3. Metz

4. Reims

5. Rouen

6. Rumersheim-le-Haut

7. Trier

8. Éprave

9-10. Fallais

11. Huy

12. Huy

13. Namur

14-15. Pry

16. Gennep

17. Maastricht,

O.L.V.-plein

18. Maastricht,

Hondstraat

\section{Bibliographie}

Chenet, 1941, p. 169

Bayard, 1990, p. 305, 307

Chenet, 1941, p. 169

Jigan, Halbout, 1987, p. 45

Schweitzer, 1977 , p. 67 , fig. 36

Chenet, 1941, p. 169

Van Houdt, 1982, fig. 3

Van Ossel, 1982a, p. 187, nos 113, 114, fig. 18, n ${ }^{\text {os }} 110,112$

Willems, 1973, p. 15, fig. 4, no 2

Docquier et al., 1984, pl. V, IX, no 2

Inédit, place Saint-Hilaire 91 SG 218, fouille SARW

Wautelet, 1977, p. 37, fig. 25-26

Inédit Ge-1482, fouille I.P.P. (Amsterdam)

fig. $2, n^{\circ} 6$

fig. $2, \mathrm{n}^{\circ} 17$
Région/Département

Ardennes

Moselle

Marne

Seine-Maritime

Haut-Rhin

Rheinland-Pfalz

Namur

Liège

Liège

Liège

Namur

Namur

Limburg

Limburg

Limburg
Code

F 5

F 13

F 19

F 20

F 21

D 3

B 1

B 2

B 7

B 7

B 12

B 14

N 5

N 7

N 7

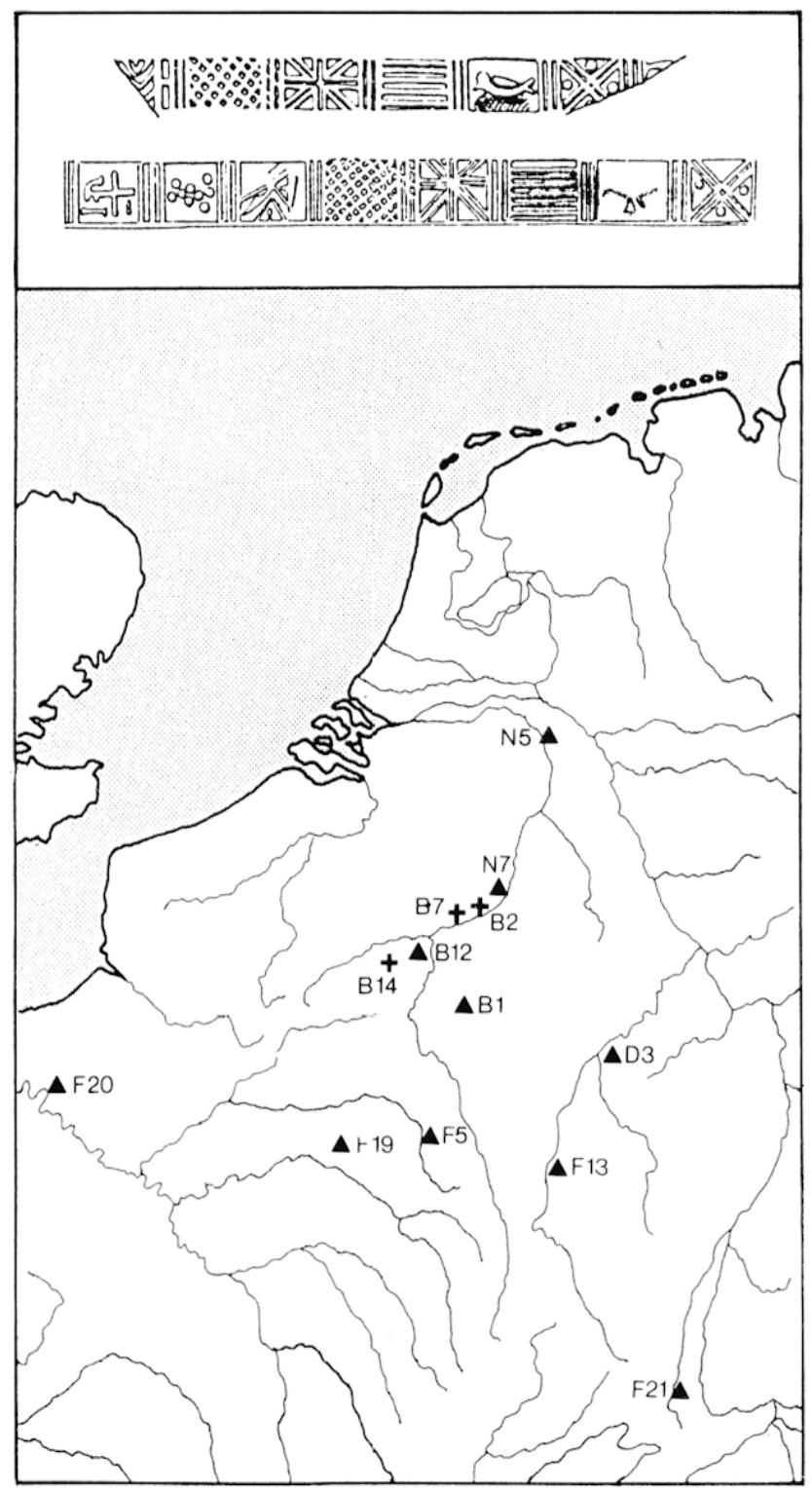

Fig. $29-$

Aire de répartition de la molette Chenet 183 $(=259)$ et variantes. 
Tableau $V$ - Molette Chenet $184(=276$ et variantes). Nombre total : 16 (fig. 30 )

Site

1. Escolives

2. Lavoye

3-5. Metz

6. Péronne

7. Reims

8. Rouen

9. Haillot

10. Herstal

11. Huy

12. Modave

13. Cuyk

14. Maastricht, Grote Staat

15. Maastricht Stokstraat

16. Maastricht Derlon

\section{Bibliographie}

Nicolle, 1962, p. 385, pl. II, no 13

Joffroy, 1974, p. 86, pl. 178, no 7

Chenet, 1941, p. 169

Bayard, 1990, p. 303, 305, 307

Piton, Bayard, 1977, p. 243, pl. 24, no 262

Chenet, 1941, p. 169

Jigan, Halbout, 1987, p. 45

Breuer, Roosens, 1957, p. 220, fig. $14, \mathrm{n}^{\circ} 6$

Van Ossel, 1984, p. 33, fig. $13, \mathrm{n}^{\circ} 36$

Rue de l'Hòpital, rens. J. Willems (Amay), avril 1991

Van Heule, 1939, p. 1441

Thijssen, 1979, p. 40, fig. 21, $\mathrm{n}^{\circ} 4$

fig. $2, n^{\circ} 2$

fig. $2, n^{\circ} 3$

fig. $2, \mathrm{n}^{\circ} 24$
Région/Département Code

Yonne $\quad \mathrm{F} 7$

Meuse $\mathrm{F} 10$

Moselle F 13

Somme F 18

Marne F 19

Seine-Maritime $\quad$ F 20

Namur B 4

Liège $\quad B \quad 6$

Liège $\quad \mathrm{B} 7$

Liège $\quad B 11$

Noord-Brabant N 2

Limburg $\quad$ N 7

Limburg $\quad$ N 7

Limburg $\quad$ N 7

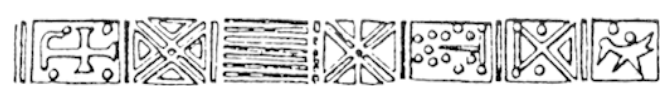

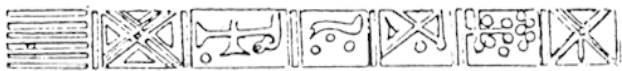

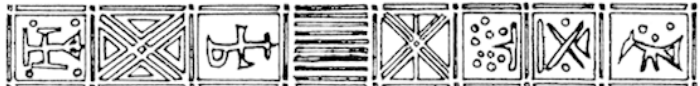

Fig. $30-$

Aire de répartition de la molette Chenet 184 $(=276)$ et variantes.

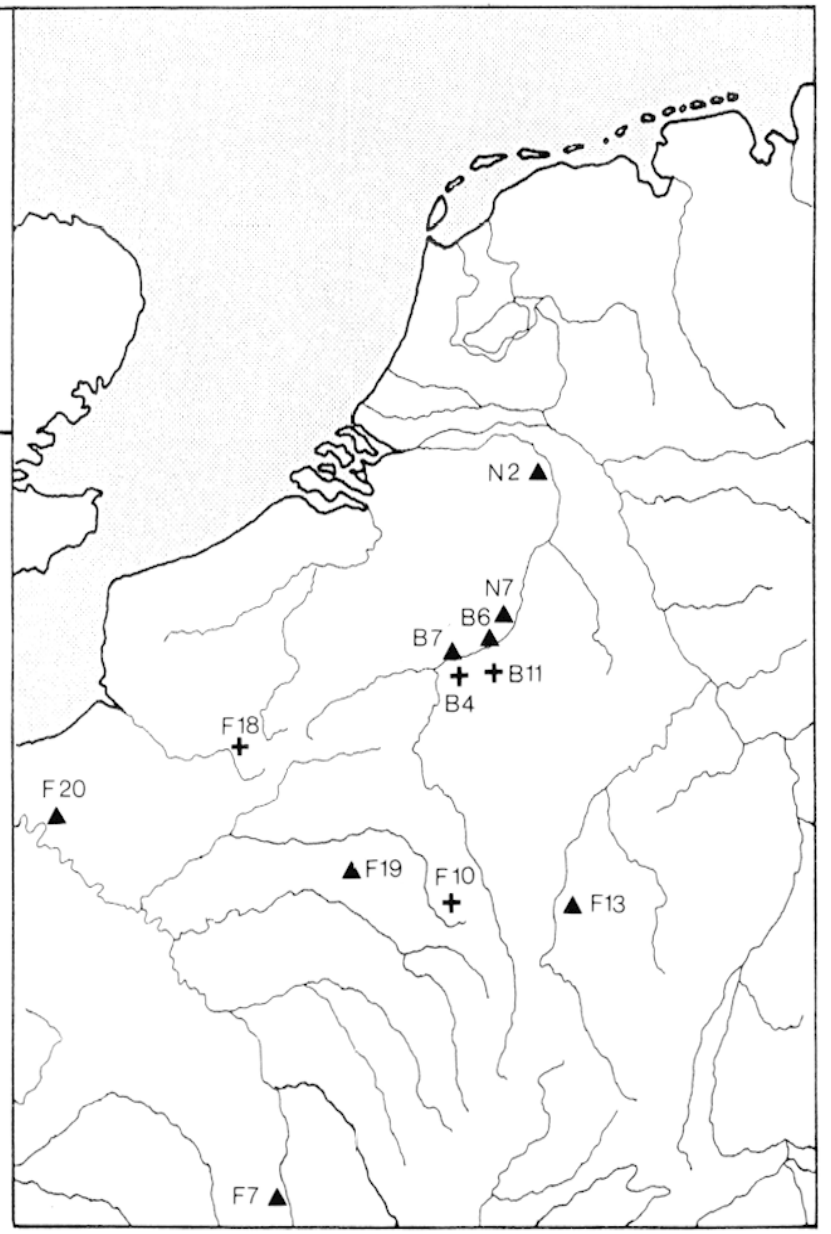


Tableau VI - Molette Chenet 185 (=263 et variantes). Nombre total : 8 (fig. 31 )

Site

1. Chàtel-Chéhéry

2. Dieue

3. Metz.

4. Reims

5. Vix

6-7. Fallais

8. Haillot
Bibliographie

Chenet, 1941, p. 169

Guillaume, 1978, p. 93, fig. $3, \mathrm{n}^{\circ} 7$

Chenet, 1941, p. 169; Bayard, 1990, p. 303

Chenet, 1941, p. 169

Chenet, 1941, p. 169

Van Ossel, 1982a, p. 187, $\mathrm{n}^{\text {os }} 115$, 116, fig. 18, ${ }^{\text {os }} 109,11$ :

Breuer, Roosens, 1957, p. 200, fig. 4, n ${ }^{\circ} 4$
Région/Département

Ardennes

Meuse

Moselle

Marne

Còte-d'Or

Liège

Namur
Code

F 5

F 6

F 13

F 19

F 25

B 2

B 4
Fig. $31-$

Aire de répartition de la molette Chenet 185 $(=263)$ et variantes. 
Tableau VII - Molette Chenet 186 (et variantes). Nombre total : 16 (fig. 32)

Site

1. Châtel-Chéhéry

2. Fère-en-Tardenois

3-4. Metz

5. Oyes

6. Reims

7. Vix

8. Huy

9. Samson

10. Sclayn

11. Dronrijp

12. Maastricht, Mabro

13. Maastricht, Mabro

14. Maastricht,

Hondstraat

15. Maastricht, Derlon

16. Voerendaal

\section{Bibliographie}

Chenet, 1941,p. 169

Chenet, 1941, p. 169

Wautelet, 1977 , p. 22, fig. 12

Chenet, 1941, p. 169; Bayard, 1990, p. 303

Chenet, 1941, p. 169

Chenet, 1941,p. 169

Chenet, 1941, p. 169

Docquier et al., 1984, pl. V

Martin, 1951, p. 95, pl. II

Rens. P. Hoffsummer (Liège)

Boeles, 1951, p. 171, fig. $36, \mathrm{n}^{\circ} 6$

fig. $2, n^{\circ} 8$

fig. $2, n^{\circ} 9$

fig. $2, \mathrm{n}^{\circ} 18$

fig. $2, \mathrm{n}^{\circ} 26$

Willems, in : Stoepker, 1988, p. 417, fig. 49
Région/Département

Ardennes

Code

Aisne

F 5

Moselle

F 13

Marne

Marne

Côte-d'Or

F 15

Liège

Namur

Namur

Friesland

Limburg

Limburg

Limburg

Limburg

Limburg

Fig. $32-$

Aire de répartition de la molette Chenet 186

Aire de répartition de la molette Chenet 186
et variantes.
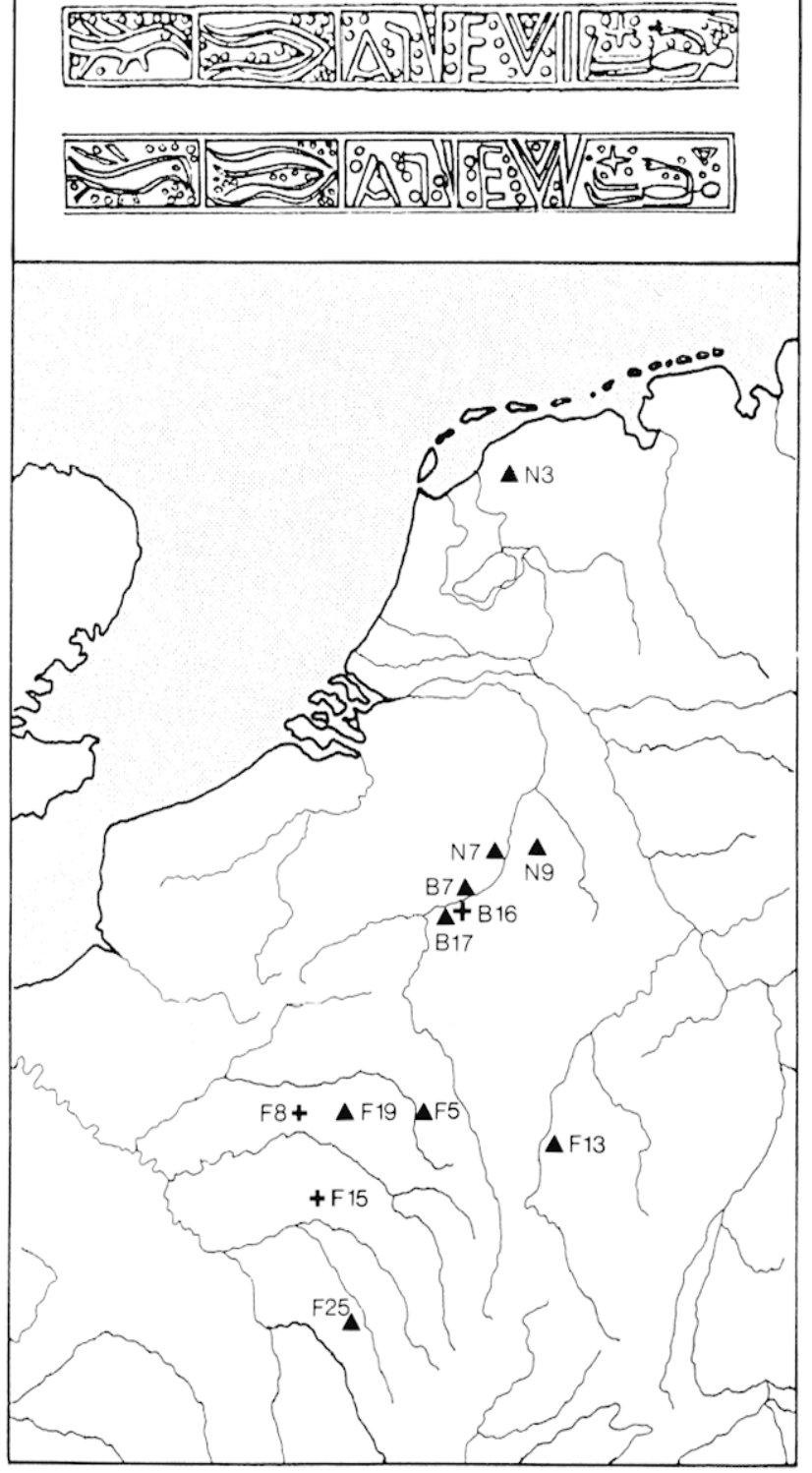
Tableau VIII - Molette Chenet 257. Nombre total : 21 (fig. 33)

Site

1-2. Amiens

3. Chàtel-Chéhéry

4. Reims

5. Rouen

6. Saint-Germainlès-Corbeil

7. Sens

8. Echternach

9. Herstal

10. Huy

11. Huy

12. Logne

13. Namur

14. Namur

15. Samson

16. Bayum

17. Ferwerd

18. Gennep

19-20. Gennep

21. Maastricht, Derlon

\section{Bibliographie}

Piton, Bayard, 1977, p. 241, pl. 22, n ${ }^{\text {os }} 240-241$

Chenet, 1941, p. 170

Bayard, 1990, p. 311

Jigan, Halbout, 1987, p. 45

Rens. P. Van Ossel

Nicolle, 1962, p. 391, pl. III, no 59

Bakker, 1981, p. 327, fig. 240, no $42 ; 241$, n $^{\circ} 42$

Van Ossel, 1984, p. 33, fig. 13, n 39

Willems, 1973, p. 16, fig. 4, n 3 , pl. VI

Saint-Séverin, rens. J. Willems (Amay), avril 1992

Observation dans "La ferme de la Bouverie» à Vieuxville, septembre 1983

Inédit, Hospice Saint-Gilles $91 \mathrm{SG} 436$, fouilles SARW

Inédit, place Saint-Hilaire 91 PSH 154, fouille SARW

Wautelet, 1977, p. 34

Boeles, 1951, p. 494, fig. $36, \mathrm{n}^{\circ} 3,38, \mathrm{n}^{\circ} 5$

Boeles, 1951, p. 494, fig. $38, \mathrm{n}^{\circ} 4$

Bloemers, 1977 , p. 22, fig. 15

Inédits. Ge-1667 et 1794, fouille I.P.P.

fig. $2, \mathrm{n}^{\circ} 25$
Région/Département

Somme

Ardennes

Marne

Seine-Maritime

Essonne

Yonne

Luxembourg

Liège

Liège

Liège

Liège

Namur

Namur

Namur

Friesland

Friesland

Limburg

Limburg

Limburg
Code

F 1

F 5

F 19

F 20

F 32

F 22

L 1

B 6

B 7

B 7

B 9

B 12

B 12

B 16

N 1

$\mathrm{N} 4$

N 5

N 5

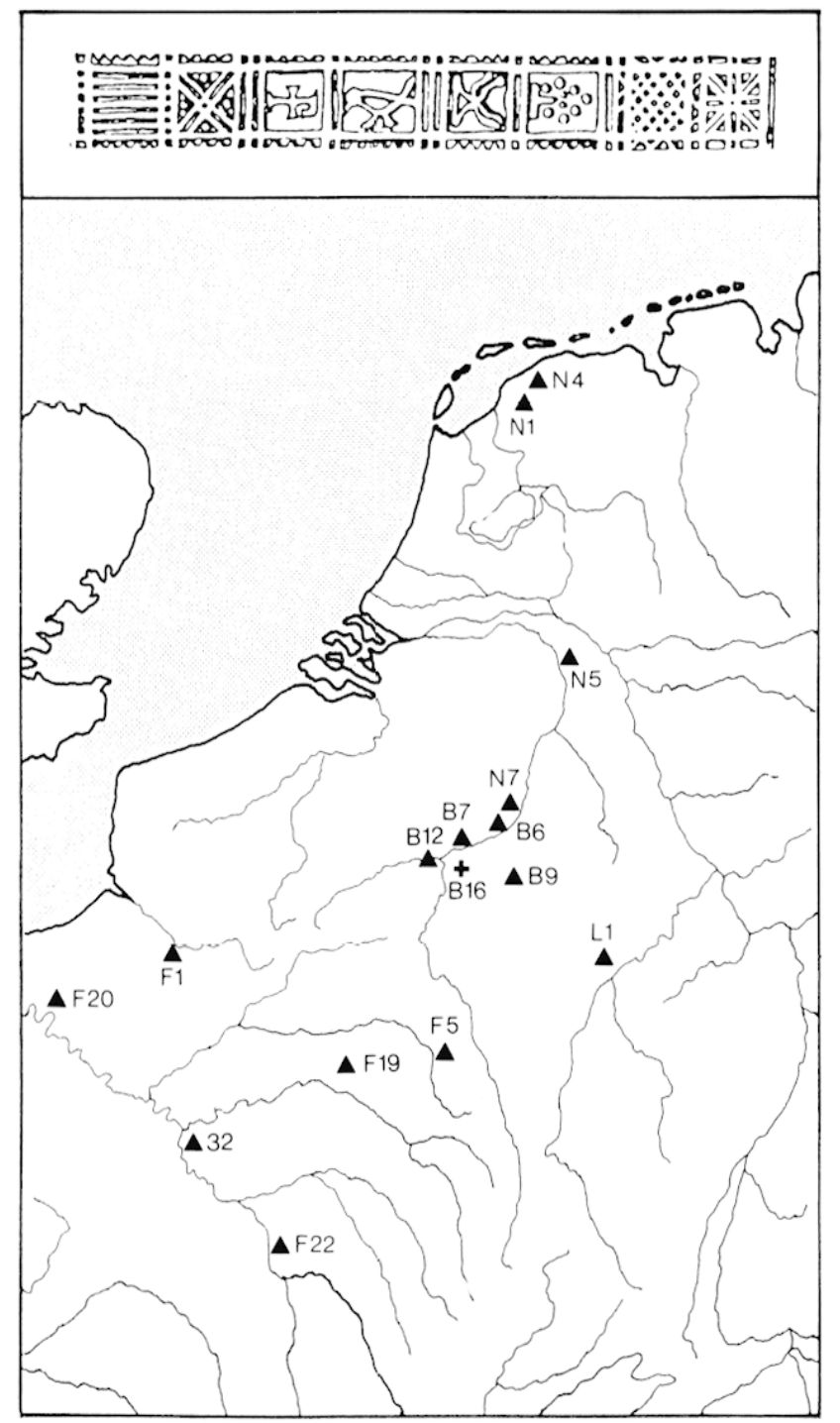

Fig. 33 -

Aire de répartition de la molette Chenet 257 . 
Tableau IX - Molette Chenet 258. Nombre total : 15 (fig. 34)

Site

1. Amiens

2. Chàtel-Chéhéry

3. Paris

4. Titz-Hasselsweiler

5-8. Herstal

9-11. Huy

12. Vieuxville

13. Maastricht, Mabro

14. Maastricht, Derlon

15. Ubbergen
Bibliographie

Piton, Bayard, 1977, p. 241, pl. 22, no 242

Chenet, 1941, p. 170

Bayard, 1990, p. 311

Inédit, rens. M. Perse (Jülich), juin 1988

Van Ossel, 1984, p. 33-35, fig. 34, 37, 38 et 40

Willems, 1973 , p. 16 , fig. 4 , no 4 , pl. VIII

Childéric-Clovis, 1983, p. 48, fig. 33a

fig. $2, \mathrm{n}^{\circ} \mathbf{1 5}$

fig. $2, n^{\circ} 30$

Inédit, rens. J. Thijssen (Nijmegen), mai 1984
Région/Département

Somme

Ardennes

Ville de Paris

Nordrhein-Westfalen D 2

Liège $\quad B \quad 6$

Liège $\quad \mathrm{B} 7$

Liège $\quad$ B 18

Limburg $\quad \mathrm{N} 7$

Limburg N 7

Gelderland N 8

Fig. $34-$ Aire de répartition de la molette Chenet 258.

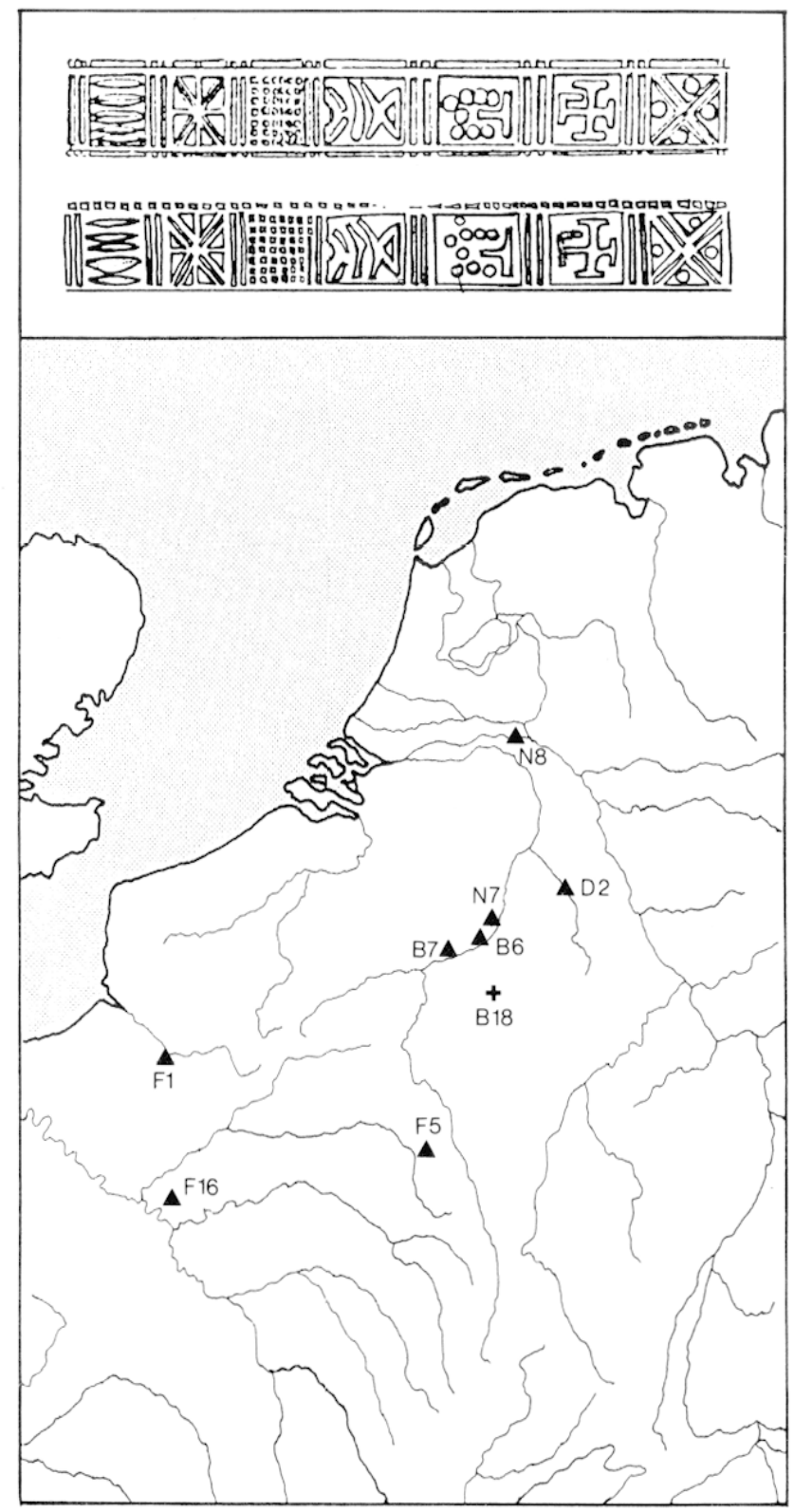


Tableau X - Molettes chrétiennes, inédites de Chenet. Nombre total : 23 (fig. 35)

Site

1. Chàtel-Chéhéry

2. Berry-au-Bac

3. Meaux

4. Michery

5. Tourcoing

6. Vireux-Molhain

7. Eprave

8. Geistingen

9. Harmignies

10. Liège

11. Merlemont

12. Namur

13. Ophoven

14. Ferwerd

15-16. Maastricht, Mabro

17. Maastricht,

Houtmaas

18. Maastricht, Derlon

19. Maastricht, Derlon

20-21. Maastricht, Derlon

22. Maastricht, Derlon

23. Maastricht, Derlon

\section{Bibliographie}

Bayard, 1990, p. 318

Bayard, 1990, p. 318

Thion, 1984, p. 144, pl. 13, n 424

Inédit, rens. D. Perrugot (Sens), août 1986

Bayard, 1990, p. 319

Lemant, 1981, p. 218, pl. $3, \mathrm{n}^{\circ} 3$

Wautelet, 1977, p. 33, fig. 22, $\mathrm{n}^{\circ} 1$

Inédit, rens. L. Bakker (Augsburg), juin 1986

Wautelet, 1977, p. 41

Degbomont, dans : M. Otte et al., 1983, p. 30;

Marcolungo, 1988, p. 142

Wautelet, 1967, p. 52-53, fig. 32

Wautelet, 1977 , p. 34

Claassen, Heymans, 1974, p. 18

Boeles, 1951, p. 494, fig. $36, \mathrm{n}^{\circ} 7$; rens. E.

Knol (Amsterdam)

fig. $2, \mathrm{n}^{\mathrm{os}} 10,11$

fig. 2,16

fig. $2, \mathrm{n}^{\circ} 20$

fig. $2, \mathrm{n}^{\circ} 27$

fig. $2, n^{08} 21,22$

fig. $2, n^{\circ} 23$

fig. $2, \mathrm{n}^{\circ} 32$
Région/Département

Ardennes

Aisne

Seine-et-Marne

Yonne

Nord

Ardennes

Namur

Limburg

Hainaut

Liège

Namur

Namur

Limburg

Friesland

Limburg

Limburg

Limburg

Limburg

Limburg

Limburg

Limburg
Code

M $2 \quad \mathrm{~F} 5$

M 4 F 26

M 2 F 17

M 2 F 14

M 5 F 27

M 2 F 24

B 1 B 1

M $3 \quad$ B 3

B 2 B 5

$\begin{array}{ll}\text { M } 3 & \text { B } 8\end{array}$

B 1 B 10

B $1 \quad$ B 12

$\begin{array}{lll}\text { M } 4 & \text { B } 13\end{array}$

M $2 \quad$ N 4

M $1 \quad$ N 7

M $2 \quad$ N 7

M 4 N 7

M $4 \quad$ N 7

M $3 \quad$ N 7

M $5 \quad \mathrm{~N} 7$

M $6 \quad$ N 7

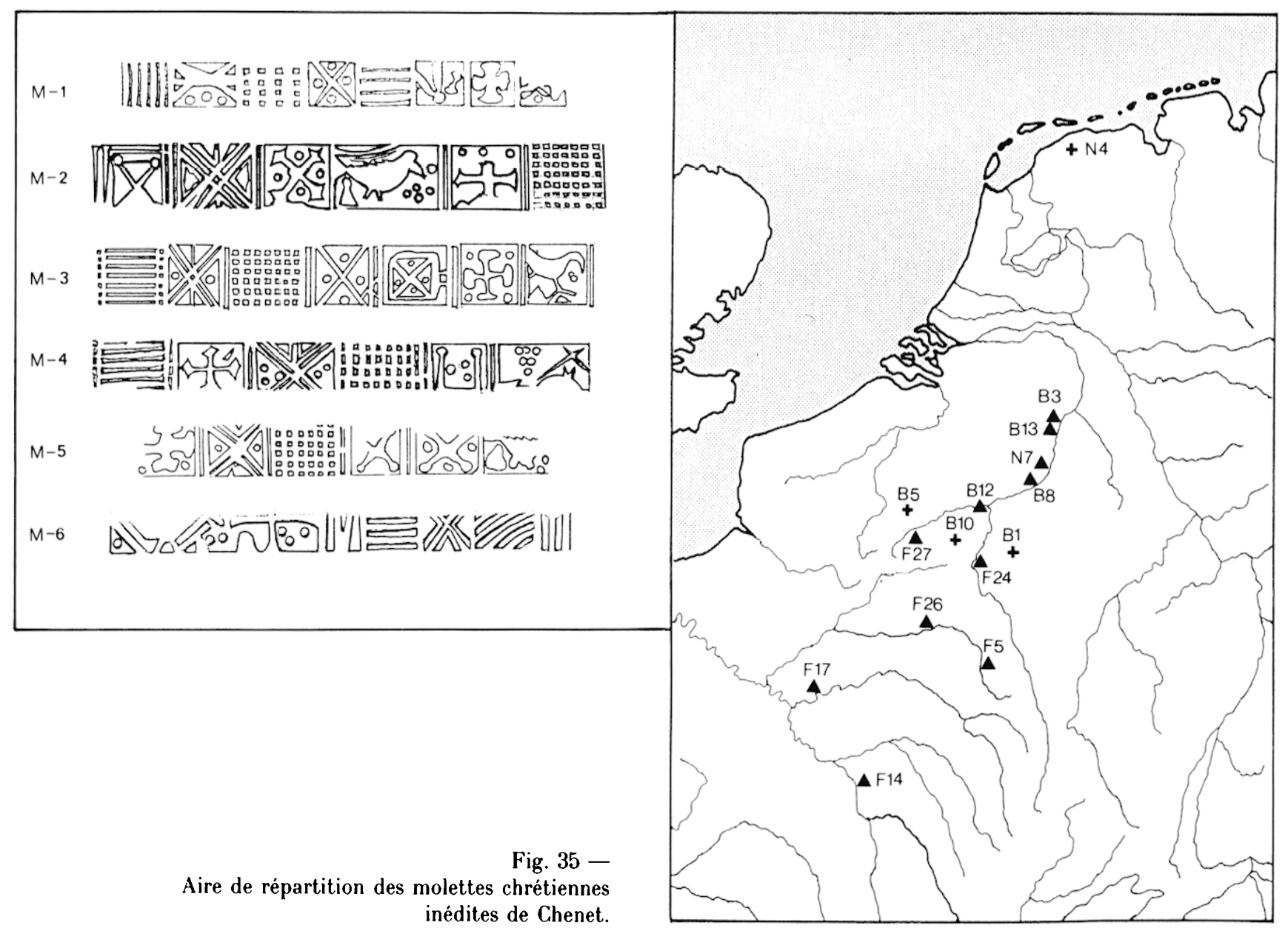




\section{INDEX DES LIEUX DE DÉCOUVERTES (fig. 36)}

France (F : 74 ex.)

$\begin{array}{lr}\text { 1. Amiens } & 4 \mathrm{ex} . \\ \text { 2. Auxerre } & 1 \mathrm{ex} . \\ \text { 3. Blois } & 1 \mathrm{ex} . \\ \text { 4. Cambrai } & 1 \mathrm{ex} . \\ \text { 5. Chatel-Chéhèry } & 11 \mathrm{ex} . \\ \text { 6. Dieue } & 1 \mathrm{ex} . \\ \text { 7. Escolives } & 1 \mathrm{ex} . \\ \text { 8. Fère-en- } & 1 \mathrm{ex} . \\ \text { Tardenois } & 1 \mathrm{ex} . \\ \text { 9. La Saulsotte } & 1 \mathrm{ex} . \\ \text { 10. Lavoye } & 1 \mathrm{ex} . \\ \text { 11. Mantes-la-Jolie } & 1 \mathrm{ex} . \\ \text { 12. Mercin-et-Vaux } & 12 \mathrm{ex} . \\ \text { 13. Metz } & 1 \mathrm{ex} . \\ \text { 14. Michery } & 1 \mathrm{ex} . \\ \text { 15. Oyes } & 4 \mathrm{ex} . \\ \text { 16. Paris } & 1 \mathrm{ex} . \\ \text { 17. Penchard (Meaux) } & 1 \mathrm{ex} . \\ \text { 18. Peronne } & 7 \mathrm{ex} . \\ \text { 19. Reims } & 4 \mathrm{ex} . \\ \text { 20. Rouen } & 1 \mathrm{ex} . \\ \text { 21. Rumersheim- } & \\ \text { le-Haut } & 4 \mathrm{ex} . \\ \text { 22. Sens } & 1 \mathrm{ex} . \\ \text { 23. Vésigneul- } & \\ \text { sur-Marne } & 1 \mathrm{ex} . \\ \text { 24. Vireux-Molhain } & 4 \mathrm{ex} . \\ \text { 25. Vix } & 1 \mathrm{ex} . \\ \text { 26. Berry-au-Bac } & 1 \mathrm{ex} . \\ \text { 27. Tourcoing } & 1 \mathrm{ex} . \\ \text { 28. Chalons-sur-Marne } & 1 \mathrm{ex} . \\ \text { 29. Chilleurs-aux-Bois } & 1 \mathrm{ex} . \\ \text { 30. Laon } & 1 \mathrm{ex} . \\ \text { 31. Vincy (Létanne) } & 1 \mathrm{ex} . \\ \text { 32. St-Germain- } \\ \text { lès-Corbeil } & \\ & \end{array}$

Fig. $36-$ Récapitulation des lieux de découverte.
Belgique (B : 50 ex.)

Luxembourg (L : 2 ex.)

$\begin{array}{lrcc}\text { 1. Eprave } & 3 \mathrm{ex} . & \text { 1. Echternach } & 2 \mathrm{ex} . \\ \text { 2. Fallais } & 7 \mathrm{ex} . & \text { Allemagne (D : } 5 \mathrm{ex} .) & \\ \text { 3. Geistingen } & 1 \mathrm{ex} . & & \\ \text { 4. Haillot } & 2 \mathrm{ex} . & \text { 1. Bornheim-Widdig } & 1 \mathrm{ex} . \\ \text { 5. Harmignies } & 1 \mathrm{ex} . & \text { 2. Titz-Hasselsweiler } & 1 \mathrm{ex} . \\ \text { 6. Herstal } & 7 \mathrm{ex} . & \text { 3. Trier } & 3 \mathrm{ex} . \\ \text { 7. Huy } & 11 \mathrm{ex} . & & \end{array}$

8. Liège $1 \mathrm{ex}$.

9. Logne $1 \mathrm{ex}$.

10. Merlemont $1 \mathrm{ex}$.

11. Modave $1 \mathrm{ex}$.

12. Namur $5 \mathrm{ex}$.

13. Ophoven $1 \mathrm{ex}$.

14. Pry 2. ex

15. Rochefort $1 \mathrm{ex}$.

16. Samson $3 \mathrm{ex}$.

17. Sclayn $1 \mathrm{ex}$.

18. Vieuxville $1 \mathrm{ex}$.
Pays-Bas ( $\mathrm{N}: 50$ ex.)

$\begin{array}{lr}\text { 1. Bayum } & 19 \mathrm{ex} . \\ \text { 2. Cuyk } & 2 \mathrm{ex} . \\ \text { 3. Dronrijp } & 1 \mathrm{ex} . \\ \text { 4. Ferwerd } & 6 \mathrm{ex} . \\ \text { 5. Gennep } & 4 \mathrm{ex} . \\ \text { 6. Iatsum } & 1 \mathrm{ex} . \\ \text { 7. Maastricht } & 33 \mathrm{ex} . \\ \text { 8. Ubbergen } & 1 \mathrm{ex} . \\ \text { 9. Voerendaal } & 1 \mathrm{ex} .\end{array}$

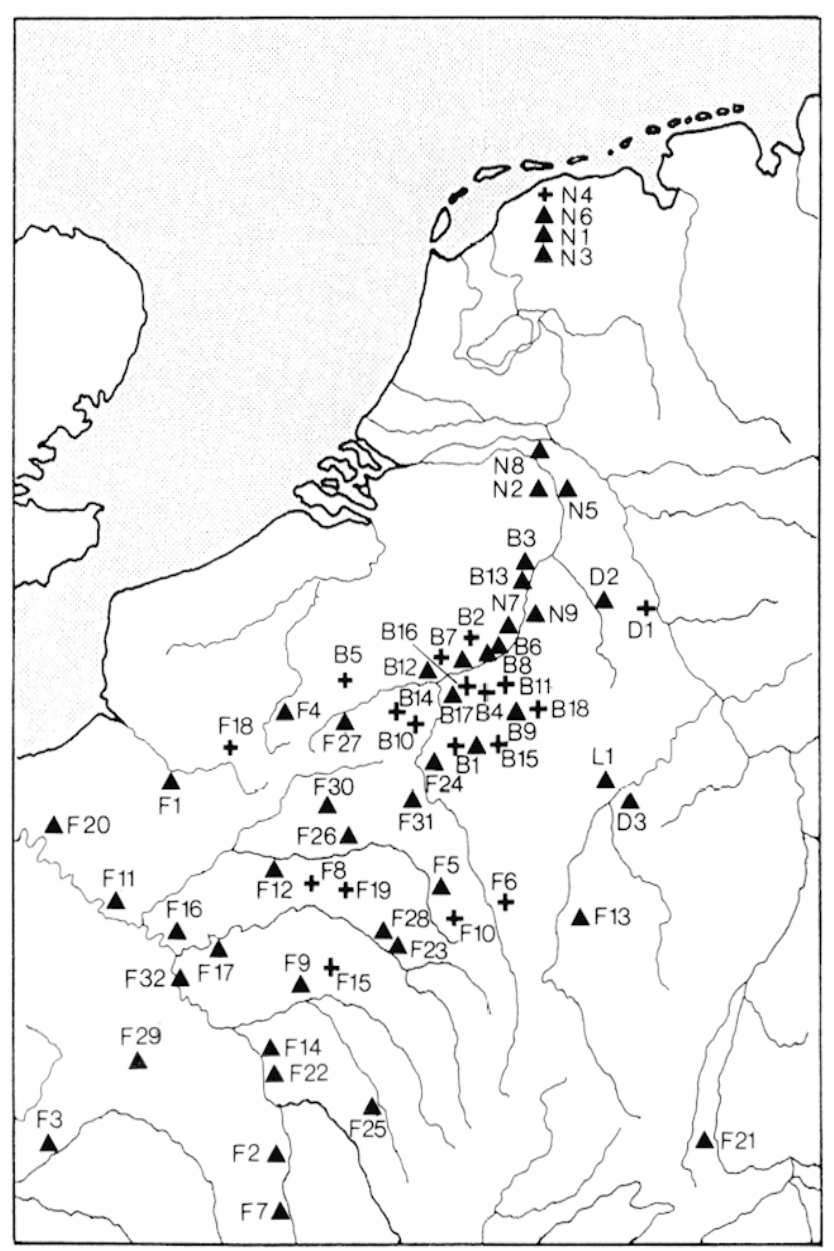




\section{BIBLIOGRAPHIE}

\author{
Alenus-Lecerf $\mathbf{J}$. \\ 1982: Le cimetière de Vieuxville, Archaeologia Belgica, 247 , \\ p. 104-108.
}

\section{Bakker L.}

1977 : Ein Grab des frühen 5. Jahrhunderts aus BornheimWiddig (Rhein-Sieg-Kreis), Bonner Jahrbücher, 177, p. 605610.

1981: Spätrömische Befestigungen und frühmittelalterliche Kirche von St. Peter und Paul, in: Metzif.r J., Zimmer J., Bаккге L., Ausgrabungen in Echternach, Luxembourg, p. 245256, 269-355.

\section{Bayard D.}

1990 : L'ensemble du grand amphithéâtre de Metz et la sigillée au v" siècle, Gallia, 47, p. 271-319.

\section{Bernhard H.}

1981 : Die spätrömischen Burgi von Bad Dürkheim-Ungstein und Eisenberg. Eine Untersuchung z.um spätantiken Siedlungswesen in ausgewählten Teilgebieten der Pfalz, Saalburg Jahrbuch, XXXVII, p. 23-85.

\section{Bloemers J. H. F.}

1973: Maastricht, Vrijthof, in: Archeologische kroniek van Limburg over de jaren 1969-1970. Publications de la Société Historique et Archéologique dans le Limbourg, p. 52-54.

1974 : De opgravingen op het Vrijthof te Maastricht in $1969 \mathrm{en}$ 1970, Actes du congrès archéologique, Tongres, p. 10-12.

1977 : Archeologische kroniek van Limburg over de jaren 19751976. Publications de la Société Historique et Archéologique dans le Limbourg, p. 22.

Boeles P. C. J. A.

1951 : Friesland tot de elfde eeuw. Zijn oudste beschaving en geschiedenis, 's Gravenhage.

\section{Boppert W.}

1986 : Die frühchristlichen Grabinschriften aus der Servatiuskirche in Maastricht: Handelingen van het Sint-Servatiuscolloquium te Alden Biesen (Bilzen), Tongeren en Maastricht, 1984, Kunst en Oudheden in Limburg, 28, p. 64-96.

Breuer J., Roosens, $\mathbf{H}$.

1957 : Le cimetiere franc de Haillot. Archaeologia Belgica, 34, Bruxelles.

\section{Brulet R.}

1978 : La fortification de Hauterecenne à Furfooz, Publications d'histoire de l'art et d'archéologie de l'Université catholique de Louvain, XIII, Louvain-la-Neuve.

\section{Carmelez J.-C.}

1986: La céramique sigillée du Bas-Empire conservée au musée de Bavay, Fouilles et Études. Archéologie et Pédagogie. Lycée de Bavay, 8, p. 91-130.

Chenet G.

1941 : La céramique gallo-romaine d'Argonne du ive siècle et la terre sigillée décorée à la molette, Màcon.

\section{Childéric-Clovis}

1982 : Childéric-Clovis, $1500^{\circ}$ anniversaire 482-1982, catalogue de l'exposition, Tournai.
Claassen A., Heymans H.

1974: Merovingische graven op Romeinse begraafplaats te Ophoven, Het Oude Land van Loon. XXIX, p. 173-216.

\section{Dasmoy A.}

1956 : Coupes en verre ornées de symboles chrétiens, Annales de la Socièté Archéologique de Namur, XLVIII, p. 360-373.

1967-1968: Le cimetière situé Devant le Mont à Éprave ( $\mathrm{v}^{\mathrm{e}}-\mathrm{vI}^{\mathrm{e}} \mathrm{s}$.), Annales de la Sociélé Archéologique de Namur, LIV, p. $61-108$.

1968 : Le cimetière du Corbois à Rochefort (ve-vir ${ }^{\mathrm{e}}$ s.), Namurcum, 40, 1, p. 1-14.

De Boe G.

1986 : De archeologische getuigen van het eerste christendom in de civitas Tungrorum, in : Handelingen van het Sint-Servatius-colloquium te Alden Biesen (Bilzen), Tongeren en Maastricht, 1984, Kunst en Oudheden in Limburg, 28, p. 37-64.

Degbomont J.-M.

1983 : La céramique romaine, in : M. OtTr (éd.), Les fouilles de la place Saint-Lamberl à Liège, 1, ERAUL, 18, p. 30-32.

Dijkman W.

1985: La terre sigillée tardive, décorée à la molette à motifs chrètiens, trouvée dans la vallée mosane, en particulier à Maastricht (Pays-Bas), SFECAG, Actes du Congrès de Reims, p. 57-62.

Docquier J. et alii

1984 : IIuy au lemps de la christianisation el des Merovingiens, Amay-lluy.

Fellmann R.

1952 : Mayener-Eifelkeramik aus den Befestigungen des spätrömischen Rheinlimes in der Schweiz, Jahrbuch der Schweizerischen Gesellschaft für Urgeschichte, 42, p. 161-173.

Gilles K.-J.

1985 : Spätrömische Höhensiedlungen in Eifel und Hunsrück, Trierer Zeitschrift, Beiheft 7, Trier.

Gricourt J.

1950 : La terre sigillée argonnaise du IV siècle décorée à la molette, à Bavai (Nord), Gallia, VIII, p. 55-76.

Guillaume J.

1978 : La chronologie des nécropoles mérovingiennes de Dieuesur-Meuse (France, Meuse), in : Fl.fury M., PÉrin P. (éd.), Problèmes de chronologie relative el absolue concernant les cimelières mérovingiens d'entre Loire et Rhin, p. 87-103.

Homes-Fredericq D., Franken H.

1984 : Argile, source de vie, sept millénaires de céramique en Jordanie, Bruxelles.

Hübener W.

1968 : Eine Studie zur spätrömischen Rädchensigillata (Argonnensigillata), Bonner.Jahrbücher, 168, p. 241-298.

Hussong L., Cüppers $\mathrm{H}$.

1972: Die Trierer Kaiserthermen. Die spätrömische und frühmittelalterliche Keramik, Trierer Grabungen und Forschungen, Bd. 1, 2, Mainz am Rhein. 
Jigan C., Halbout P.

1987 : La céramique d'Argonne décorée à la molette des $\mathrm{IV}^{\mathrm{e}}$ $v^{\mathrm{r}}$ siècles en Normandie, SFECAG, Actes du Congrès de Caen. p. $45-50$.

Joffroy $\mathbf{R}$.

1974 : Le cimetière de Lavoye (Meuse), nécropole mérovingienne, Paris.

Kirschbaum E. (éd.)

1970 : Lexicon der christlichen Ikonographie, II, Rom, Freiburg, Basel, Wien.

Lemant J.-P.

1981 : Sauvetages sur les Sites Archéologiques de Vireux, Revue Hislorique Ardennaise, XVI, p. 270-229.

Lith S. M. E. van

1985 : Laat-Romeins en vroegmiddeleeuws glas uit Maastricht, De Maasgouw, jaargang 104, p. 146-156.

1987: Late Roman and Early Merovingian Glass from a Settlement Site at Maastricht (Dutch South Limburg), Part I, Journal of Glass Studies, 29, p. 47-59.

1988 : Late Roman and Early Merovingian Glass from a Settlement Site at Maastricht (Dutch South Limburg), Part II, Journal of Glass Studies, 30, p. 62-76.

Marcolungo D.

1988: La céramique gallo-romaine, in: M. Otre (èd.), Les fouilles de la place Saint-Lambert à Liège, 2, Le vieux marché, ERALL, 23, Liège. p. 142-166.

Martin J.

1951 : La céramique décorée à la roulette du Musée de Namur, Annales de la Société Archéologique de Namur, XLVI, p. 73-99.

\section{Mitard P.-H.}

1975: La céramique d'Argonne au Ive $^{\mathrm{e}}$ siècle. Les Dossiers de 'Archéologie, 9, mars-avril, p. 79-83.

Nicolle $\mathbf{J}$.

1962: La céramique d'Argonne décorée à la molette dans le département de l'Yonne, Gallia, XX, p. 380-392.

Oelmann F.

1914 : Die Keramik des Kastells Niederbieber, Materialien zur röm.-germ. Keramik, I, Frankfurt am Main.

Oldenstein $\mathrm{J}$.

1986 : Neue Forschungen im spätrömischen Kastell von Alzey. Vorbericht über die Ausgrabungen 1981-1985, Bericht der Römisch-Germanischen Kommission, 67, p. 290-356.

Oswald F. et alii (éd.)

1966 : Vorromanische Kirchenbauten. Kalalog der Denkmäler bis zum Ausgang der Ottonen, München.

\section{Paar I., Rüger Ch.}

1971: Kastell Gelduba. Die jüngeren Grabungen im Ortsbereich. Die Grabungen 1964-1968, Beiträge zur Archäologie des römischen Rheinlands, II, p. 276-280.

Panhuysen T. A. S. M.

1984 : Maastricht staat op zijn verleden, Maastricht.

1986 : Wat weten we over de continuiteit van Maastricht?, Handelingen van het Sint-Servatius-colloquium te Alden Biesen (Bilzen). Tongeren en Maastricht, 1984. Kunst en Oudheden in Limburg. 28, p. 125-147.

1990: Die Maastrichter Servatiuskirche im Frühmittelalter. Ein vorbericht über die jüngsten Grabungen des Städtischen Amtes für Bodendenkmalpflege Maastricht, Kunstchronik, 43 , p. 541-553, Abb. 1-6.
1991: Maastricht in het eerste millenum. De vroegste stadsontwikkeling in .Vederland, in : La genèse et les premiers siècles des villes médiévales dans les Pays-Bas méridionaux. Un problème archéologique et historique, Actes du $14^{\circ}$ colloque international, Spa 6-8 sept. 1988, Crédit communal, coll. Histoire, série in-8 $8^{\circ}, 83$, p. $411-455$.

Petrikovits $\mathrm{H}$. von

1937 : Schneppenbaum (Kreis Kleve), Bonner Jahrbücher, 142, p. 325-339.

Piton D., Bayard D.

1977 : La sigillée d'Argonne décorée à la molette dans le NordOuest de la France, Cahiers Archéologiques de Picardie, 4, p. $221-275$.

Ravetz A.

1964 : The Fourth-Century Inflation and Romano-British Coin Finds, Numismatic Chronicle, p. 201-231.

Robert C.

1969: La terre sigillée décorée à la molette de la Roche à Lomme, Dourbes (Belgique), Gallia, 27, p. 135-147.

Schallmayer E.

1987 : Zur Chronologie in der römischen Archäologie, Archäologisches Korrespondenzblatt, 17, p. 483-497.

Schweitzer R.

1977 : Contribution à l'étude de la céramique du Bas-Empire, Bulletin du Musée IIistorique de Mulhouse, 84, p. 65-73.

Spors S.

1986: Spätrömische Drehscheibenkeramik vom Glauberg (Wetteraukreis), Jahrbuch des römisch-germanischen Zentralmuseums, 33, p. 417-468.

Straus J.-A.

1985 : Les plus anciennes sources archéologiques chrétiennes du bassin mosan entre . Namur et Liège, Les Études Classiques, 53, p. $137-152$

Thion P.

1984 : Céramique sigillée, in : Collectif, Ville de Meaux. Catalogues des Collections du Musée Bossuet, 1. Préhistoire, Protohistoire, Gallo-romain, Meaux, p. 117-145.

Thijssen J. R. A. M.

1979 : De radstempelsigillala uit Cuyk, Thèse inédite, Univ. de Nijmegen.

Tilkin-Peters C., Marcolungo D.

1986 : Le matériel mérovingien de la rue des Augustins à Huy, Activités 84 à 85 du SOS Fouilles, 4, p. 201-209.

Trombetta P.-J.

1976: La fouille de la place Valin de la Vaissière à Blois, Archeologia, 94, p. 13-19.

Tuffreau-Libre M.

1981: Fouilles de Mercin et Vaux (Aisne). La céramique commune, Cahiers Archéologiques de Picardie, 8, p. 97-114.

Unverzagt $\mathbf{W}$.

1916 : Die Keramik des Kastells Alzey, Materialien zur röm.germ. Keramik, II, Frankfurt am Main.

Vanderhoeven $\mathbf{M}$.

1979 : De terra sigillata te Tongeren, $\mathrm{V}$, de radjessigillata, Tongeren.

Van Heule $\mathbf{H}$.

1939 : La céramique sigillée du Iv ${ }^{e}$ siècle décorée à la molette, 
du Musée Archéologique Liégeois, Association française pour l'avancement des Sciences, 63e Session, Liège, p. 1438-1442.

\section{Van Houdt $\mathrm{H}$.}

1982 : Versierd Terra Sigillata. Eprave 82/001, Mens en Grondspoor, 3, fig. 3 .

\section{Van Ossel P.}

1976 : La nécropole de Fallais, Annales de la Fédération des Cercles d'Archéologie et d'Histoire de Belgique, XLIV Session, Congrès de Huy, I, p. 71-73.

1982a : La nécropole du Mont-Saint-Sauveur à Fallais, Bulletin de l'Institut Archéologique Liégeois, XCIV, p. 143-231.

1982b : Les molettes chrétiennes sur vases en sigillee, in: Childéric-Clovis, 1500 anniversaire 482-1982, Tournai, p. 170172.

1984 : Époque romaine et haut Moyen Age, in : LENSEN J.-P., VAn Osser. P., Le Pré Wigy à Herstal, ERAUL, 20, Liège, p. 29-48.

1986 : Céramiques de la fin du $\mathrm{Iv}^{\mathrm{e}}$ et du v viècle en Gaule Belgique, Bulletin de la Société Archéologique Champenoise, 79, 2 , p. 63-71.
Verbeek A.

1958: Spuren der frühen Bischofskirchen in Tongern und Maastricht, Bonner Jahrbücher, 58, p. 346-371.

Verwers W. J. H.

1986 : Het grafveld in de Pandhof van de Sint-Servaas te Maastricht, Munsters in de Maasgouw, Maastricht, p. 56-71.

Vin J. P. A. van der, Panhuysen T. A. S. M.

1983: Romeinse en vroegmiddeleeuwse munten uit een stadskernopgraving in Maastricht, De Beeldenaar, 4, p. 121125.

\section{Wautelet Y.}

1967: La nécropole franque de Merlemont, Archaeologia Belgica, 100, Bruxelles.

1977 : L'important problème de la "pseudo-sigillée" dans la province de Namur, Pro Antiqua, VII, p. 1-64.

Willems J.

1973 : Le quartier artisanal gallo-romain et mérovingien de "Batta ḋ Huy, Archaeologia Belgica, 148, Bruxelles.

Willems W. J. H.

1988 : Voerendaal, in : H. STOEPKER, Archeologische Kroniek van Limburg over 1987, Publications de la Société Historique et Archéologique dans le Limbourg, 124, p. 404-417. 